\title{
ADHESION AND DURABILITY OF COATINGS ON POLYPROPYLENE EXTERIOR SIDINGS
}

\author{
A Project Report \\ presented to \\ the Faculty of California Polytechnic State University, \\ San Luis Obispo
}

\author{
In Partial Fulfillment \\ of the Requirements for the Degree \\ Master of Science in Polymers and Coatings \\ by \\ Logan Riekio Stark \\ December 2011
}


(C) 2011

Logan Riekio Stark

ALL RIGHTS RESERVED 


\section{COMMITTEE MEMBERSHIP}

TITLE:

Adhesion and Durability of Coatings on Polypropylene

Exterior Sidings

AUTHOR: $\quad$ Logan Riekio Stark

DATE SUBMITTED: December 2011

COMMITTEE CHAIR: $\quad$ Raymond H. Fernando, Ph.D.

COMMITTEE MEMBER: Dane R. Jones, Ph.D.

COMMITTEE MEMBER: Philip J. Costanzo, Ph.D. 
Adhesion and Durability of Coatings on Polypropylene Exterior Sidings

Logan Riekio Stark

Plastics have become a universal material for use in a myriad of commercial and consumer products. One such product, exterior siding, is the focus of this project. Although siding products were originally made from wood, vinyl siding, which offered superior performance, was introduced in the 1950's. More recently, polypropylene (PP) siding has been introduced; PP provides a stronger product, which allows for deeper patterns and better edge detailing. PP siding, compared to traditional wood siding, doesn't warp, crack, or degrade as easily with extended exposure to the elements, and is cheaper to maintain. However, even plastic siding must be coated. The requirements of a coating for siding are good adhesion, durability, and a suitable appearance. However, polypropylene, like many plastics, has a low surface energy, making wetting and coating adhesion difficult.

One of the many ways to increase the surface energy of polypropylene, thus increasing wettability and adhesion, is plasma treatment. The primary focus of this project was to study how plasma treatment improved adhesion of a water-reducible coating. This coating represented a product used in commercial siding. The surface tension of the panels was increased from $\sim 30$ dynes $/ \mathrm{cm}$ to $60+$ dynes $/ \mathrm{cm}$ with plasma treatment. This increased the adhesion of the coating to the polypropylene panel from virtually no adhesion to almost perfect adhesion. Adhesion was tested according to ASTM D3359, the crosscut adhesion test. Pull-off adhesion testing (ASTM D4541-09) was also conducted, using a Deflesko PosiTest AT-A automatic adhesion tester. The average force needed to remove a dolly from a plasma treated panel was $233 \pm 47 \mathrm{psi}$ 
$(1,605 \pm 325 \mathrm{kPa})$, compared to $92 \pm 26 \mathrm{psi}(634 \pm 179 \mathrm{kPa})$ for non-treated and corona treated panels.

The sponsor of the project provided Cal Poly with 16 different compositions of polypropylene containing different amounts of UV stabilizers, adhesion promoters, and lubricants. The effect of substrate composition on coating adhesion and performance was measured. Crosscut adhesion testing results revealed all polypropylene compositions improved from virtually no adhesion to perfect adhesion after plasma treatment. Pull-off adhesion testing revealed the adhesion force of all compositions improved from less than $100 \mathrm{psi}$ to greater than $200 \mathrm{psi}$. One polypropylene composition, Category 16, resulted in unusually high pull-off forces. This composition was investigated using X-ray Photoelectron Spectroscopy (XPS) and FT-IR spectroscopy. XPS was used to examine the surface composition between non-treated and plasma treated PP panels. It was observed that plasma treatment provides a larger amount of oxygen species and nitrogen when compared to untreated panels. The category 16 panels did not reveal any significant surface differences compared to the category 7 panels (which represented the standard production material). FT-IR spectroscopy of the category 16 panels also showed no unusual characteristics.

The secondary focus of this project was to study the durability of coated, plasma treated polypropylene siding. Accelerated weathering testing was conducted on 12 of the 16 different compositions of polypropylene. Changes in gloss and the LAB colorspace of coated, plasma treated polypropylene panels of different compositions, upon exposure to long-term weathering conditions, were monitored via ASTM G53 using a Q-Panel lab product QUV/se weathering tester. After 2400 hours, all PP compositions tested shared 
negligible changes in color, but the gloss of each category panel showed a steady increase.

An approach to improve durability of siding is to apply a clearcoat over already coated PP panels. This approach was tested in a limited manner by adding a clearcoat to coated, plasma treated polypropylene panels. These panels were then exposed to a variety of common, household cleaning agents using a modified double rub test (ASTM D4752 and ASTM D5402). The samples with a clearcoat showed improved cleaning agent resistance compared to samples without the clearcoat.

Keywords: Plasma Treatment, Polypropylene, Adhesion, Surface Tension, Surface Energy, Cleaner Resistance, Pull-off Adhesion, Coating, Siding, Crosscut Adhesion 


\section{ACKNOWLEDGEMENTS}

I would like to thank CertainTeed company for funding, as well as Dr. Dane Jones and Dr. Philip Costanzo for their support. I would also like to thank Megan Hart and Jason Kurian for their assistance. Finally, I would like to thank Dr. Raymond Fernando for his support, guidance, patience, and sense of humor.

Table of Contents 
List of Tables ..................................................................................................

List of Figures ................................................................................................... xii

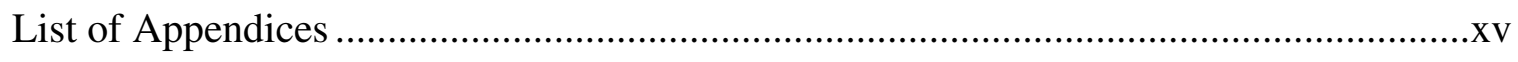

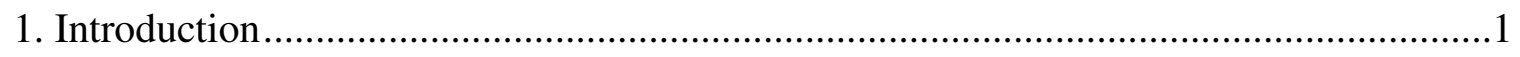

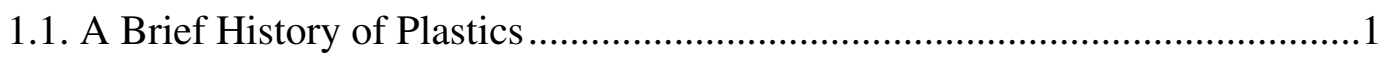

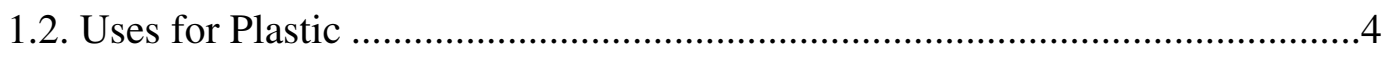

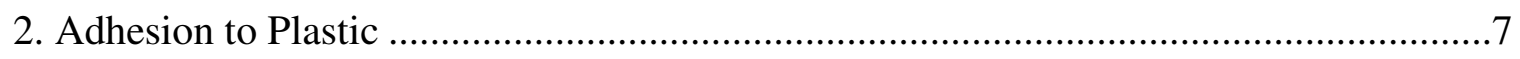

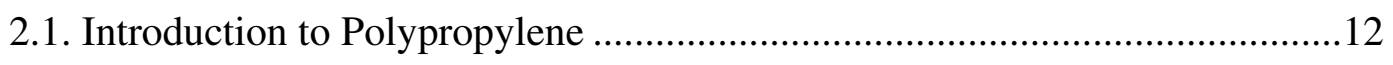

2.2. Polypropylene Applications ........................................................... 15

2.3. Increasing Adhesion to Polypropylene ................................................... 17

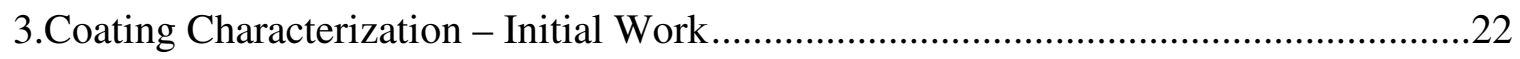

3.1. Project Overview ...............................................................................22

3.1.1. Materials and Methods..............................................................23

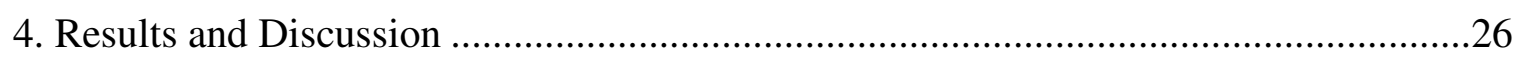

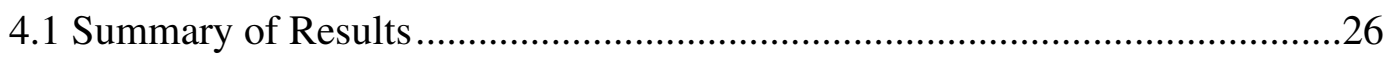

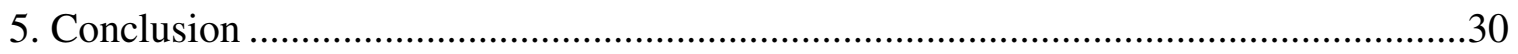

6. Primary Objectives of the Project - Adhesion ..................................................... 31

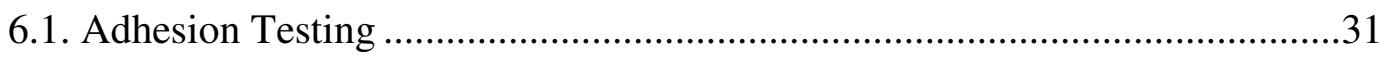

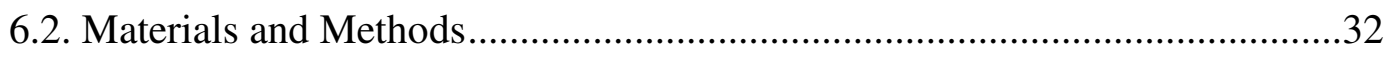

6.2.1. Plasma Treatment - Initial Testing .........................................32

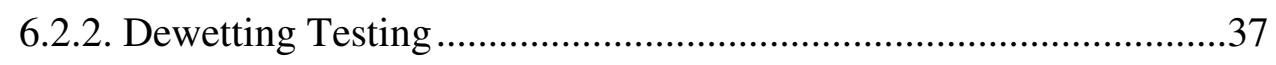

6.2.3. Ideal Process Conditions Using the Plasma Treater .......................37

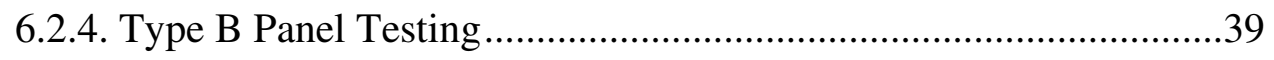

6.2.5. X-ray Photoelectron Spectroscopy (XPS) .....................................39 
6.2.6. Adhesion Testing .....

6.2.6.1. Adhesion Testing with Type B Panels...........................40

6.2.6.2. Polypropylene Composition Variations ........................42

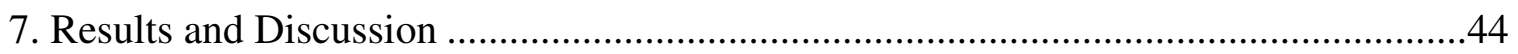

7.1. Plasma Treatment Results With Type A Panels ..........................................44

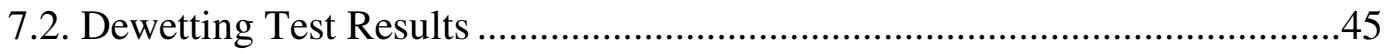

7.3. Optimum Plasma Treater Conditions.................................................46

7.4. Adhesion Testing on Type B Panels .........................................................49

7.4.1. Pull-Off Adhesion Testing on Type B Panels.................................54

7.4.2. Problems With the Coating on Type C Panels..............................59

7.4.3. Revised Procedure - Adhesion Testing Results ............................64

7.4.4. Peculiar Adhesion Result Investigation .....................................68

7.4.4.1. Peculiar Adhesion Characteristics ................................68

7.4.4.2. Peculiar Adhesion Test Results ..................................70

7.4.4.3. X-ray Photoelectron Spectroscopy Results.....................79

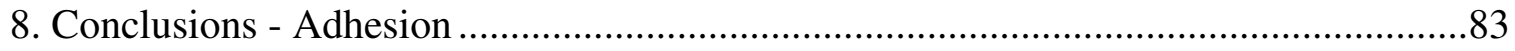

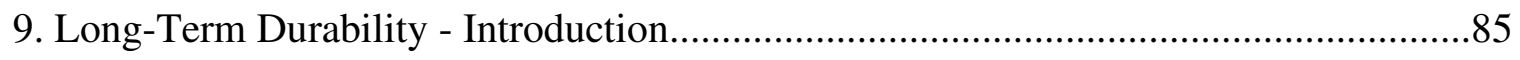

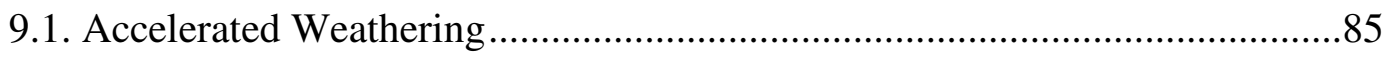

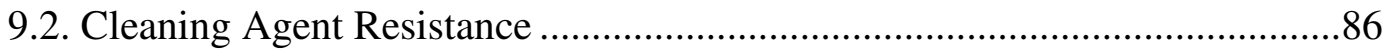

9.3. Real World Samples from Outdoors ................................................... 87

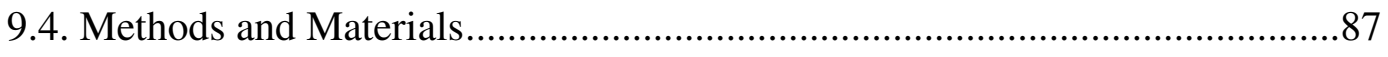

9.4.1. QUV Weathering Testing ..........................................87

9.4.2. Cleaning Agent Resistance Testing .................................89

9.4.3. Real World Samples ....................................................91 
10. Results and Discussion - Durability.....

10.1. QUV Testing

10.1.1. QUV Testing - Microscopy …..................................97

10.1.2. QUV Testing - Adhesion Results.................................98

10.2. Cleaning Agent Resistance Results ......................................................99

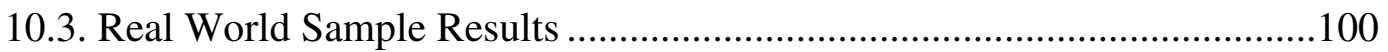

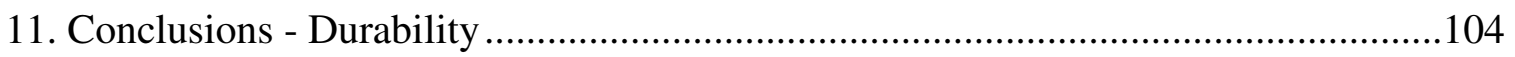

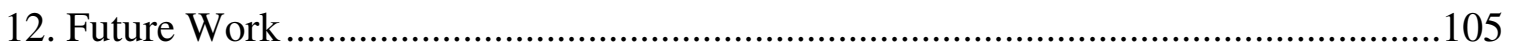

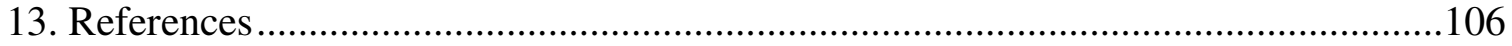

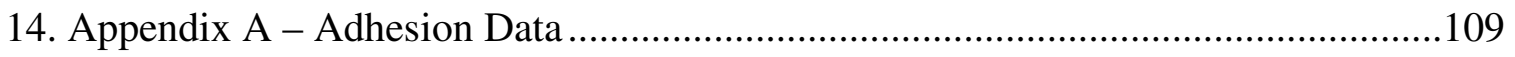

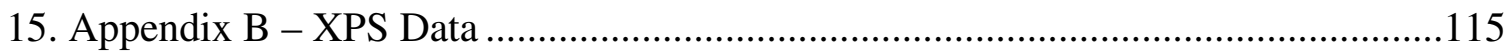

\section{LIST OF TABLES}

Table

1. Characterization results for coating lots \#1 and \#2 26

2. Adhesion test results (ASTM D3359) 29 
3. Descriptions of Type C polypropylene panels 34

4. Wetting results from initial plasma treatment testing on Type A panels 44

5. Dewetting results from plasma and corona treatment testing in Type A panels 45

6. Effect of plasma treatment time on crosscut adhesion results (Type A panel) 47

7. Effect of plasma treater distance (Type A panel) 47

8. Effect of plasma treater blower speed (Type A panel) 48

9. Wetting results from plasma treatment testing on Type B panels 49

10. Plasma and corona treatment dewetting test on Type B panels 50

11. Wetting results from plasma treatment testing on Category 7 and

Category 16 panels $\quad 52$

12. Plasma treatment dewetting test on Category 7 panels 53

13. Crosscut adhesion test results for Type B panels 54

14. Average pull-off adhesion test results fro Type B panels 54

15. Viscosity results 63

16. Crosscut adhesion results for Type C panels 65

17. Pull-off adhesion test results of the 16 Type C panels 66

18. Repeat of pull-off adhesion testing 68

19. Pull-off adhesion results - Category 16 panels 71

20. Pull-off results for non-coated Category 7 and 16 panels 78

21. Wide-spectrum survey results from XPS testing 80

22. High-resolution C1s results from XPS testing 81

23. Pull-off adhesion results - QUV accelerated weathering 98

24. Cleaning agent resistance rankings $\quad 100$ 


\section{LIST OF FIGURES}

$\begin{array}{lll}\text { Figure } & \text { Page }\end{array}$

1. Adhesive and cohesive forces $\quad 8$

2. Different types of stress 9

3. Contact angle ( ) of a liquid on a solid substrate 11

4. Polypropylene 13 
5. Rheology results for brown coating (lot \#1) - 2, 5, 10, and 20 minute tests

6. Rheology results for brown coating (lot \#2) - 2, 5, 10, and 20 minute tests

7. The three polypropylene panel types tested. From left to right: Type A panel, Type B panel, and Type C panels.

8. Plasma treater set-up

9. Aluminum dollies after removal from the surface of the PP panel by the

PosiTest adhesion tester

10. Cohesive failure of polypropylene

11. Example of a poor pull-off

12. Excess epoxy around the dolly

13. Example of the results from using the cutting tool provided with the PosiTest

14. Tape holding the dollies down to improve the excess epoxy wipe-off process

15. Mud-cracking or dewetting can be seen on both the treated and untreated

Category 8 panels (treated on the left)

16. Testing for surface energy differences throughout the Type $\mathrm{C}$ panels

17. Viscosity vs. shear rate at 5-minute ramping time

18. Cohesive failure of the PP substrate

19. Diagram depicting panel locations of FTIR analysis

20. IR spectra of the dried coating (spot 1)

21. IR spectra of the area under the removed dolly (spot 2)

22. IR spectra of the area underneath the random samples of epoxy were placed (spot 3)

23. IR spectra of the underside of the coating that had epoxy on top of it (spot 4)

24. IR spectra of the bare substrate (spot 5) 
25. IR spectra of the epoxy (spot 6)

26. Wide-spectrum (left) and high-resolution spectrum (right) of 30-second plasma treated Category 7 sample

27. Cleaning agent resistance test panel

28. Change in $\mathrm{L}^{*}$ as a function of time

29. Change in $\mathrm{a}^{*}$ as a function of time

30. Change in $b^{*}$ as a function of time

31. Change in $E$ values as a function of time

32. Delta $\mathrm{E}$ as a function of time

33. Gloss $\left(85^{\circ}\right)$ values as a function of time

34. FT-IR results (CertainTeed)

\section{LIST OF APPENDICES}

Appendix

Page

A - Adhesion Data

109

B - XPS Data 


\section{Introduction}

\subsection{A Brief History of Plastics}

From the early twentieth century to today, plastics have become an integral part of the world we live in. A fundamental reason for this is plastics, as a group, can be adapted to what the consumer desires; some plastics are able to take on different shapes, textures, densities, and can be altered in ways that wood, stone, and metals cannot. Although we have grown up in the plastic century, plastics were not always a well-known or wellreceived material. Plastics had to be developed, manufacturers had to be convinced to use them in products, and the public had to be persuaded to buy them (Meikle, 1997). On a world-history time-scale, this did not take a long time. However, the history of plastic is not brief.

Plastics are generally petroleum-based materials that can be shaped and molded, and they are made from polymers. A polymer is a long-chain molecule that is composed of repeating units of shorter compounds called monomers. An almost infinite amount of monomers can be combined in different ways to make an endless array of plastics with varying properties.

The first man-made plastic was created by Alexander Parkes and was showcased in 1862 at the Great International Exhibition in London (Meikle, 1997). The material was derived from cellulose and was able to be molded into a variety of shapes, and after heating and cooling, would retain that shape. However, investors were not happy with the high price of the raw materials needed to produce the plastic, and Parkes invention quickly met its demise (Meikle, 1997).

The next plastic was created in response to a contest - a $\$ 10,000$ offer from a billiard ball company to find a material that could replace the current ivory-based billiard 
balls (Meikle, 1997). In 1869, John Wesley Hyatt came up with the solution by creating celluloid. He used a mixture of nitrocellulose and ground camphor, heated it, compressed it in a mold, and obtained a new substance that was hard, shiny, and durable (Meikle, 1997). Although the material became very successful and had multiple uses (piano keys, combs, denture plates), Hyatt, never received the $\$ 10,000$ prize he was originally aiming for (Meikle, 1997).

The next major plastic breakthrough was Bakelite, the first synthetic, man-made substance. At the time, shellac was being made from the shells of beetles; a substitute for shellac was needed. In 1907, Leo Baekeland attempted to make a synthetic shellac. After experimenting with a reaction between phenol and formaldehyde, Baekeland was not successful in creating the desired product. He did, however, notice the resin that was produced had unique and interesting properties. The resin would take the shape of its container and rapidly harden. Once it hardened, the material became infusible and would resist heat, electricity, and even the toughest solvents; it was "immortal" and had obtained the highest degree of chemical stability (Meikle, 1997). This product came to be known as Bakelite, and it quickly became one of the most widely used products in the military (as it was incorporated into many weapons during World War II) as well as in the domestic arena (electrical insulators, kitchenware, toys). The invention of Bakelite was so influential, it inspired an entire class of plastics - phenolic resins.

In 1855 , a search for a synthetic silk was underway. Georges Audemars created the first of its kind that year, but the manufacturing process was impractical (Meikle, 1997). Louis Marie Hilaire Bernigaut developed the first commercially produced synthetic silk in 1891; however, it was highly flammable and promptly removed from the marketplace (Meikle, 1997). Finally, in 1894, Charles Cross and colleagues created their 
synthetic silk, which they named 'viscose,' which later came to be known as Rayon (Meikle, 1997). Rayon, like celluloid, was a modified cellulose product. Rayon was a major success in the textile industry, as it was a versatile fiber and could imitate silk, wool, and other fibers. Cellophane, discovered by Dr. Jacques Brandenberger in 1900, was an important plastic that utilized a similar process to that of Rayon (Meikle, 1997).

Consumers were becoming more and more familiar with plastics, and by the 1920s, a plastics craze was taking effect. One of the leading companies in plastics innovation was DuPont, and the head of one of their labs was Wallace Carothers. In 1935, Carothers produced Nylon, which was then known as Fiber 66 (Meikle, 1997). This product of a reaction between a diamine and a dicarboxylic acid eventually became the first commercially successful synthetic polymer, as it was used in a variety of applications, including the bristles in toothbrushes and as a replacement for silk stockings.

Two years prior to the production of nylon, E.W. Fawcett and R.O. Gibson reacted ethylene and benzaldehyde under tremendous pressure, but their experiment went wrong and the reaction vessel sprang a leak. These experimental failures lead to the discovery of a white, waxy substance that looked like a plastic (Meikle, 1997). This substance eventually became known as polyethylene, a revolutionary product for the world at the time. Polyethylene was instrumental in World War II as it was used as a lightweight insulating material, allowing previously heavy radar systems to be carried onboard planes. These radar systems allowed the Allied air force, which was greatly outnumbered by the Germans, to detect the German bombers in all weather conditions (Meikle, 1997). After the war, polyethylene became a commercial success, eventually 
developing into the first plastic in the United States to sell more than a billion pounds in a year (Meikle, 1997).

The 1940's and 1950's saw a boom in new plastic materials (such as polypropylene, discussed in section 2) and a rise in the commercial use of plastic products, such as polyvinyl chloride, "SaranTM", "Teflon", "Velcro", and even "Silly Putty" (which was one of the fastest selling toys of its time). As the decades have passed, plastics have grown into a major industry and become a necessity we depend on in our day-to-day lives. New products and technologies that could not be realized by other materials have been introduced and used in technologies such as computers, televisions and cars. In just over a century, plastic has spread through the world, evolving from a little known material at a trade show to a multi-billion dollar industry that dominates the world we live in.

\subsection{Uses for Plastic}

Plastics have become more and more prevalent in everyday and commercial uses. The reason consumers chose to use plastic before other, often 'better' materials (such as metal) is because plastics are relatively cheap to manufacture, they have good performance, they have great corrosion resistance, and they can be molded into a variety of shapes.

There are many types of plastics, providing manufacturers with a large selection to choose from for their products. However, recyclability, which is a big issue in industry due to the large amount of governmental regulations and the limited supply of raw materials in most countries, is a key determinant in the selection of plastics because of the solid waste disposal problem (Ryntz, 1994). There are two main categories of plastics, thermosets and thermoplastics. Thermosets are plastics that do not flow when heated and 
are insoluble, only being reused as reground material (Ryntz, 1994). Thermoplastics, on the other hand, can soften, flow and be molded when heated, and therefore are recyclable (Ryntz, 1994).

Other reasons a manufacturer uses a certain plastic include material requirements and design flexibility. One important material requirement is photo-stability. Many applications for plastics require the plastic to be outdoors, so photodegradation by UV rays and photo-oxidation must be taken into consideration when choosing a plastic and a manufacturing process. Both of these degradation phenomena have the ability to change the plastic chemically, which can alter its physical properties, such as shape and color. Stabilizers, such as antioxidants, ultraviolet absorbers, and hindered amine light stabilizers, are often added to plastics to hinder the effects of degradation (Ryntz, 1994). Another material requirement is environmental stability. A plastic may be subjected to varying degrees of humidity, light exposure, and other environmental conditions; many plastics perform differently depending on their chemical composition. Although these material requirements are good indicators when deciding which plastic to use under certain conditions, there are still other factors involved, such as solvent sensitivity, flexural modulus, and, a main focus of this project, paintabililty (Ryntz 1994).

As plastic has been incorporated into our lives and the utility for it increases, there is a greater need to be able to coat plastics as we would coat metal, wood, and other substrates. Coating plastics can enhance their aesthetics, durability, surface quality and their resistance to harsh chemicals. However, plastics typically have low surface energies, and organic coatings have high surface energies, making it challenging for a coating to wet the surface of a plastic. Wetting is achieved when a liquid (a coating) maintains 
constant contact with a surface. Furthermore, plastics are generally nonporous, smooth substrates, which make it even more difficult for a coating to adhere to the surface.

\section{Adhesion to Plastic}

As the use of coatings in the plastic industry increases, it is becoming more of a challenge to paint plastic substrates because the topcoat doesn't adhere well to the plastic, sometimes even after application of a primer. To counteract this, one must understand surface chemistry and wettability. 
Adhesion is the force that holds a substrate and a coating together in opposition to stresses exerted to pull the coating and substrate apart (ASC, n.d.). It is generally agreed adhesion is comprised of three components: primary chemical bonding, secondary (or polar) bonding and mechanical bonding (Weldon, 2009). The primary bonds that contribute to adhesion are the ones that keep molecules together, that is, covalent and ionic bonds. This type of bonding between a coating and a substrate is the most desirable because of the bonds high strength. Secondary chemical bonding is created from polar interactions between molecules where dipoles are formed, most notably Van Der Waals and hydrogen bonding forces (Weldon, 2009). Coatings with functional groups that have large electronegativity differences are most likely to induce dipoles in other molecules, and therefore form polar bonds. Mechanical bonding is the third contributor to adhesion, and mainly has to do with the roughness of the surface of the substrate the coating will be applied to.

An adhesive can be used to hold two substrates together. Adhesive and cohesive forces would act upon the substrate and the adhesive itself (Figure 1). Cohesion is oftentimes complementary to adhesion. They are not, however, the same. Cohesion is the attraction of particles within the adhesive or coating (adhesive and coating will be used interchangeably) that holds the adhesive together as a result of the interactions it has with the substrate. The difference between the two can be seen in Figure 1. 


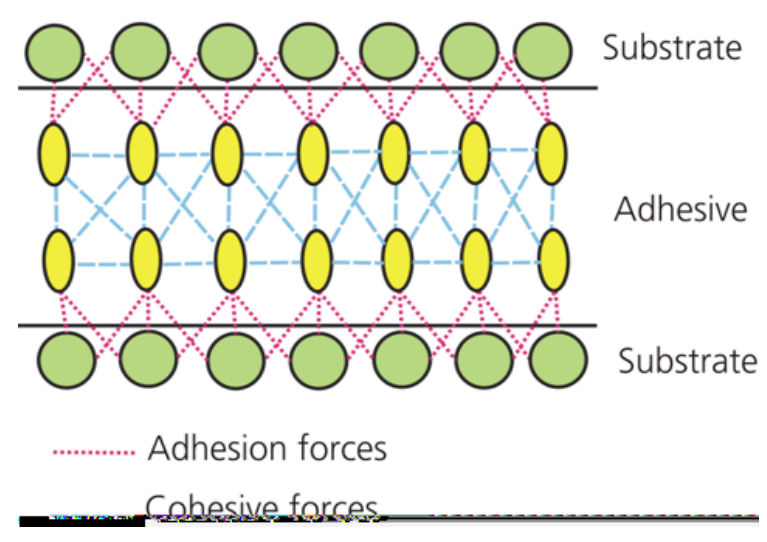

Figure 1: Adhesive and Cohesive forces (ASC, n.d.)

Four molecular properties dictate the properties of the adhesive in the cohesion zone (where the adhesive is): (1) the chemical bonds within the polymers of the adhesive; (2) the chemical bonds due to crosslinking of the polymer; (3) the intermolecular interactions between the molecules in the adhesive; and (4) the mechanical adhesion between the different molecules in the adhesive (ASC, n.d.). Both cohesion and adhesion have a role in maximizing the strength and effectiveness with which an adhesive adheres to a substrate. When a bond fails, it can be due to adhesive failure, cohesive failure, or substrate failure. An adhesive failure occurs if the adhesive and the substrate separate, a cohesive failure occurs if the adhesive itself breaks, and a substrate failure can occur from a tensile stress causing the substrate to break or a flexural stress causing the substrate to fail before the adhesive. A substrate failure can also be thought of as a cohesive failure of the substrate. In general, most adhesives will perform better if the primary stress felt is tensile or shear stress (ASC, n.d.). These types of stresses pull evenly on the substrate and adhesive. A peel or cleavage stress, on the other hand, causes an uneven stress to be felt by the adhesive. With these types of stresses, one side of the adhesive joint is theoretically under zero stress, while the opposite side has a relatively small, concentrated stress being applied to it, making it possible to cause failure at lower 
levels of stress than that of shear and tensile stress. A combination of the stresses described often occurs, making single-stress laboratory testing unrepresentative of real world samples. Examples of the four types of stresses typically experienced can be seen in Figure 2.

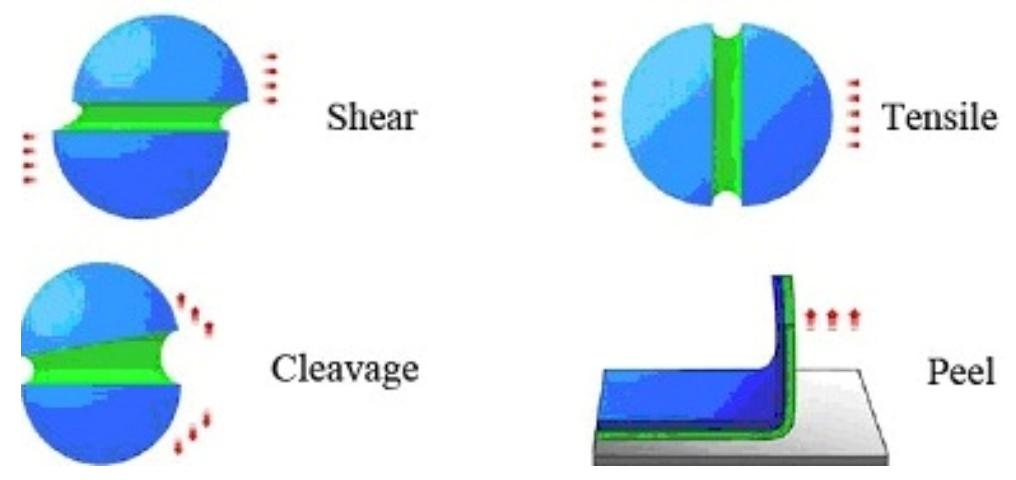

Figure 2: Different types of stress (ASC, n.d.)

The main characteristics of plastic substrates and the coating applied that affect adhesion are substrate topography, coating rheology, and substrate wetting. The topography of the substrate can influence adhesion, especially if the substrate has a rough surface. A rough surface creates physical points for a coating to mechanically interlock, or latch onto a substrate. The coating could also chemically interact with the substrate, helping achieve adhesion. Adhesion on a smooth surface, on the other hand, would only occur by chemical interactions.

Rheology is the deformation and flow of matter, be it solid, liquid, or gas. The viscosity and other rheological properties of the coating are important in determining the ability of the coating to wet the substrate (ASC, n.d.). The molecular structure of the polymer, specifically its chain length and the number of side chains and polar groups, influences the viscosity. Side chains and polar groups can have an effect on the movement and freedom of both the main and side chains; the longer the chains and the 
more interactions polar groups have with each other, the less freedom the coating structure has to move about, thus increasing viscosity. A high viscosity is advantageous in coatings where one would want minimize excess flow of the coating on the substrate (especially if the coating or adhesive was sandwiched between bonded joints). However, various viscosity requirements are applicable, depending on the application. Lower viscosities are needed for applications where the coating needs to exhibit a greater degree of flow, such as atomization in spray-coatings. Depending on the formulation of the coating, its viscosity can generally be increased or decreased by adding thickening agents or solvents, respectively. Most waterborne coatings, such as the coating used in this study, demonstrate complex rheological behavior, such as shear thinning and thixotropy. A shear thinning coating will display a reduction in viscosity as the shear rate of a stress is increased. If a coating's viscosity decreases as a function of time of shearing, the coating displays thixotropic behavior. Waterborne coatings, such as the one in this study, can have their rheology modified with thickeners such as hydroxyethyl cellulose.

Thixotropic flow allows for a coating to recover its viscosity fast enough so there is little sagging but slow enough to allow for good leveling (Wicks, 2007).

The final characteristic is wetting. Wetting is the ability of a liquid to form an interface with a solid substrate. Wetting can be measured in a variety of ways, but the most quantitative and direct technique measures the contact angle of a liquid droplet on the surface of the substrate of interest (Wicks, 2007). The contact angle is the angle formed between a droplet of the liquid and the substrate as shown in figure 3 . Better the wetting, the smaller the contact angle.

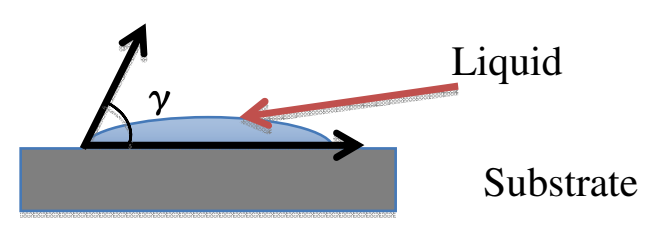


Figure 3: Contact angle ( ) of a liquid on a solid substrate

Although not the only factor to influence adhesion of a coating to a substrate, wetting is a major factor leading to adhesion. Complete wetting enables full coatability, that is, the coating will completely cover the substrate. This will allow for intermolecular contact and ultimately lead to interaction and a large contribution to adhesion (Wicks, 2007). The relative surface tension of the coating and the surface energy of the substrate determines if wetting will occur.

Surface energy is the excess free energy associated with molecules at the surface compared to molecules in the bulk of a liquid (Weldon, 2009). Surface tension is dependent on the forces of attraction between the molecules that make up the coating. In general, the more polar groups in the coating, the stronger the attractive forces, which give rise to a high surface tension and the tendency to form droplets on surfaces (Wicks, 2007).

The coating must have a surface tension lower than the surface energy of the substrate to achieve wetting. However, the surface energy of common plastic substrates can vary drastically. For example, the surface energy of Teflon is $\sim 20 \mathrm{erg} / \mathrm{cm}^{2}$, while the surface energy of polyethylene terephthalate and polypropylene are 44 and $\sim 30 \mathrm{erg} / \mathrm{cm}^{2}$, respectively (Smeets, 2004). Polymers like polypropylene are composed of hydrocarbons, and the forces holding the hydrocarbons together are weaker than those that hold the coating together. Therefore organic coatings, with typical surface energies above 50 $\mathrm{erg} / \mathrm{cm}^{2}$, will typically not wet the surface of a polyolefin such as polypropylene (Smeets, 2004).

\subsection{Introduction to Polypropylene}


As mentioned in section 1.2, most polymers used in industry have low surface energy and do not have polar functional groups on their surface. Both of these factors result in poor adhesion properties. For years, industry has done extensive research on adhesives and how they work. More recently, adhesion research has become focused on polymers due to their appealing bulk, mechanical, and surface properties, low costs, and design flexibility. It has been concluded the chemical groups at or near the surface ((i.e. short range forces) control adhesion between polymers and coatings. However, not all coatings applied to polymers stick. This is mainly due to the polymer, as certain types have poor adhesive properties. Research (Bikerman 1968, Brewis 1985, Levine 1964) has concluded that when trying to improve surface tension, the main aims are to remove weak boundary layers (transcrystalline low cohesive strength regions of low molecular mass compounds (Carrino, 2004)), and to improve on the inadequate chemical functionality of polyolefins and increase the surface tension of the substrate to allow for improved wettability on the polymer surface. The coating must have a surface tension equal to or lower than that of the substrate to achieve good wetting, and therefore good adhesion. Plastics have a variety of surface tensions, but most are very low. Polypropylene (Figure 4) in particular has a low surface energy $\left(30.1 \mathrm{erg} / \mathrm{cm}^{2}\right)$, making it very hard to coat (Lawniczak, 1993).

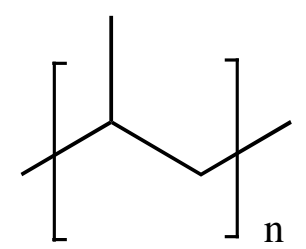

Figure 4: Polypropylene

Polypropylene was discovered in 1951 by Paul Hogan and Robert L. Banks, researchers at Phillips Petroleum Company (ACS, 1999). They accidentally discovered 
polypropylene and polyethylene while trying to convert propylene and ethylene (hydrocarbons produced when refining natural gas) into components for gasoline (ACS, 1999). During these undertakings, the two researchers studied catalysts and decided to modify the catalyst they originally used (nickel oxide) with small amounts of chromium oxide (ACS, 1999). After the reaction went to completion, they noticed the products with nickel oxide as the catalyst had produced the typical liquids, but the catalyst with the chromium oxide produced a white, solid material (ACS, 1999). They then switched the focus of their research from making component for gasoline into making plastics. In less than six years, Phillips management took the new plastics from the initial discovery and research phase to a full-scale plastic processing plant (ACS, 1999). Even today, the chromium catalyst (and different variants) is used to make plastics such as polyethylene and polypropylene.

Polypropylene has many variations - there can be isotactic (all methyl groups are positioned on the same side of the backbone), syndiotactic (the position of the methyl groups alternate), and atactic (random positioning) versions, as well as homopolymers (one polymer) and copolymers (more than one polymer). Random copolymers are generally formulated using ethylene (or higher alkene) as copolymers. The number of crystalline and amorphous regions in the polymer dictates certain characteristics, so ethylene introduced into the polypropylene manifests itself as a defect in the chain regularity, thus inhibiting the chain's crystalizability (Karian, 2003). This gives the thermoplastic better impact properties, improved clarity, a lower melting point, and superior flexibility. Block copolymers are also used, and unlike random copolymers, they contain two or more distinct blocks of polymers. The copolymerized part of the material has the potential to be rubbery and may form a separate dispersed phase within the PP 
matrix. Therefore, block copolymers can be tougher than homopolymers and have better impact resistance, even at low temperatures (albeit at the expense of transparency and softening point) (Tanizaki, 1999). Depending on the blocks, both types of PP copolymers may give a softer feel to film and fiber products when compared to PP homopolymers, although they may be more expensive.

Additives such as heat stabilizers, release agents, antistatics, and UV stabilizers are often used in processing PP (Pijpers, 2001). Fillers such as glass fibers, lime, talc, carbon black, and pigments are used as well (Pijpers, 2001). Fillers are often used as extenders, reducing the final cost of the product. They are also used to improve stiffness and impact resistance. The fibrous fillers tend to increase properties such as tensile and flexural strength, heat deflection temperature, and creep resistance. Depending on the end-use of the polypropylene, different properties such as modulus and density can vary as well. Therefore, the results of testing done on one type of polypropylene will not always be the same with another type of PP, and the manufacturing process of PP should be taken into account when using and testing samples.

\subsection{Polypropylene Applications}

Different types of molding processes exist to shape plastics, such as extrusion and injection molding. Injection molding consists of mixing and heating the components, which are then injected into a mold where the polymer cools and hardens. On the other hand, extrusion molding melting the components into a liquid and then forcing them through a die, forming the polymer into a long tube shape, which is subsequently cooled. The biggest outlets for PP are injection-molding applications. Uses include packaging, parts for electronic and electrical appliances, caps and closure, toys, luggage and a variety 
of household and miscellaneous goods (ICIS, n.d.). The next largest outlet is the fibers sector. Applications include carpet face yarn, sportswear, thermal underwear, and uses in the non-woven market. Advantages offered for fibers and fabrics by PP include low specific gravity (which means greater bulk per given weight), strength, chemical resistance, and stain resistance (Karian 2003). PP has been especially useful as sheets for thermoforming applications. Thermoforming is a process where a plastic sheet is heated so it can be stretched and formed to a specific shape (by a mold), and then cooled and trimmed. Thermoforming is used to make film grade PP, which offers excellent optical clarity and low moisture vapor transmission. These films are often used in the packaging of sweets, snack foods, cigarettes, capacitors and other electronic films, photography applications, graphic arts applications, and pressure sensitive tape backing and labels (ICIS, n.d.). The blow molding and extrusion molding of PP have much smaller markets, as other polymers dominate them. An application of these two molding types includes bottles for food items. Polypropylene is also used extensively in the automotive industry because of its low density, good mechanical properties, and good injection molding characteristics (ICIS, n.d.). PP has been used to make battery cases, heat and air conditioning ducts, fan blades, interior trim, and other car fascia. Its heat resistance also makes it ideal for use in components around the engine.

Finally, PP is used in the construction industry as siding for residences. Siding is used on the exterior of homes to provide protection from the elements and to shed water. Siding is also decorative in nature, and can add to the value of a property. In the past, siding was made primarily from wood. However, this proved to be ineffective, especially for those living in very humid and wet conditions, as the panels would rot, warp, and deteriorate. However, as technology has advanced, siding made from polymers was 
introduced into the commercial market. Initially, polymeric siding had many problems, such as fading, cracking, heat sensitivity, lack of insulation, and poor aesthetics. Most of these problems have now been alleviated as technology has advanced.

The most common polymer siding is vinyl siding (polyvinyl chloride), although polypropylene siding (the subject of the report), has become more common as the molding process allows for deeper patterns and crisper edges than in vinyl siding. CertainTeed is one of the leading polypropylene siding manufacturers, and samples of their injection molded polypropylene siding are tested in this study.

Polypropylene siding doesn't warp, crack, or rot as easily as wood with extended exposure to the elements. Another key selling feature for most consumers is the fact that polypropylene siding does not have to be repainted. As in many commercial products, it is often important to have a wide range of textures and colors available to the consumer. As technology has improved, the range of textures and colors available for consumers has increased for the polypropylene siding market. The best way to add color to siding without adding pigments directly to the formulation of the polymer is to coat the siding. Again, this poses a challenge, as plastics are generally hard to wet by coatings and adequate adhesion is hard to achieve.

\subsection{Increasing Adhesion to Polypropylene}

One of the main ways to increase the adhesive strength between a high surface tension, polar organic coating and a low surface energy, nonpolar polymer substrate is to form a block copolymer of the nonpolar substrate. To form a block copolymer, amphiphilic polymers (polymers with both hydrophobic and hydrophilic portions) are attached to the substrate, with the polar ends available to interact with organic coatings. For this case, there are two possible adhesion mechanisms. Dispersion forces are the 
main attractive term in a sharp interface (Brewis, 1985). The other mechanism would be the formation of a diffuse interface resulting from interdiffusion and entanglement of the polymers from both phases (Polini, 2002). This technique requires high molecular weight polymers, at least high enough so entanglement will take place. The cohesive fracture energy of polystyrene, for example, declines by several orders in magnitude when the molecular weight is reduced to $\mathrm{Mw} \sim 3,000$ (Hintze-Bruning, 2000).

Treating the surface of a polymer substrate to increase adhesion is popular as well, and there are various ways to achieve a surface treatment. Chemical treatments can improve adhesion by removing potential weak boundary layers (WBL) of plastics, increasing the surface roughness, and preparing the surface for diffusion by softening or plasticizing the outermost layer (Ryntz, 1994). Weak boundary layers are transcrystalline low cohesive strength regions of low molecular mass compounds (Carrino, 2004). They have an inverse relationship with adhesion, as the low molecular weight species discourages mechanical interlocking between the adhesive and the substrate. Weak boundary layers are often introduced into polymers during the processing stage. For example, during extrusion molding, the convection currents experienced by the material upon heating can bring additives to the surface (Carrino, 2004). During injection molding, the mold itself can contain additives. The additives from both types of processing can introduce weak boundary layers onto the surface of the polymer.

Chemical treatments also have the ability to create new chemical/functional groups at the surface of a substrate. One method to achieve this is chemical modification with acids and oxidizers, which can increase the surface polarity of a substrate. This added polarity would increase the interaction of molecular forces between substrate and coating, which would in turn increase the adhesion between the two. Using solvents also 
provides the added benefit of cleaning the substrate of any organic contaminants or soils, both of which can reduce adhesion. Other ways to promote adhesion include surface treatments with corona, flame, and plasma.

Corona, flame, and plasma treatments are effective and allow for surface modification of the substrate without affecting the bulk properties. The term 'corona' is used to describe the condition of a gas, usually air, between two electrodes. Under a strong enough electric field, air breaks down into radicals, ionized molecules, ions, and photons, which conduct electricity (Awaja, 2009). This process ruptures covalent bonds on the surface of the substrate. Free radicals created on the surface can combine with radical oxygen and other species in the air, increasing polarity and subsequently, surface energy (Awaja, 2009). Corona treatment produces a very high voltage discharge, up to 50,000 volts. This can cause streaking and other surface marks, as well as complete surface deformation.

A corona discharge unit has two parallel electrodes adjacent to each other, and the electrodes cannot be spaced further than 0.125 inches $(3 \mathrm{~mm})$ apart (LECTRO, n.d.). Due to this limitation, corona treatment is generally not used to treat surfaces of extruded or blow-molded objects of three-dimensional shape (LECTRO, n.d.).

Flame treatment can be used to improve the bond characteristics of threedimensional parts, among other things (LECTRO, n.d.). Flame treatment is essentially a very fast and controlled intensive oxidation of the very thin surface layer of a polymer surface. In other words, the surface is exposed to a flame at a certain temperature and for a set amount of time. This treatment has a variety of drawbacks, most notably that it is unsafe to expose plastics to hot flames due to charring. Other drawbacks include 
availability of natural gases used, and the increase of insurance premiums for companies that use this treatment (LECTRO, n.d.).

Corona treatment produces an electric arc that is uncontrolled and may deform the substrate being treated. Plasma treatment, on the other hand, is designed to 'soften' the arc in order to control and lessen the extent of damage to the surface. A blower in the plasma discharge head supplies a constant flow of air, which deflects the arc and spreads it out. Compared to corona arcs, the arc produced by a plasma treater produces a much smaller voltage, with a maximum around 15,000 volts. Plasma is an ionized gas containing both charged and neutral particles, such as electrons, ions, atoms, molecules, and radicals (Polini, 2002). Inert gas plasmas (such as Ar) are used to help crosslink polymer surfaces. Reactive plasma treatments (such as $\mathrm{N}_{2}, \mathrm{NH}_{3}, \mathrm{O}_{2}, \mathrm{CF}_{4}$, and $\mathrm{SF}_{6}$ ) create functional groups. In general, such treatments alter surfaces in one or more of the following ways: (i) by removing weak boundary layers; (ii) by changing the surface topography; (iii) by changing the chemical nature of the surface; (iv) by modifying the physical structure (Sorrentino, 2004). Green and others found surface pretreatments are especially effective on polyolefins such as polypropylene (Green, 2002). It was found corona discharge, flame, fluorination, $0 \mathrm{~N}$ vacuum plasma, and air plasma were all highly effective in increasing adhesion. The listed pretreatments added functional groups to the surface or caused molecular modification at different depths of the surface. Functional groups reported to aid adhesion at the surface of polymers such as PP include $\mathrm{C}=\mathrm{O}$, in particular, but also $\mathrm{CO} \sim, \mathrm{COO} \sim, \sim \mathrm{OH}$ and $\sim \mathrm{OOH}$ (Awaja, 2009). Besides adding functionality to the surface, the pretreatments can modify the surface topography of the polypropylene, roughening the surface as to create more points for molecular and mechanical interlocking. 
Although ideal for introducing functional groups to achieve better adhesion, an ageing affect must be taken into account when using plasma and flame treated substrates. Ageing can lead to chalking, crack formation, discoloring, and most importantly, loss of adhesion. Uptake of environmental contaminants, re-orientation of surface groups and further chemical reactions at the surface with time can reverse the increase in adhesion gained by the surface treatment (Awaja, 2009). Some studies have suggested this is due to the newly formed polar molecules reorienting themselves into the bulk material (Awaja, 2009). Another theory suggests polar chemical groups diffuse into the polymer matrix, a side effect being surface degradation through the rapid interaction of the polymer with radicals or ions (Awaja, 2009). It has also been suggested that the bulk material plays a role, but further research is needed to examine the polymer sub-surface layers and explain their effect on surface properties. 


\section{Coating Characterization - Initial Work}

A major part of this project is investigating the effectiveness of one of the aforementioned solutions to improve adhesion to polypropylene - surface modification by plasma treatment. CertainTeed provided Cal Poly with samples of their polypropylene siding, which is not pure polypropylene, but compounded polypropylene (contains fillers, processing additives, etc.). They also provided samples of a brown color coating used to paint their siding. Characterizing this coating was the focus of the initial work. The work was done with materials and equipment supplied by CertainTeed Company and the Cal Poly Chemistry and Biochemistry stockroom. The author of this report and another graduate student, Megan Hart, completed the initial work. In-depth analysis and results from the initial coating characterization work are seen in Megan Hart's Graduate Project Report, entitled: Evaluation of Stain Blocking Primer Coatings with Low Volatile Organic Compound (VOC) Content and Effects of Drying Conditions on the Properties of Water Reducible Coatings for Polypropylene. This report can be found at the library of California Polytechnic State University, San Luis Obispo. The author repeated coating 
characterization tests described in the initial work, on a new batch of coating that was supplied. The initial and repeated works were then compared.

\subsection{Project Overview}

The main objective of early testing was to raise the surface tension of the supplied polypropylene (PP) siding sample from $\sim 30$ dynes $/ \mathrm{cm}$ to 60 dynes $/ \mathrm{cm}$, as well as increase the adhesion of the water-reducible coating supplied by CertainTeed company. The ideal conditions to achieve this goal were to be determined by varying the PP substrate's surface treatment and the drying time of the coating that was applied following the treatment. Presently, the practice followed by CertainTeed for drying the coated PP siding is to let the product dry at room temperature for seven days, preceded by partially drying the PP in an oven. Another objective of the early work was to reduce the sevenday hold time that is placed upon the coated PP. A more detailed description of this work can be found in a prior study (Hart, 2011). The results are described in a future section.

\subsubsection{Materials and Methods}

Two batches of brown coating (lot \# 1, received 9/13/2010, and lot \# 2 received 3/30/2011) were characterized and compared. This coating type was used throughout the study. Composition of the coating is proprietary information. A stainless steel pycnometer was used to determine the coating density in pounds per gallon according to ASTM D1457-98. The percent solids by weight were determined according to ASTM D2369-07. This method is written for solvent-based paints, so in place of acetone, $3 \mathrm{~mL}$ of deionized water was added to each pan. Volatile organic compound (VOC) levels were determined by D6886-03 using an Agilent GC/MS/FID. Rheology measurements were done on a TA Instruments AR 2000 Rheometer. Oven temperature profiling was done 
using a Despatch LFD Series Oven combined with a Vernier Stainless Steel Temperature Probe along with Vernier Logger Lite software. The oven was used at $60^{\circ} \mathrm{C}$ and $70^{\circ} \mathrm{C}$.

A key indicator of the state of drying of the coating is the amount of residual solvent left in the coating after coating application. Solvent retention data was obtained using a TA Insturments Q500 thermogravimetric Analysis (TGA) device with aluminum pans. The samples were prepared doing a drawdown, using a 4 mil Byrd drawdown applicator, on a clean panel of glass. The samples were then allowed to dry for various amounts of time before they were removed from the glass panel with a razor blade. The removed sample was subsequently cut into pieces, and three of the pieces were placed into a tared aluminum pan, which was used to run the TGA experiments. The samples were heated at a rate of $20^{\circ} \mathrm{C}$ per minute from ambient temperature to $590^{\circ} \mathrm{C}$.

Finally, adhesion testing was conducted on PP panels coated with the supplied waterreducible organic coating. For initial testing, the PP was first treated with a UVSP Dyne Laboratories Corona Treatr no. N001-020 for 0, 5, 15, or 30 seconds. The entire panel was corona treated. The increase in surface tension was measured using AccuDyne Test dynes solutions (made by Diversified Enterprises). Dyne solutions are solutions of known surface tension and come in individual bottles, with Dyne solutions ranging from 30 dynes $/ \mathrm{cm}$ to 70 dynes $/ \mathrm{cm}$, in increments of 2 dynes $/ \mathrm{cm}$. The surface tension of a substrate or coating can be inferred by placing a droplet of a Dyne solution onto the surface of the substrate and visually observing the degree of wetting of the Dyne solution on the substrate. For example, if you place a 66 dynes/cm Dyne solution onto a substrate and the solution dewets, it can be deduced that the surface tension of the substrate is lower than 66 dynes/cm. However, if you place a 64 dynes/cm Dyne solution onto the same substrate, and the solution wets the surface of the substrate, it can be determined the 
surface tension of the substrate is between 64 and 65 dynes $/ \mathrm{cm}$. The Dyne solution's degree of wetting is visually observed, so reproducibility is a problem; a more precise method to determine surface tension is with contact angle measurements. However, this is not practical in a manufacturing setting, so Dyne solutions were used for this project. Dyne solutions are the most popular field method to empirically test surface tension (Stewart, 2005).

For the different lengths of corona treatment, four panels were made, for a total of 16 panels. Two of the four coated panels from each treatment time were allowed to dry at room temperature for 24 hours, while the other two were dried in the Despatch oven at $70^{\circ} \mathrm{C}$ for 5 minutes and then at room temperature for 24 hours. The adhesion testing followed ASTM D3359, and used a Byko-Cut Universal tool to make the crosscut. Scotch tape 375 was used for the pull-off portion of the test. The oven-temperature profiling procedure is described in another work (Hart, 2011). 


\section{Results and Discussion}

\subsection{Summary of Results}

Table 1 shows the results for density, percent solids by weight, and VOC measurements for the first batch and second batch of brown coating. The density is shown in both weight per gallon and grams per liter units. The second batch of the same brown coating was supplied at a later time, and the testing was repeated to ensure the second batch of brown coating was similar to the first batch.

Table 1: Characterization results for coating lots \#1 and \#2

\begin{tabular}{|c|c|c|c|c|c|c|}
\hline \multirow[t]{2}{*}{ Coating } & \multicolumn{2}{|c|}{ Density } & \multirow{2}{*}{$\begin{array}{l}\text { \% Solids } \\
\text { by weight }\end{array}$} & \multirow{2}{*}{\multicolumn{3}{|c|}{ VOC $(g / L)$}} \\
\hline & $(g / L)$ & (lbs/gal) & & & & \\
\hline \multirow[t]{3}{*}{$\begin{array}{c}\text { Brown } \\
\text { (Lot \#1) }\end{array}$} & \multirow[t]{3}{*}{1090} & \multirow[t]{3}{*}{9.1} & \multirow[t]{3}{*}{36.5} & & $\begin{array}{c}\text { Coating } \\
\text { VOC }\end{array}$ & $\begin{array}{c}\text { Material } \\
\text { VOC }\end{array}$ \\
\hline & & & & Run 1 & 270 & 110 \\
\hline & & & & Run 2 & 250 & 100 \\
\hline \multirow{2}{*}{$\begin{array}{c}\text { Brown } \\
\text { (Lot \#2) }\end{array}$} & \multirow[t]{2}{*}{1095} & \multirow[t]{2}{*}{9.1} & \multirow[t]{2}{*}{34.4} & Run 1 & 269 & 110 \\
\hline & & & & Run 2 & 252 & 103 \\
\hline
\end{tabular}

As can be seen from the data in Table 1, the density, solids, and VOC content from the initial work are very similar, so it can be said with reasonable confidence the coatings are the same. It is interesting to note the second batch had $\sim 2 \%$ less solids by weight.

Rheological testing in the form of viscosity as a function of shear rate was completed. Initially, the viscosity versus shear rate data was obtained at shear rates from 
$0.02 \mathrm{~s}^{-1}$ to $200 \mathrm{~s}^{-1}$ with 10 points per decade at $25^{\circ} \mathrm{C}$. A continuous ramp method was also used with times of 2, 5, 10, and 20 minutes. However, inconsistent and scattered plots were obtained. Numerous attempts were made to generate clean results without success. Upon close examination of the cone-and-plate fixture on the rheometer, it was found there was dried coating around the edges of the fixture. This was due to the length of viscosity measurement procedure ( 40 minutes). More consistent plots were achieved (Figure 5) by scanning the shear rate range in shorter lengths of time $(2,5,10$, and 20 minutes).

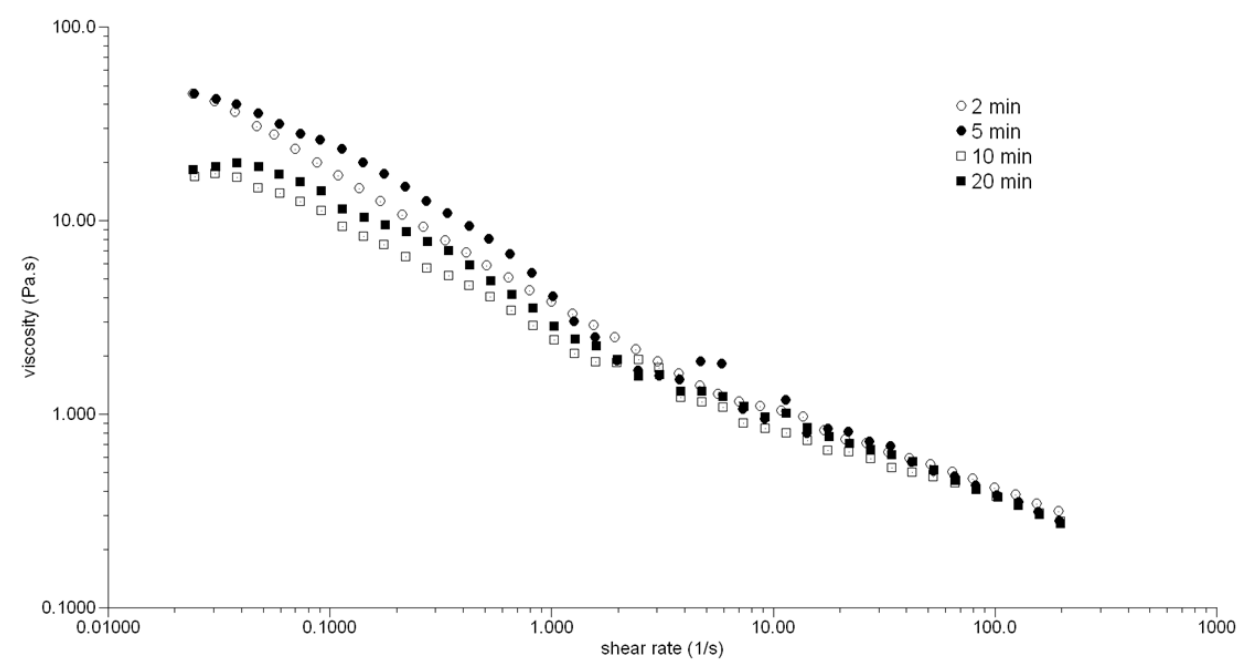

Figure 5: Rheology results for brown coating (lot \#1) - 2, 5, 10, and 20 minute tests The same tests were done for the second batch of the coating. Similar problems and results were experienced for the 40-minute test. The continuous ramp method was repeated and similar results were seen when the 40-minute test was omitted (Figure 6). 


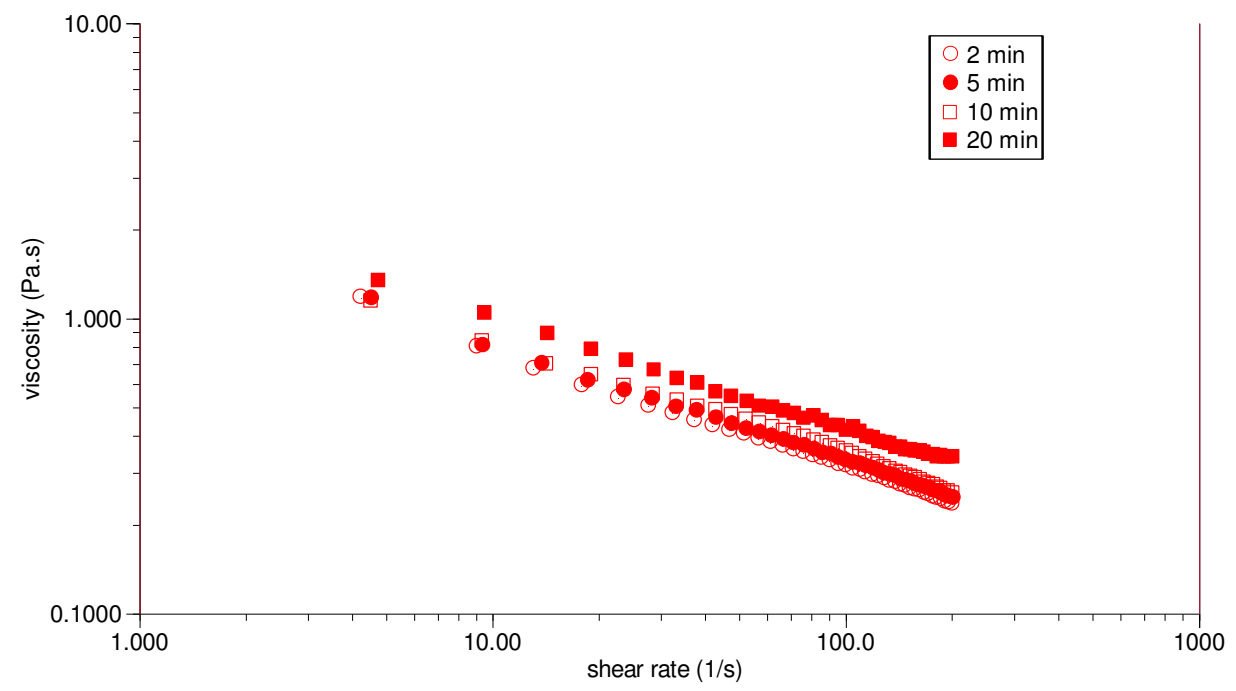

Figure 6: Rheology results for brown coating (lot \#2) - 2, 5, 10, and 20 minute tests As Table 2 and Figures 5 and 6 show, the rheological results from the first batch of

brown coating and the second batch are very similar. Therefore, it can be assumed the new batch of coating (lot \#2) will perform similar to how the first batch of coating (lot \#1) would during testing.

The results for the oven temperature profiling can be found in the previous study (Hart, 2011). Based on that work, it was determined that optimum oven placement to dry the panels was against the back wall of the oven, as this provided drying temperature consistency.

The solvent retention results, completed on a TGA, can be found in the previous study (Hart, 2011). Based on that work, it was found that coated polypropylene panels only need three days of room temperature drying is to reach complete drying

Adhesion testing was performed on coated (brown coating, lot \#1), corona treated samples of polypropylene siding. The treatment time of the polypropylene substrate was varied from 0 seconds to 120 seconds. The surface tension was measured using AccuDyne Test dynes solutions. For all corona treatment times ranging from 15 to 60 seconds, the polypropylene sample's surface tension increased from $\sim 30$ dynes/cm to 38 . 
A corona treatment time of 120 seconds increases the surface tension to 40 dynes $/ \mathrm{cm}$.

Samples treated for more than 60 seconds would have melted or become physically deformed from overexposure to the corona arc. Samples treated for 0, 5, 15, and 30 seconds were visually undamaged and chosen for testing. They were coated and then allowed to dry, and adhesion testing was completed following the procedure described in section 3.1.1. Table 2 shows the results from this procedure.

Table 2: Adhesion test results (ASTM D3359)

\begin{tabular}{|c|c|c|}
\hline Treatment (Seconds) & $\begin{array}{c}24 \text { hrs. @ Room } \\
\text { Temperature }\end{array}$ & 5 min. @ $70^{\circ} \mathrm{C}$ \\
\hline 0 & $0 \mathrm{~B}$ & $0 \mathrm{~B}$ \\
\hline 5 & 0B & $0 \mathrm{~B}$ \\
\hline 15 & $1 \mathrm{~B}$ & $2 \mathrm{~B}$ \\
\hline 30 & 4B & $3 \mathrm{~B}$ \\
\hline
\end{tabular}

* 0B - worst; 5B - best

The polypropylene samples with no corona treatment ( 0 seconds) showed poor adhesion regardless of the drying procedure, with paint lifting from the surface everywhere the tape was in contact with it. As treatment time increased, the adhesion increased. The ranking values ranged from $\mathrm{OB}$ to $5 \mathrm{~B}$. A ranking of $\mathrm{OB}$ was the worst ranking - this ranking meant greater than $65 \%$ of the test area paint was removed from the crosscut test area. A ranking of 5B was the best ranking - this ranking meant none of the test area paint was removed from the crosscut test area. The rankings in Table 2 were average rankings taken between 3 samples for each treatment time and drying procedure, for a total of 24 samples tested. 


\section{Conclusion}

The results produced a characterization and comparison of two batches of the brown water-reducible paint provided by CertainTeed. The results showed the new batch of paint had similar physical properties to the batch of paint used in work described earlier (Hart, 2011). It was concluded the holding time of the coated panels for 7 days could be reduced to 3 days, as there was negligible differences in solvent retention after 3 days. This reduction in holding time was recommended to CertainTeed, although the 7 day holding time was followed for all work done in this report. Corona treatment of the PP panels raises the surface energy from $\sim 30$ dynes $/ \mathrm{cm}$ to 38 dynes $/ \mathrm{cm}$. This greatly affects the adhesion of the coating to the PP substrate. Adhesion testing confirmed this, as untreated panels showed $0 \mathrm{~B}$ adhesion, while treated panels showed vastly improved adhesion up to $4 \mathrm{~B}$ (using the crosscut adhesion test). 


\section{Primary Objectives of the Project - Adhesion}

This project required the completion of two main objectives: (1) quantify the effects of substrate composition modifications on coating adhesion; and (2) quantify long-term durability of coatings applied to polypropylene siding product. Additional tasks included initial testing to calibrate the plasma treater and the test procedure for an adhesion pulloff tester, investigation of the difference between weathered and non-weathered samples of siding taken from a test installation in North Carolina, and cleaning agent resistance improvements due to application of a clear-coat on top of the color coat.

All work discussed in this report was done with materials and equipment supplied by CertainTeed Company and the Cal Poly Chemistry and Biochemistry stockroom.

\subsection{Adhesion Testing}

This work relates to the adhesive bond between a coating and a solid polypropylene panel. Although the complex exchange between the two substances interacting is still unclear, hypothesized mechanisms have been discussed in section 1.3 , and ways to improve adhesion between two substrates were discussed in section 2.3. The increase in adhesion can be measured using instruments that measure adhesion. There are many techniques to achieve these measurements, and many are specific for the type of adhesion that has occurred (i.e., adhesion of a coating or adhesion of an adhesive). 
A semi-quantitative method to measure adhesion between a coating and a substrate is by the crosscut adhesion test (ASTM D3359). In this test, a hand-held device equipped with a small interchangeable blade has pressure applied to it (by hand) and is moved across the coated substrate so the blade cuts through the coating to the substrate. Another pass of the blade, this time perpendicular to the first pass, is completed. Then, a piece of Shurtape Hold Strong \# 00H39 tape is placed over the cross-hatch pattern, firmly pressed down upon the coating, and then pulled quickly from the test piece. The amount of coating that remains on the substrate is then visually compared to the guidelines listed in ASTM D3359.

A more quantitative way to measure adhesion between a coating and a substrate is by the pull-off adhesion method. In this method, an aluminum dolly is adhered via epoxy to the coated substrate of interest. A hydraulic pump is attached over the dolly and pressure is applied to remove the dolly. The force (in psi/MPa) required to remove the dolly is recorded and displayed on the pull-off instrument. This method offers more quantitative results, although similar to the crosscut test, repeatability has been a concern (Brown, 2005) (Placzankis, 2009).

Currently, these are two of the leading methods to measure the strength of the adhesive bond formed between a coating and a substrate. The crosscut adhesion method relies on quantitative results based on visual rankings. On the other hand, the pull-off adhesion method is lacking in reproducibility. Both tests are employed to evaluate the difference in adhesion between a coating on a treated substrate and on an untreated substrate.

\subsection{Materials and Methods}

\subsubsection{Plasma Treatment - Initial Testing}


Three types of polypropylene (PP) samples were tested. The PP panels from the initial work mentioned in section 3 were white, non-glossy panels and will be referred to as Type A panels. The inventory of the Type A PP panels was depleted, and CertainTeed provided Cal Poly with a different type of PP panel. These panels will be referred to as Type B panels. The inventory of the Type B panels was also depleted, and the sponsor once again provided a different set of PP panels. These panels were provided along with 15 other categories of panels with different chemical compositions. The different categories of panels contained different types and amounts of hindered amine light stabilizers (HALS), waxes, and adhesion promoters. This was done in the hopes of finding a PP formulation that would increase coating adhesion when compared to the original, standard production panel (the Category 7 panels - Table 3). All of the panels are referred to as Type $\mathrm{C}$ panels, and each category of panels are referred to by their Category number (i.e., Categories 1-16). A photograph of all panel types can be seen in Figure 9. The compositional differences are listed in Table 3. 
Table 3: Descriptions of Type C polypropylene panels

\begin{tabular}{|c|c|}
\hline Category \# & Description \\
\hline 1 & Control \\
\hline 2 & $0.4 \%$ HALS 1 \\
\hline 3 & $0.4 \%$ HALS $1+0.4 \%$ HALS \\
\hline 4 & $1 / 2$ the typical amount of lubricant \\
\hline 5 & The typical amount of lubricants \\
\hline 6 & $2.5 \mathrm{x}$ 's the typical amount of lubricants \\
\hline 7 & The typical amount of lubricants $+0.4 \%$ HALS $1+0.4 \%$ HALS 2 \\
\hline 8 & $0.5 \%$ EBS wax \\
\hline 9 & The typical amount of lubricants $+0.4 \%$ HALS 1 \\
\hline 10 & $\begin{array}{l}\text { The typical amount of lubricants }+0.4 \% \text { HALS } 1+0.4 \% \text { HALS } 2+ \\
1 \% \text { MAPP }\end{array}$ \\
\hline 11 & $\begin{array}{l}\text { The typical amount of lubricants }+0.4 \% \text { HALS } 1+0.4 \% \text { HALS } 2+ \\
3 \% \text { MAPP }\end{array}$ \\
\hline 12 & $\begin{array}{l}\text { The typical amount of lubricants }+0.4 \% \text { HALS } 1+0.4 \% \text { HALS } 2+ \\
10 \% \text { MAPP }\end{array}$ \\
\hline 13 & $\begin{array}{l}1 / 2 \text { the typical amount of lubricants }+0.4 \% \text { HALS } 1+0.4 \% \text { HALS } 2+ \\
3 \% \text { MAPE }\end{array}$ \\
\hline 14 & $\begin{array}{l}\text { The typical amount of lubricants }+0.4 \% \text { HALS } 1+0.4 \% \text { HALS } 2+ \\
1 \% \text { MAPE }\end{array}$ \\
\hline 15 & $\begin{array}{l}\text { The typical amount of lubricants }+0.4 \% \text { HALS } 1+0.4 \% \text { HALS } 2+ \\
3 \% \text { MAPE }\end{array}$ \\
\hline 16 & $\begin{array}{l}\text { The typical amount of lubricants }+0.4 \% \text { HALS } 1+0.4 \% \text { HALS } 2+ \\
10 \% \text { MAPE }\end{array}$ \\
\hline
\end{tabular}


Of the 16 types of polypropylene panels, categories 10-16 incorporated a certain amount of maleic anhydride emulsifiable waxes into the panels. There were two types used, with the first type being a maleic anhydride grafted polypropylene that functions as a coupling agent, which improves the processability and surface characteristics of plastics. This was referred to as MAPP in Table 3. The second is a maleic anhydride grafted polyethylene that functions as a coupling agent, and provides a balanced attraction between polar fillers/reinforcements and nonpolar polymers. This was referred to as MAPE in Table 3.

The Type A panels were $10 \mathrm{~cm} \times 13.6 \mathrm{~cm}$ x $0.3 \mathrm{~cm}$ and both Type $\mathrm{B}$ and Type $\mathrm{C}$ panels were $10 \mathrm{~cm} \times 15 \mathrm{~cm} \times 0.3 \mathrm{~cm}$ in dimension.

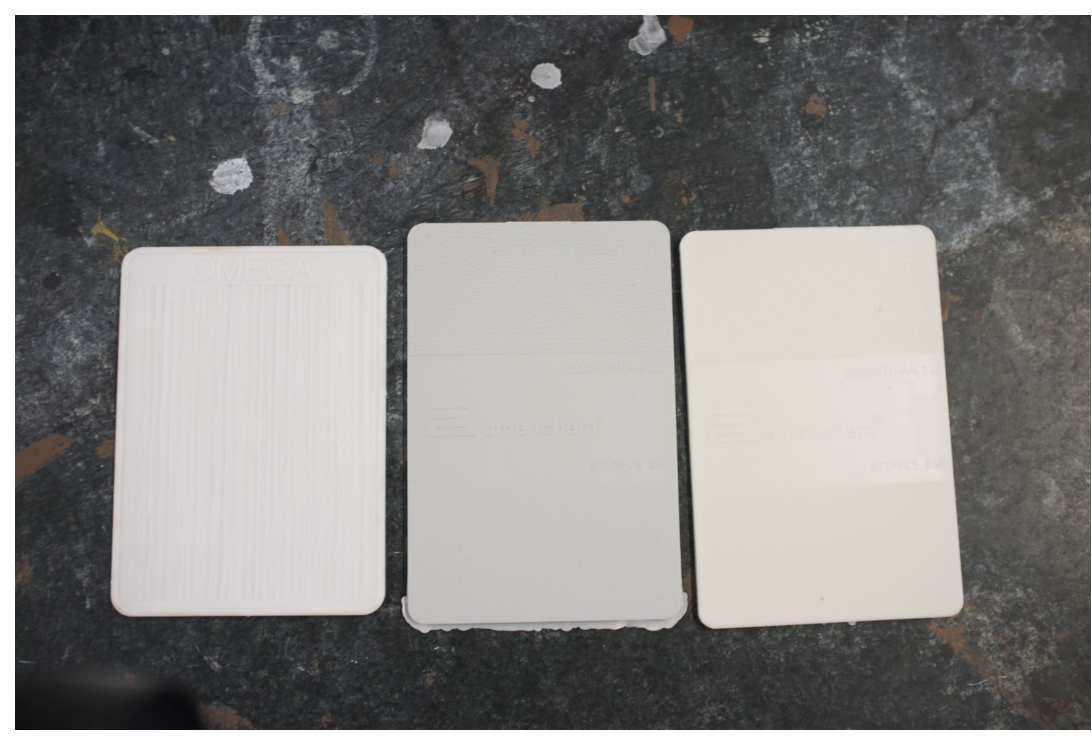

Figure 7: The three polypropylene panel types tested. From left to right: Type A, Type $\mathrm{B}$, and Type $\mathrm{C}$ panels

A Lectro Engineering Co. LTIII Forced Air plasma treater was used to treat polypropylene samples. The discharge head was held and stabilized with a conventional ring-stand and clamp set-up, as seen in Figure 8. 


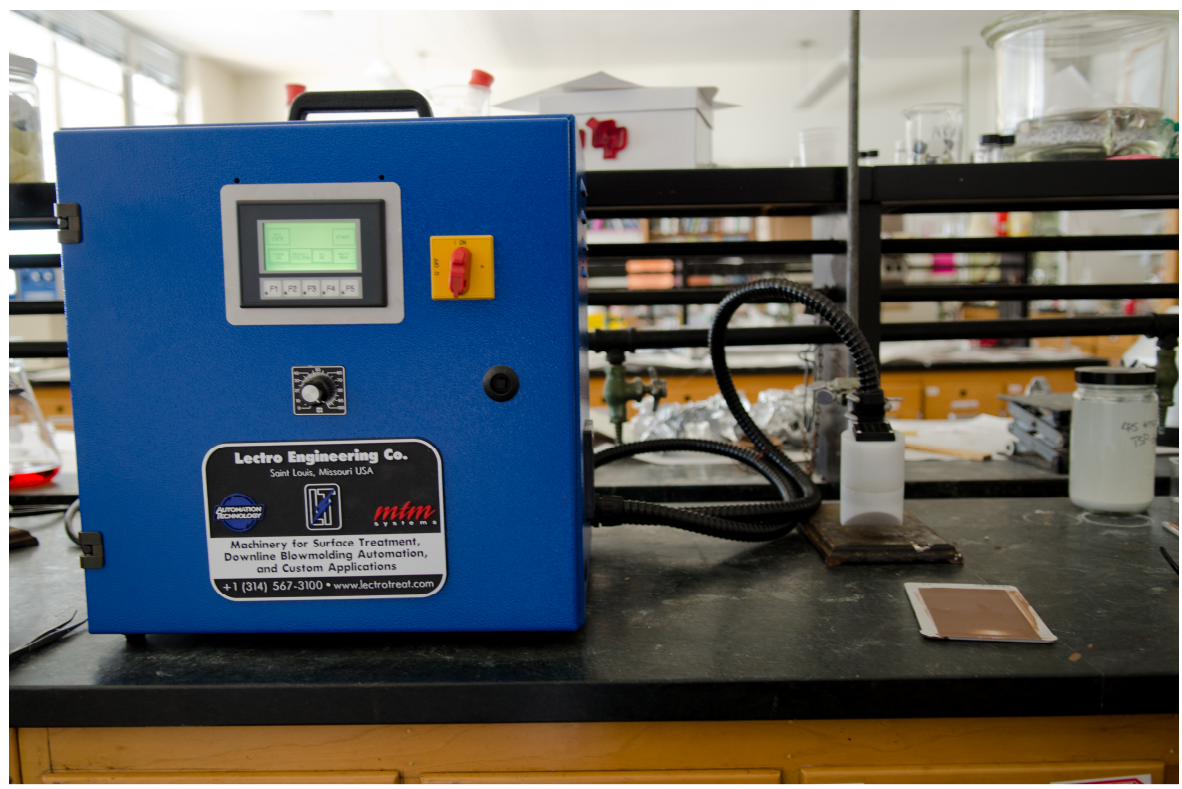

Figure 8: Plasma treater set-up

The adjustable variables for the plasma treater were distance from the discharge head to the sample surface, time of plasma treatment, and speed of air being blown by the blower. The velocity the air is blown directly affects the plasma arc, with a high velocity causing it to spread to the outer end of the electrodes. The speed can be adjusted by a potentiometer located on the front of the instrument. The potentiometer ranges from 0 100, with 100 being full-speed.

Initial testing was done to discover what affect the plasma treater had on the wettability of the Type A polypropylene samples. The PP panels were placed under the discharge head at a distance of $\sim 6 \mathrm{~mm}$, the blower was on the $100 \%$ speed setting, and an area as large as the discharge head (approximately 4in. x 3 in.) was treated for 15 seconds. Throughout this work, two approaches were used to test the affect of the plasma treater on the PP panels using Dyne solutions (Dyne solutions are described in section 3.1.1). The first approach is referred to as wetting testing. For wetting testing, Dyne solutions were placed on the surface of the PP via a disposable pipette. The solutions were placed as a droplet both on the treated area and an untreated area for a visual 
comparison. The wetting tension was recorded in a qualitative manner using Dyne solutions, and the degree of wetting was inferred.

\subsubsection{Dewetting Testing}

The second approach to test the affect of the plasma treater on the PP panels using Dyne solutions is referred to as dewetting testing. Dewetting is when the coating is spread onto the surface and then retracts to form droplets on the substrate. This occurs because the surface tension of the coating is greater than the surface energy of the substrate. The procedure is the same as in the previous section (for wetting testing), except after the solutions are placed on the surface of the PP as a droplet, the droplets were spread out using the same pipette used to dispense the droplet. The degree of dewetting was assessed in a qualitative manner. This entire test was repeated with the corona treater to compare the affects of plasma and corona treatment on PP samples. The corona treater and plasma treater shared identical test parameters.

\subsubsection{Ideal Process Conditions Using the Plasma Treater}

Testing was done to find the ideal parameters for the variables that could be adjusted for the plasma treatment. The process conditions that lead to improved wettability and adhesion were established by varying the distance from the discharge head to the sample surface, the time of plasma treatment, and the speed of air being blown by the blower. The testing was conducted using the Type A PP panels. The first test was to determine the shortest amount of time the panels could be exposed to the plasma arc while still exhibiting significantly improved adhesion. However, this was chosen to be 5 seconds due to the constraints of large-scale factory operations, as any more than 5 seconds of treatment would not be practical. The initial testing in section 4.1 
described that longer treatment times (greater than 60 seconds) would physically deform and discolor the surface of the panels.

Testing was done to see if the distance from the electrode head to the PP panel made a difference in adhesion, wetting, and dewetting. The plasma treater was placed 0.5 , $1,1.5,2,2.5$, and $3 \mathrm{~cm}$ from the PP panel. Two panels were tested for each distance. One panel was to test the wetting and dewetting (as in sections 6.2.1 and 6.2.2) at 30 and 40 dynes $/ \mathrm{cm}$. The second panel was used to test the wetting and dewetting at 50 and 60 dynes $/ \mathrm{cm}$. A total of six panels were also plasma treated, coated with the brown coating (lot \#2), let set for 5 minutes at ambient temperature, followed by 5 minutes in the oven at $70^{\circ} \mathrm{C}$ and then allowed to dry in ambient conditions for 7 days. They were then prepared for crosscut adhesion testing (following the procedure listed in section 3.1.1). Each panel used a blower speed of $100 \%$, a treatment time of 5 seconds, and one of the six distances being tested.

To determine the ideal speed of air being blown by the blower, the previously determined distance of the discharge head was set and the treatment time was held at 5 seconds, while the potentiometer controlling the air flow of the plasma unit was tested at 60-100 percent speed, in 10 percent intervals. Two panels were tested for each speed. One panel was to test the wetting and dewetting (as in sections 6.2.1 and 6.2.2.) at 30 and 40 dynes/cm. The second panel was used to test the wetting and dewetting at 50 and 60 dynes/cm. A total of five panels were also plasma treated, coated with the brown coating (lot \#2), let set for 5 minutes at ambient temperature, followed by 5 minutes in the oven at $70^{\circ} \mathrm{C}$ and then allowed to dry in ambient conditions for 7 days. They were then prepared for crosscut adhesion testing (according to the procedure listed in 3.1.1). Each 
panel used a distance of $0.5 \mathrm{~cm}$, a treatment time of 5 seconds, and one of the five blower speeds being tested.

The final parameters $(0.5 \mathrm{~cm}$ distance, $100 \%$ blower speed, and 5 second treatment time) were used for the remainder of the tests. It is possible other combinations may produce better results, as multi-variable testing was not done.

\subsubsection{Type B Panel Testing}

Wetting and dewetting testing was repeated with Type B panels. The methods described in 6.2.1 and 6.2.2 were followed, along with the new plasma treater parameters determined in the previous section (section 6.2.3.).

\subsubsection{X-ray Photoelectron Spectroscopy (XPS)}

X-ray Photoelectron Spectroscopy was used to quantify the chemical changes occurring on the surface of the polypropylene panels, as well as quantify the difference between the corona and plasma treatments. A Kratos Axis Ultra XPS instrument, located at the University of California, Santa Barbara (materials engineering department), was used with the help of Dr. Thomas Mates.

Untreated $1 \mathrm{~cm} \times 1 \mathrm{~cm}$ samples of Category 7 and Category 16 panels (refer to Table 3) were tested, as well as Category 7 samples that were corona treated for 5 seconds and 30 seconds. Category 7 and Category 16 samples that were plasma treated for 5 and 30 seconds were also tested. Category 16 samples were chosen in particular due to unusually high initial pull-off adhesion results. The samples were prepared using the parameters defined in section 6.2.3.

\subsubsection{Adhesion Testing}


Adhesion testing was done to indirectly quantify the increase of functional groups and mechanical interlocking points on the PP panels due to plasma treatment. Initial adhesion testing was performed on the Type A PP panels, and the panels were prepared as described in section 6.2.3. Crosscut adhesion testing followed the same procedure as described in section 3.1.1, except the plasma treater was used in place of the corona treater, and the two test panels were treated for 5 seconds in 8 different sections. This allowed for the entire panel to be treated. An untreated control panel was also tested.

\subsubsection{Adhesion Testing with Type B Panels}

Once the testing on the Type A PP panels was completed, Type B panels were used for testing. However, the Type B panels had raised serial numbers on them, which hindered the drawdown process. Therefore, a 4 mil drawdown bar was used to avoid the serial numbers, which would have made for incomplete drawdowns. Crosscut adhesion testing was done on both plasma treated and corona treated panels. The procedure for treating the samples was described in section 6.2.3. The samples were then coated with the brown coating using a 4 mil drawdown bar, allowed to set for 5 minutes in ambient conditions, then placed in the oven at $70^{\circ} \mathrm{C}$ for 5 minutes, followed by 7 days of room temperature drying. Crosscut adhesion testing followed that of section 3.1.1, with 3 panels being tested for both types of treatment.

A Deflesko PosiTest AT-A automatic adhesion tester was used in an attempt to better quantify adhesion results. The PosiTest measures the force (in psi/MPa) required to pull a specified test diameter of coating away from a substrate using hydraulic pressure. Metal dollies of varying size (this experiment used $20 \mathrm{~mm}$ diameter dollies) are adhered to the clean surface of the coated substrate by a commercial epoxy adhesive. The adhesive is allowed to dry overnight and then the self-aligning, quick-coupling actuator is 
placed over the dolly. The hydraulic pump applies pressure to remove the dolly and adhered coating from the surface. An example of a dolly after removal from a panel can be seen in Figure 9.

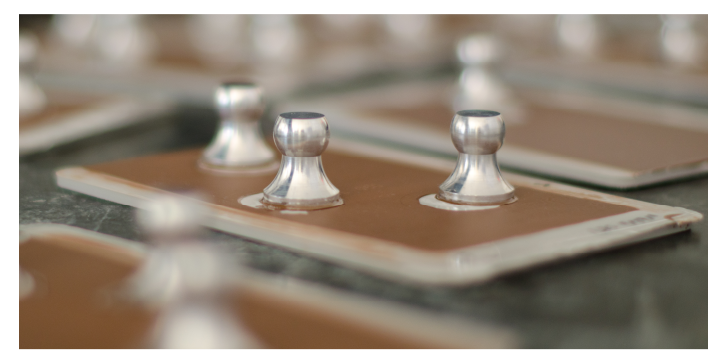

Figure 9: Aluminum dollies after removal from the surface of the PP panel by the PosiTest adhesion tester

There is a digital Pull Rate Indicator that monitors how much pressure it takes to pull the dolly off the surface.

The testing was completed following ASTM D4541-09. Samples were prepared as all other surface treated panels were, although multiple treatments were tested (no treatment, plasma treatment, and corona treatment). Four panels for each treatment variation were tested. The procedure for the treated samples started with a plasma or corona treatment for five seconds, which was followed by a drawdown of the brown coating. The samples were allowed to dry in ambient conditions for 5 minutes. They were then placed in the oven at $70^{\circ} \mathrm{C}$ for 5 minutes, taken out and allowed to dry for 7 days. The dollies to be applied to each panel were prepared by rubbing the bottom of the dolly four times across a 3M abrasive hand pad. Three dollies were used for each panel, giving a total of 12 results for each treatment variation. After the samples had dried for 7 days, the surfaces were wiped with a KimWipe to remove any lingering dust or impurities. The dollies had a thin layer of epoxy adhesive applied to their underside, and then they were placed firmly onto the PP panel's coated surface. Excess epoxy was removed by cotton 
swab, with care being taken not to move or twist the dolly. The panels were left to dry overnight, and then the PosiTest pull-off instrument was used.

The removal of the excess epoxy from the dolly was a persistent problem throughout testing, as the dollies would continue to rotate on the coated panels whenever the excess epoxy were attempted to be removed. This introduced air bubbles into the epoxy, which weaken the adhesive bond. A new method was devised to apply the dollies. A call with the manufacturer of the plasma treater and dollies confirmed the new method was acceptable. After the epoxy was applied to the dolly, the dolly was placed on the coated panel. A piece of Shurtape Hold Strong \# 00H39 tape, at least as wide as the top of the dolly, was placed over the dolly and secured onto both sides of the panel. This applied constant pressure on the dolly and allowed for much easier and thorough removal of the excess epoxy without moving the dolly to the same extent as in the previous method.

\subsubsection{Polypropylene Composition Variations}

Many compositional variations (16 in total) of the Type $\mathrm{C}$ polypropylene samples were tested to see if composition had an effect on adhesion and subsequently, on weathering performance. The previous methods of sample preparation were altered to create a more standardized procedure. The new sample preparation started by wetting a KimWipe with acetone and using it to wipe the surface of the polypropylene. This was done to remove impurities such as oil, dirt and other such contaminants that would interfere with the adhesion and wetting process. The entire panel was then plasma treated using the parameters defined in section 6.2.3. The coating method is similar to coating methods performed before: after plasma treatment, the panels are coated with the brown coating, allowed to dry for 5 minutes at room temperature, and then placed in the oven at 
$70^{\circ} \mathrm{C}$ for 5 minutes. This was followed by a 7-day delay period, to allow the residual solvents in the coating to evaporate.

The coated panels were then subjected to adhesion testing, both pull-off and crosscut, following the methods described in 8.3.6 and 8.3.6.1. Six panels from each category were tested for a total of 18 data points for pull-off adhesion, with three dollies applied to each panel ( 9 treated and 9 untreated). Four panels from each category were tested for a total of 12 data points for crosscut adhesion testing, with two dollies applied to each panel (6 treated and 6 untreated). Pull-off adhesion testing was later repeated for Category 14, 15, and 16 panels due to a pull-off adhesion result outlier observed for the Category 16 panels.

\section{Results and Discussion}

\subsection{Plasma Treatment Results with Type A Panels}


The Type A panels were plasma treated following the procedure from section 6.2.1, and Dyne solutions were used to test the wetting of the treated and untreated panels (treatment time of 15 seconds). The results are in Table 4.

Table 4: Wetting results from initial plasma treatment testing on Type A panels

\begin{tabular}{|c|c|c|}
\hline $\begin{array}{c}\text { Surface Tension of Dyne } \\
\text { Solution (dynes/cm) }\end{array}$ & Untreated & Treated \\
\hline 30 & Non-wetting & Complete wetting \\
\hline 38 & $\begin{array}{c}\text { Non-wetting (Contact angle } \\
\text { increased) }\end{array}$ & Almost complete wetting \\
\hline 46 & $\begin{array}{c}\text { Non-wetting (Contact angle } \\
\text { increased) }\end{array}$ & $\begin{array}{c}\text { Very small contact angle, } \\
\text { but not complete wetting }\end{array}$ \\
\hline 50 & $\begin{array}{c}\text { Non-wetting (Contact angle } \\
\text { increased) }\end{array}$ & $\begin{array}{c}\text { Larger contact angle, wet } \\
\text { the surface }\end{array}$ \\
\hline 60 & $\begin{array}{c}\text { Non-wetting (Contact angle } \\
\text { increased) }\end{array}$ & Non-wetting \\
\hline
\end{tabular}

Table 4 shows there was a noticeable difference in the wetting of the substrate by Dyne solutions between the untreated and treated PP. As previously mentioned in section 1.3, complete wetting implies the Dyne solutions have a contact angle of $0^{\circ}$ with respect to the PP panel. Complete wetting suggests the organic paint used to coat these panels will wet the surface very well; it will not de-wet. As the surface energy of the Dyne solutions increased, the contact angle for both the treated and untreated panels increased. However, the treated portion of the panels showed a smaller increase in the contact angle, and the 30 dyne/cm solution showed complete wetting, while the same Dyne solution did not show complete wetting for the untreated sample. This testing method proved was not sensitive enough to differentiate between the different Dyne solutions. The plasma treatment should have a substantial effect on the surface energy of the substrate, but this was not observed. Therefore, dewetting testing was conducted.

\subsection{Dewetting Test Results}


Dewetting testing, outlined in section 6.2.2, was performed on treated and untreated Type A panels. Both plasma and corona treatments were compared as well. All test parameters were identical. The results from this test can be seen in Table 5 .

Table 5: Dewetting results from plasma and corona treatment testing on Type A panels*

\begin{tabular}{|c|c|c|c|c|}
\hline \multirow{2}{*}{$\begin{array}{c}\text { Surface Tension } \\
\text { of Dyne Solution } \\
(\mathbf{d y n e s} / \mathbf{c m})\end{array}$} & \multicolumn{2}{|c|}{ Untreated } & \multicolumn{2}{c|}{ Treated } \\
\cline { 2 - 5 } & & & Plasma & Corona \\
\hline 30 & $\mathrm{~W}$ & $\mathrm{~W}$ & $\mathrm{~W}$ & $\mathrm{~W}$ \\
\hline 32 & $\mathrm{~W}$ & $\mathrm{~W}$ & $\mathrm{~W}$ & $\mathrm{~W}$ \\
\hline 34 & $\mathrm{D}$ & $\mathrm{D}$ & $\mathrm{W}$ & $\mathrm{W}$ \\
\hline 36 & $\mathrm{D}$ & $\mathrm{D}$ & $\mathrm{W}$ & $\mathrm{W}$ \\
\hline 38 & $\mathrm{D}$ & $\mathrm{D}$ & $\mathrm{W}$ & $\mathrm{W}$ \\
\hline 40 & $\mathrm{D}$ & $\mathrm{D}$ & $\mathrm{W}$ & $\mathrm{W}$ \\
\hline 42 & $\mathrm{D}$ & $\mathrm{D}$ & $\mathrm{W}$ & $\mathrm{W}$ \\
\hline 44 & $\mathrm{D}$ & $\mathrm{D}$ & $\mathrm{W}$ & $\mathrm{W}$ \\
\hline 46 & $\mathrm{D}$ & $\mathrm{D}$ & $\mathrm{W}$ & $\mathrm{W}$ \\
\hline 48 & $\mathrm{D}$ & $\mathrm{D}$ & $\mathrm{W}$ & $\mathrm{W}$ \\
\hline 50 & $\mathrm{D}$ & $\mathrm{D}$ & $\mathrm{W}$ & $\mathrm{W}$ \\
\hline 52 & $\mathrm{D}$ & $\mathrm{D}$ & $\mathrm{W}$ & $\mathrm{W}$ \\
\hline 54 & $\mathrm{D}$ & $\mathrm{D}$ & $\mathrm{W}$ & $\mathrm{W}$ \\
\hline 56 & $\mathrm{D}$ & $\mathrm{D}$ & $\mathrm{W}$ & $\mathrm{W}$ \\
\hline 58 & $\mathrm{D}$ & $\mathrm{D}$ & $\mathrm{W}$ & $\mathrm{W}$ \\
\hline 60 & $\mathrm{D}$ & $\mathrm{D}$ & $\mathrm{W}$ & $\mathrm{W}$ \\
\hline 62 & $\mathrm{D}$ & $\mathrm{D}$ & $\mathrm{W}$ & $\mathrm{W}$ \\
\hline 64 & $\mathrm{D}$ & $\mathrm{D}$ & $\mathrm{D}$ & $\mathrm{D}$ \\
\hline 66 & $\mathrm{D}$ & $\mathrm{D}$ & $\mathrm{D}$ & $\mathrm{D}$ \\
\hline 68 & $\mathrm{D}$ & $\mathrm{D}$ & $\mathrm{D}$ & $\mathrm{D}$ \\
\hline 70 & $\mathrm{D}$ & $\mathrm{D}$ & $\mathrm{D}$ & $\mathrm{D}$ \\
\hline
\end{tabular}

* A "W" means the Dyne solution wets the surface, and there was no visible de-wetting. A "D" means that following spreading of the Dyne solutions, de-wetting occurred.

When the Dyne solution was spread onto the substrate, it would garner a D ranking if it temporarily spread out and then retreated back into a droplet shape. It was very noticeable for the untreated samples when de-wetting occurred; almost immediately after spreading, the solution retracted back into a small rounded shape. For the treated samples, de-wetting was only noticeable at 64 dynes/cm and above. Retraction of the solution after being spread out did not happen quickly; it was slow compared to the 
untreated sample. Since the retraction took a longer time on the treated samples, the Dyne solutions actually stained the panels as they slowly withdrew into a smaller liquid form; the outline of where the solution had been spread to was visible on the panel's surface.

This test was a much better test than the previous test, and the results were much more distinguishable than the results from section 7.1. The effect the plasma treater had on the surface energy of the polypropylene panels was clearly evident.

The exact same results were observed for the plasma treated panels were seen for the corona treated samples. The plasma treated panels should have outperformed the corona treated panels as the plasma treaters plasma arc is more controlled. However, a difference was not seen. The most likely reason being that the Dyne solution tests are not sensitive enough to differentiate the performance of the two treatment types, or there was no difference between the two treatment types.

\subsection{Optimum Plasma Treater Conditions}

Testing was completed to establish the ideal parameters for the plasma treater. All testing was completed as described in section 6.2.3. The brown coating (lot \# 2) was used to coat all panels. The crosscut adhesion test results are the average from the four panels tested.

Table 6: Effect of plasma treatment time on crosscut adhesion results (Type A panel)*

\begin{tabular}{|c|c|}
\hline Exposure Time (s) & Adhesion Ranking \\
\hline 0 & 0B \\
\hline 5 & $5 \mathrm{~B}$ \\
\hline 10 & $5 \mathrm{~B}$ \\
\hline 30 & $5 \mathrm{~B}$ \\
\hline 60 & $5 \mathrm{~B}$ \\
\hline 120 & $5 \mathrm{~B}$ \\
\hline
\end{tabular}

* 0B - worst; 5B - best 
The results in Table 6 verify the treatment time of 5 seconds is adequate to improve adhesion. Within the limit of the crosscut adhesion test there was no noticeable improvement in adhesion as the exposure time increased. A treatment time longer than 5 seconds was deemed unnecessary (and not cost-effective).

The distance between the panel and the discharge head of the plasma treater has an effect on adhesion. The results for this testing can be seen in Table 7.

Table 7: Effect of plasma treater distance (Type A panel)*

\begin{tabular}{|c|c|c|c|c|c|c|c|c|c|}
\hline & \multicolumn{4}{|c|}{ Wetting (dynes/cm) } & \multicolumn{3}{c|}{ Dewetting (dynes/cm) } & Adhesion \\
\hline $\begin{array}{c}\text { Distance } \\
(\mathbf{c m})\end{array}$ & 30 & 40 & 50 & 60 & 30 & 40 & 50 & 60 & \\
\hline 0.5 & $\mathrm{~W}$ & $\mathrm{~W}$ & $\mathrm{D}$ & $\mathrm{D}$ & $\mathrm{W}$ & $\mathrm{W}$ & $\mathrm{D}$ & $\mathrm{D}$ & $5 \mathrm{~B}$ \\
\hline 1.0 & $\mathrm{~W}$ & $\mathrm{~W}$ & $\mathrm{D}$ & $\mathrm{D}$ & $\mathrm{W}$ & $\mathrm{W}$ & $\mathrm{D}$ & $\mathrm{D}$ & $5 \mathrm{~B}$ \\
\hline 1.5 & $\mathrm{~W}$ & $\mathrm{D}$ & $\mathrm{D}$ & $\mathrm{D}$ & $\mathrm{W}$ & $\mathrm{D}$ & $\mathrm{D}$ & $\mathrm{D}$ & $5 \mathrm{~B}$ \\
\hline 2.0 & $\mathrm{~W}$ & $\mathrm{D}$ & $\mathrm{D}$ & $\mathrm{D}$ & $\mathrm{W}$ & $\mathrm{D}$ & $\mathrm{D}$ & $\mathrm{D}$ & $3 \mathrm{~B}$ \\
\hline 2.5 & $\mathrm{~W}$ & $\mathrm{D}$ & $\mathrm{D}$ & $\mathrm{D}$ & $\mathrm{W}$ & $\mathrm{D}$ & $\mathrm{D}$ & $\mathrm{D}$ & $1 \mathrm{~B}$ \\
\hline 3.0 & $\mathrm{~W}$ & $\mathrm{D}$ & $\mathrm{D}$ & $\mathrm{D}$ & $\mathrm{W}$ & $\mathrm{D}$ & $\mathrm{D}$ & $\mathrm{D}$ & $0 \mathrm{~B}$ \\
\hline
\end{tabular}

* A "W" means the Dyne solution wets the surface, and there was no visible de-wetting. $A$ " $D$ " means that following spreading of the Dyne solutions, de-wetting occurred. * $0 \mathrm{~B}$ - worst; $5 \mathrm{~B}$ - best

The results for the wetting and dewetting are expected and support data already established from prior testing. After treatment, the Dyne solutions will wet the panel surface up to $40 \mathrm{dynes} / \mathrm{cm}$. The distance plays a role in wetting/dewetting, as wetting did not occur for the $40 \mathrm{dyne} / \mathrm{cm}$ solution after the distance was raised to $1.5 \mathrm{~cm}$. Dewetting of the dyne solutions did not occur until 40 dynes $/ \mathrm{cm}$, and only after a distance of $2.5 \mathrm{~cm}$ was reached. From the adhesion testing, it can be further established that distance has an effect on treatment, as the adhesion results declined after $1.5 \mathrm{~cm}$. From $0.5-1.5 \mathrm{~cm}$, the adhesion revealed a ranking of $5 \mathrm{~B}$, which is the best result possible. From this data, it was established that $0.5-1.5 \mathrm{~cm}$ distances was best for testing.

Although $0.5,1$, and $1.5 \mathrm{~cm}$ distances all received 5B adhesion rankings, there was a visual difference between the panels after the pull-off test. Since the plasma 
treater's arc is confined to a certain radius ( 2 inches), only the area on the panel that is directly in contact with the arc is treated. Therefore, the places on the panel that do not touch the arc and are not treated showed an extreme loss of adhesion during these tests; the paint was completely removed. The 0.5 and $1 \mathrm{~cm}$ panels showed the least amount of paint removal, even in areas that were not directly treated by the plasma. The plasma arc affects a larger area when it is closer to the surface, therefore, the closest distance was chosen $(0.5 \mathrm{~cm})$.

The next variable tested was the blower speed. The results are shown in Table 8 .

Table 8: Effect of plasma treater blower speed (Type A panel)*

\begin{tabular}{|c|c|c|c|c|c|c|c|c|c|}
\hline & \multicolumn{4}{|c|}{ Wetting (dynes/cm) } & \multicolumn{4}{c|}{ Dewetting (dynes/cm) } & Adhesion \\
\hline $\begin{array}{c}\text { Blower } \\
\text { Speed (\%) }\end{array}$ & 30 & 40 & 50 & 60 & 30 & 40 & 50 & 60 & \\
\hline 60 & $\mathrm{~W}$ & $\mathrm{~W}$ & $\mathrm{D}$ & $\mathrm{D}$ & $\mathrm{W}$ & $\mathrm{W}$ & $\mathrm{D}$ & $\mathrm{D}$ & $3 \mathrm{~B}$ \\
\hline 70 & $\mathrm{~W}$ & $\mathrm{~W}$ & $\mathrm{D}$ & $\mathrm{D}$ & $\mathrm{W}$ & $\mathrm{W}$ & $\mathrm{D}$ & $\mathrm{D}$ & $4 \mathrm{~B}$ \\
\hline 80 & $\mathrm{~W}$ & $\mathrm{~W}$ & $\mathrm{D}$ & $\mathrm{D}$ & $\mathrm{W}$ & $\mathrm{W}$ & $\mathrm{D}$ & $\mathrm{D}$ & $4 \mathrm{~B}$ \\
\hline 90 & $\mathrm{~W}$ & $\mathrm{~W}$ & $\mathrm{D}$ & $\mathrm{D}$ & $\mathrm{W}$ & $\mathrm{W}$ & $\mathrm{D}$ & $\mathrm{D}$ & $5 \mathrm{~B}$ \\
\hline 100 & $\mathrm{~W}$ & $\mathrm{~W}$ & $\mathrm{D}$ & $\mathrm{D}$ & $\mathrm{W}$ & $\mathrm{W}$ & $\mathrm{D}$ & $\mathrm{D}$ & $5 \mathrm{~B}$ \\
\hline
\end{tabular}

*A"W" means the Dyne solution wets the surface, and there was no visible dewetting. A "D" means that following spreading of the Dyne solutions, de-wetting occurred.

* 0B - worst; 5B - best

Although the results in Table 8 do not show anything unexpected in the wetting or dewetting categories, the appearance of the Dyne solutions on the panels differed between test methods. For the 30 dyne/cm solutions, the extent that the solution wet the surface increased as the blower speed was increased. This was seen for 40 dynes $/ \mathrm{cm}$ as well, and although this occurred for 50 and $60 \mathrm{dynes} / \mathrm{cm}$, it was much less noticeable and could not be deemed 'wetting'. For the entire range of Dyne solutions, the amount of dewetting lessened as the blower speed increased. The adhesion rankings were significantly different, and seemed to depend on the blower speed. A blower speed of $60 \%$ only attained an adhesion ranking of $3 \mathrm{~B}$, while a blower speed of $90 \%$ or $100 \%$ 
increased the adhesion ranking to 5B. It was decided to use the blower speed of $100 \%$. The final parameters, and the parameters that will be used for the remaining tests, are a blower speed of $100 \%$, a distance of $0.5 \mathrm{~cm}$, and an exposure time of 5 seconds.

\subsection{Adhesion Testing on Type B Panels}

The previous tests, both for plasma and corona treatment, were repeated. At this point in testing, the panels supplied to Cal Poly were manufactured by a different company than before. The Type A panels were no longer going to be used for testing, so it was necessary to repeat the tests with the new Type B PP panels. The same test procedures and parameters from section 6.2.1. were used, and similar results were expected. The brown coating (lot \# 2) was used to coat all panels.

Table 9: Wetting results from plasma treatment testing on Type B panels

\begin{tabular}{|c|c|c|}
\hline $\begin{array}{c}\text { Surface Tension of Dyne } \\
\text { Solution (dynes/cm) }\end{array}$ & Untreated & Treated \\
\hline 30 & Non-wetting & Complete wetting \\
\hline 38 & $\begin{array}{c}\text { Non-wetting (Contact angle } \\
\text { increased) }\end{array}$ & Almost complete wetting \\
\hline 46 & $\begin{array}{c}\text { Non-wetting (Contact angle } \\
\text { increased) }\end{array}$ & $\begin{array}{c}\text { Very small contact angle, } \\
\text { but not complete wetting }\end{array}$ \\
\hline 50 & $\begin{array}{c}\text { Non-wetting (Contact angle } \\
\text { increased) }\end{array}$ & $\begin{array}{c}\text { Larger contact angle, wet } \\
\text { the surface }\end{array}$ \\
\hline 60 & $\begin{array}{c}\text { Non-wetting (Contact angle } \\
\text { increased) }\end{array}$ & Non-wetting \\
\hline
\end{tabular}

As can be seen in Table 9, the results using the Dyne solutions are exactly the same as those from Table 4, which used the Type A PP panels. Dewetting testing was repeated on the Type B panels. Both corona and plasma treatment was compared on untreated and treated panels. The results are given below.

Table 10: Plasma and corona treatment dewetting test on Type B panels*

\begin{tabular}{|c|c|c|c|c|}
\hline \multirow{2}{*}{$\begin{array}{c}\text { Surface Tension } \\
\text { of Dyne Solution } \\
\text { (dynes/cm) }\end{array}$} & \multicolumn{2}{|c|}{ Untreated } & \multicolumn{2}{c|}{ Treated } \\
\cline { 2 - 5 } & Plasma & Corona & Plasma & Corona \\
\hline 30 & $\mathrm{~W}$ & $\mathrm{~W}$ & $\mathrm{~W}$ & $\mathrm{~W}$ \\
\hline 32 & $\mathrm{D}$ & $\mathrm{W}$ & $\mathrm{W}$ & $\mathrm{W}$ \\
\hline 34 & $\mathrm{D}$ & $\mathrm{D}$ & $\mathrm{W}$ & $\mathrm{W}$ \\
\hline
\end{tabular}




\begin{tabular}{|c|c|c|c|c|}
\hline 36 & $\mathrm{D}$ & $\mathrm{D}$ & $\mathrm{W}$ & $\mathrm{W}$ \\
\hline 38 & $\mathrm{D}$ & $\mathrm{D}$ & $\mathrm{W}$ & $\mathrm{W}$ \\
\hline 40 & $\mathrm{D}$ & $\mathrm{D}$ & $\mathrm{W}$ & $\mathrm{W}$ \\
\hline 42 & $\mathrm{D}$ & $\mathrm{D}$ & $\mathrm{W}$ & $\mathrm{W}$ \\
\hline 44 & $\mathrm{D}$ & $\mathrm{D}$ & $\mathrm{W}$ & $\mathrm{W}$ \\
\hline 46 & $\mathrm{D}$ & $\mathrm{D}$ & $\mathrm{W}$ & $\mathrm{W}$ \\
\hline 48 & $\mathrm{D}$ & $\mathrm{D}$ & $\mathrm{W}$ & $\mathrm{W}$ \\
\hline 50 & $\mathrm{D}$ & $\mathrm{D}$ & $\mathrm{W}$ & $\mathrm{W}$ \\
\hline 52 & $\mathrm{D}$ & $\mathrm{D}$ & $\mathrm{W}$ & $\mathrm{W}$ \\
\hline 54 & $\mathrm{D}$ & $\mathrm{D}$ & $\mathrm{W}$ & $\mathrm{W}$ \\
\hline 56 & $\mathrm{D}$ & $\mathrm{D}$ & $\mathrm{W}$ & $\mathrm{W}$ \\
\hline 58 & $\mathrm{D}$ & $\mathrm{D}$ & $\mathrm{W}$ & $\mathrm{W}$ \\
\hline 60 & $\mathrm{D}$ & $\mathrm{D}$ & $\mathrm{W}$ & $\mathrm{W}$ \\
\hline 62 & $\mathrm{D}$ & $\mathrm{D}$ & $\mathrm{W}$ & $\mathrm{W}$ \\
\hline 64 & $\mathrm{D}$ & $\mathrm{D}$ & $\mathrm{W}$ & $\mathrm{W}$ \\
\hline 66 & $\mathrm{D}$ & $\mathrm{D}$ & $\mathrm{W}$ & $\mathrm{W}$ \\
\hline 68 & $\mathrm{D}$ & $\mathrm{D}$ & $\mathrm{W}$ & $\mathrm{W}$ \\
\hline 70 & $\mathrm{D}$ & $\mathrm{D}$ & $\mathrm{W}$ & $\mathrm{W}$ \\
\hline
\end{tabular}

* A"W" means the Dyne solution wets the surface, and there was no visible de-wetting. A "D" means that following spreading of the Dyne solutions, de-wetting occurred.

Compared to the Type A panels, the Type B panels displayed no dewetting throughout the entire Dyne solution spectrum. It was also noted that the amount of dewetting on the parts of the panels that were not touched by the plasma were very pronounced. Once the droplet of dyne solution was placed on the treated area and then spread out, it wet fairly well at almost all levels of dyne solution. If the solution was spread out farther than the treated area, the amount of retraction back to the treated area was prominent and happened rapidly. Similar to the results from the Type A panel testing, there was no noticeable difference between the corona treated and the plasma treated panels. The corona treated panels also showed improved wetting.

The wetting test was repeated once more, as the supply of original test panels was depleted and the supplier provided a new type of panel - Type $C$ panels. Category 7 and Category 16 panels were tested to compare wetting characteristics. Category 7 panels 
were CertainTeed's standard production panel, and category 16 panels had the highest percentage of MAPE (which theoretically should increase the wettability).

Table 11: Wetting results from plasma treatment testing on Category 7 and Category 16 panels

\begin{tabular}{|c|c|c|c|c|}
\hline & \multicolumn{2}{|c|}{ Category 7} & \multicolumn{2}{|c|}{ Category 16} \\
\hline $\begin{array}{c}\text { Surface } \\
\text { Tension of } \\
\text { Dyne } \\
\text { Solution } \\
\text { (dynes/cm) }\end{array}$ & Untreated & Treated & Untreated & Treated \\
\hline 30 & Non-wetting & $\begin{array}{c}\text { Complete } \\
\text { wetting }\end{array}$ & Non-wetting & Complete wetting \\
\hline 36 & $\begin{array}{c}\text { Non-wetting } \\
\text { (Contact angle } \\
\text { increased) }\end{array}$ & $\begin{array}{c}\text { Complete } \\
\text { wetting }\end{array}$ & $\begin{array}{c}\text { Non-wetting } \\
\text { (Contact angle } \\
\text { increased) }\end{array}$ & Complete wetting \\
\hline 40 & $\begin{array}{l}\text { Non-wetting } \\
\text { (Contact angle }\end{array}$ & $\begin{array}{l}\text { Partial Wetting } \\
\text { (contact angle }\end{array}$ & $\begin{array}{l}\text { Non-wetting } \\
\text { (Contact angle }\end{array}$ & $\begin{array}{l}\text { Partial Wetting } \\
\text { (contact angle }\end{array}$ \\
\hline
\end{tabular}




\begin{tabular}{|c|c|c|c|c|}
\hline & increased) & increased) & increased) & increased) \\
\hline 46 & $\begin{array}{c}\text { Non-wetting } \\
\text { (Contact angle } \\
\text { increased) }\end{array}$ & $\begin{array}{l}\text { Partial Wetting } \\
\text { (contact angle } \\
\text { increased) }\end{array}$ & $\begin{array}{c}\text { Non-wetting } \\
\text { (Contact angle } \\
\text { increased) }\end{array}$ & $\begin{array}{l}\text { Partial Wetting } \\
\text { (contact angle } \\
\text { increased) }\end{array}$ \\
\hline 50 & $\begin{array}{c}\text { Non-wetting } \\
\text { (Contact angle } \\
\text { increased) } \\
\end{array}$ & $\begin{array}{l}\text { Partial Wetting } \\
\text { (contact angle } \\
\text { increased) }\end{array}$ & $\begin{array}{c}\text { Non-wetting } \\
\text { (Contact angle } \\
\text { increased) }\end{array}$ & $\begin{array}{l}\text { Partial Wetting } \\
\text { (contact angle } \\
\text { increased) } \\
\end{array}$ \\
\hline 56 & $\begin{array}{c}\text { Non-wetting } \\
\text { (Contact angle } \\
\text { increased) } \\
\end{array}$ & $\begin{array}{l}\text { Partial Wetting } \\
\text { (contact angle } \\
\text { increased) }\end{array}$ & $\begin{array}{c}\text { Non-wetting } \\
\text { (Contact angle } \\
\text { increased) } \\
\end{array}$ & $\begin{array}{c}\text { Partial Wetting } \\
\text { (contact angle } \\
\text { increased) }\end{array}$ \\
\hline 60 & $\begin{array}{c}\text { Non-wetting } \\
\text { (Contact angle } \\
\text { increased) } \\
\end{array}$ & $\begin{array}{l}\text { Partial Wetting } \\
\text { (contact angle } \\
\text { increased) }\end{array}$ & $\begin{array}{c}\text { Non-wetting } \\
\text { (Contact angle } \\
\text { increased) } \\
\end{array}$ & $\begin{array}{c}\text { Partial Wetting } \\
\text { (contact angle } \\
\text { increased) } \\
\end{array}$ \\
\hline 66 & $\begin{array}{c}\text { Non-wetting } \\
\text { (Contact angle } \\
\text { increased) }\end{array}$ & $\begin{array}{l}\text { Partial Wetting } \\
\text { (contact angle } \\
\text { increased) }\end{array}$ & $\begin{array}{c}\text { Non-wetting } \\
\text { (Contact angle } \\
\text { increased) }\end{array}$ & $\begin{array}{l}\text { Partial Wetting } \\
\text { (contact angle } \\
\text { increased) }\end{array}$ \\
\hline
\end{tabular}

Table 11 shows that the Category 7 and Category 16 panels display similar wetting results to all previous results. There was also no visible difference between the results of Category 7 and Category 16 panels. In both cases, as the Dyne solution increased in surface tension, the contact angle increased for the untreated panels and no wetting was observed. For both categories, complete wetting was seen up to $36 \mathrm{dynes} / \mathrm{cm}$, and as the surface tension increased, the amount of wetting decreased proportionally.

Dewetting testing was done for plasma treated category 7 panels.

Table 12: Plasma treatment dewetting test on Category 7 panels*

\begin{tabular}{|c|c|c|}
\hline $\begin{array}{c}\text { Surface Tension of Dyne } \\
\text { Solution (dynes/cm) }\end{array}$ & Untreated & Treated \\
\hline 30 & W & W \\
\hline 32 & W & W \\
\hline 34 & D & W \\
\hline 36 & D & W \\
\hline 38 & D & W \\
\hline 40 & D & W \\
\hline 42 & D & W \\
\hline 44 & D & W \\
\hline 46 & D & W \\
\hline 48 & D & W \\
\hline 50 & D & W \\
\hline 52 & D & D \\
\hline 54 & &
\end{tabular}




\begin{tabular}{|c|c|c|}
\hline 56 & D & W \\
\hline 58 & D & W \\
\hline 60 & D & W \\
\hline 62 & D & W \\
\hline 64 & D & W \\
\hline 66 & D & W \\
\hline 68 & D & W \\
\hline 70 & D & \\
\hline
\end{tabular}

* A"W" means the Dyne solution wets the surface, and there was no visible de-wetting. $A$ " $D$ " means that following spreading of the Dyne solutions, de-wetting occurred.

The results found in Table 12 are similar to those given in Table 10. There is no dewetting on the plasma treated panels.

Another method to quantify the difference between plasma and corona treatment on the polypropylene panels was sought. X-ray Photoelectron Spectroscopy (XPS) was an option, as it can characterize the surface of treated PP by quantifying the percentage of elements and identifying functional groups present on the surface before and after surface treatment (Pijpers, 2001). This method was utilized, as described in a later section.

The results of the adhesion testing done on Type B panels are shown in Table 13. The results are an average of the rankings of the three panels tested for each type of treatment.

Table 13: Crosscut adhesion test results for Type B panels*

\begin{tabular}{|c|c|c|}
\hline Sample & Treated & Untreated \\
\hline 1 (Plasma Treated) & $4 \mathrm{~B}$ & $0 \mathrm{~B}$ \\
\hline 2 (Corona Treated) & $4 \mathrm{~B}$ & $0 \mathrm{~B}$ \\
\hline
\end{tabular}

* $0 \mathrm{~B}$ - worst; $5 \mathrm{~B}$ - best

As expected, the two treated samples showed much better adhesion than the untreated samples. When the tape was removed from the untreated samples, all of the coating was removed from the surface of the panels. Although the results did not show an 
advantage in adhesion improvements between the two treatment types, plasma treatment provided a much larger area of treatment than corona treatment.

\subsubsection{Pull-Off Adhesion Testing on Type B Panels}

Pull-off adhesion testing was done following the procedure described in section 6.2.6.1. The brown coating (lot \# 2) was used to coat all panels. When applying the dollies to the sample surface, spots that would likely fail, such as edges, places where paint and substrate meet, or places where parts of the bare substrate were showing through, were avoided. The average results given in Table 14, while the full results can be seen in appendix A.

Table 14: Average pull-off adhesion test results for Type B panels

\begin{tabular}{|c|c|}
\hline Treatment & Average (psi) \\
\hline None & $92 \pm 26$ \\
\hline Corona & $251 \pm 40$ \\
\hline Plasma & $233 \pm 47$ \\
\hline
\end{tabular}

The non-treated samples performed much worse than both the corona and plasma treated samples. The plasma treated samples took about 2.5 times more force to remove the dolly from the panel than the non-treated samples, while the corona treated samples took about 2.7 times as much force; the two treatment types produced the same results within the experimental error.

All three samples experienced adhesive failure between the coating and the substrate. An interesting finding was the recurrence of cohesive failure of the PP substrate. This was seen in almost all plasma and corona treated as a small portion of PP remained adhered to the bottom of the dolly after removal. A photographic example can be seen in Figure 10, where a small grey piece of PP is stuck to the bottom of the organic coating on the dolly (far right dolly). 


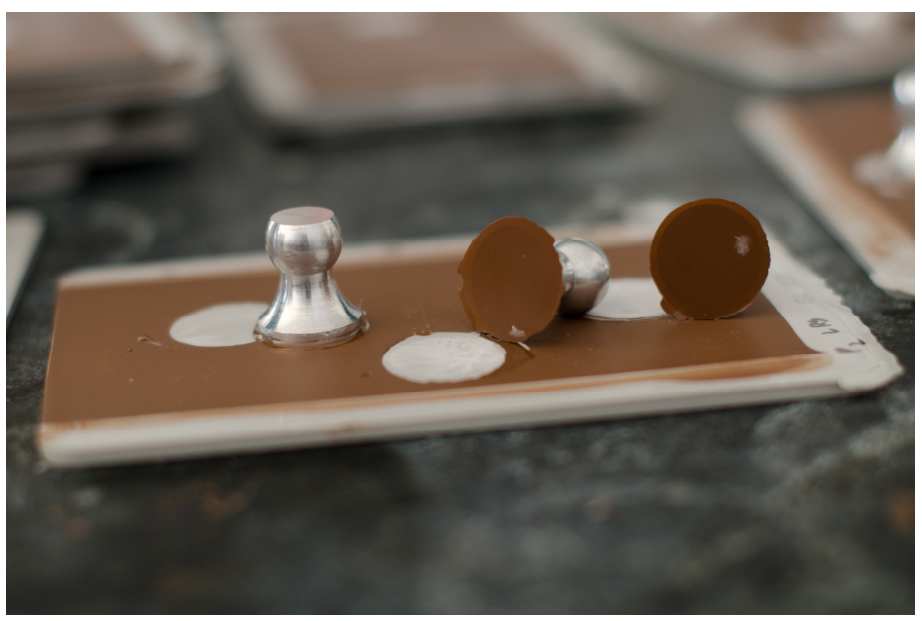

Figure 10: Cohesive failure of polypropylene

One of the possible reasons the results from all samples were not very consistent, and why the plasma treated samples did not require the most force, is the amount of excess epoxy that was around the dollies. After applying the epoxy to the dolly, the dolly is placed on the PP panel with slight, hand-induced pressure. In doing so, excess epoxy is squeezed out from the underside of the dolly. The excess epoxy is to be wiped off with a cotton swab. However, during this process, the dolly is not supposed to move, and especially not supposed to turn, as this would introduce air bubbles into the epoxy, subsequently weakening adhesion. The removal of the excess epoxy is very difficult on this particular coated substrate, and repeated attempts to remove the epoxy resulted in moving of the dolly. Attempts were made to remove as much epoxy as possible while keeping the dolly from moving. A fine balance was found, but the results seem to show that a more careful procedure needs to be instituted.

When the dolly is removed from the substrate (via the PosiTest), the removal should be clean and the dolly should not have excess coating attached to it. There should only be coating that is in the shape of the dolly removed, and an equally shaped spot on the sample where bare substrate should be seen. This would be classified as a 'clean' 
removal. However, many of the samples from the experiments that produced Table 14 do not show clean removals. The removal of many of the samples depicts excess coating attached, as seen in Figure 11.

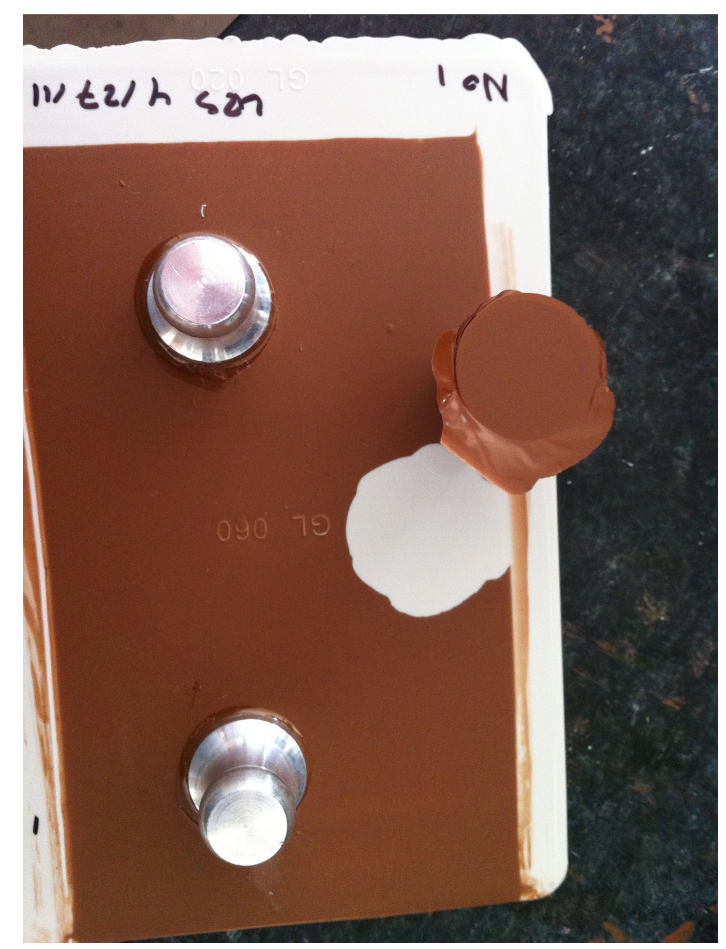

Figure 11: Example of a poor pull-off

The poor pull-off was due to excess epoxy, which not only cures between the dolly and the substrate, but around the dolly as well, providing a non-uniform pull-off and a source of error. An example of the excess epoxy around the dolly is shown in Figure 12.

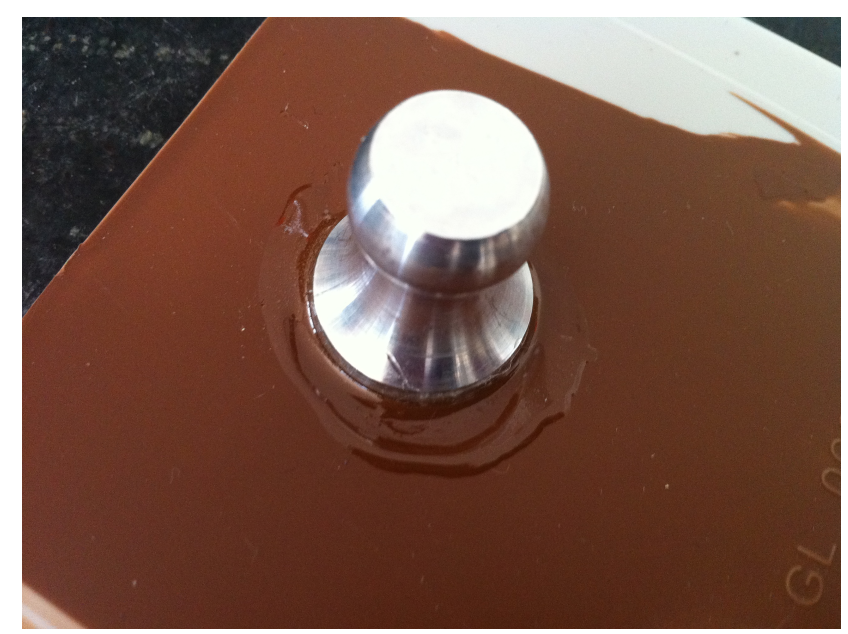

Figure 12: Excess epoxy around the dolly 
To counteract the excess epoxy error, the manufacture of the PosiTest provides a circular cutting tool to cut around the dolly, so any excess epoxy can be removed. However, there is a chance that this cutting may reduce the bond between the epoxy, dolly, and substrate. The tool is also typically used for thicker, stronger substrates than PP. Nevertheless, the tool was still tested to see if the results would become more consistent, but repeatability was poor. The substrate was completely damaged as the tool cut very deeply into the PP, as seen in Figure 13.

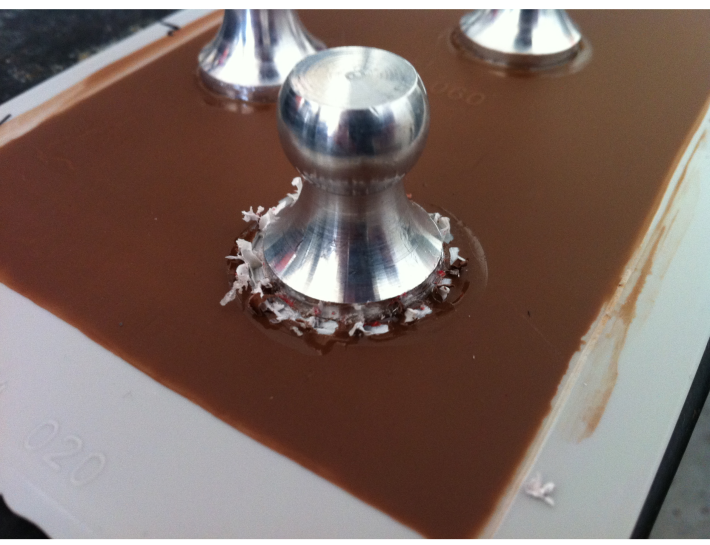

Figure 13: Example of the results from using the cutting tool provided with the PosiTest

A new epoxy application method was devised to solve the inconsistencies in the data. The application of the dollies for all testing from this point forward followed the method listed at the end of section 6.2.6.1. Essentially, a piece of tape was applied to the top of the dolly, which restricted its motion and applied a uniform pressure, allowing for the excess epoxy to be removed in a more secure way. Figure 14 depicts the new approach. 


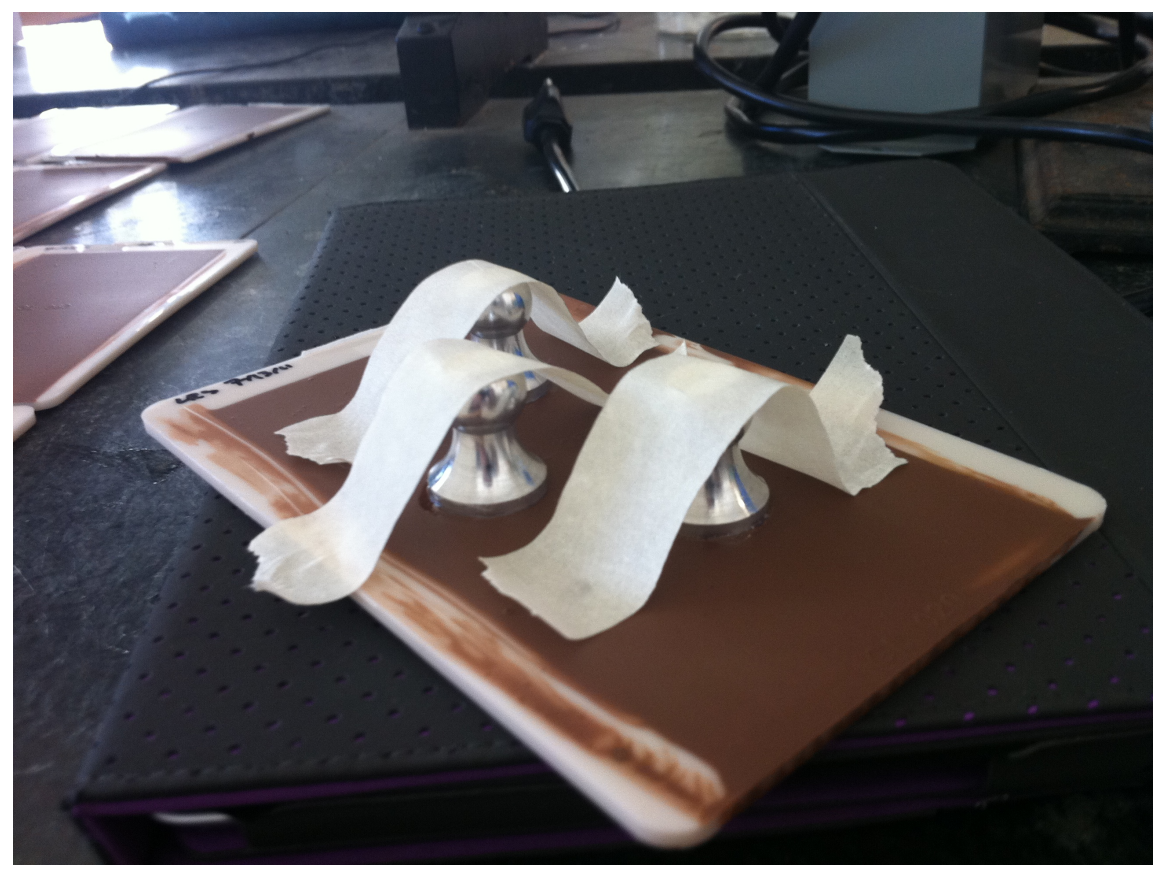

Figure 14: Tape holding the dollies down to improve the excess epoxy wipe-off step

Although this method reduced the inconsistencies of the pull-off adhesion testing, further problems were encountered during the preparation of the polypropylene samples once the newest polypropylene panels, Type $\mathrm{C}$, were used [at this point in the project, the Type B panels were completely used, and the supplier provided Cal Poly with a new type of PP panel - Type C panels, which were used for the remainder of testing].

\subsubsection{Problems With the Coating on Type C Panels}

A number of unexpected coating problems were encountered with the Type $C$ panels. These problems included mudcracking, dewetting and pinholing. Mudcracking is when the paint film dries with shrinkage, and the film experiences a faster volume loss than the substrate it is on. This produces a stress in the film, and a crack appears. However, due to the size of the 'mudcracking,' it was also hypothesized the phenomena might be dewetting - the coating seems to initially wet the surface of the polypropylene, but shortly after or during drying, the coating film appears to retract. This is due to 
surface energy differences, and a manufacturing impurity is suspected as the cause. The pinhole problem is generally associated with trapped solvent or air that had not evaporated from the coating film. The top layer of the coating might dry first, before the solvent or air underneath could leave the film. The solvent or air eventually will escape the coating, leaving behind a hole in its place. An example of these problems can be seen in Figure 15.

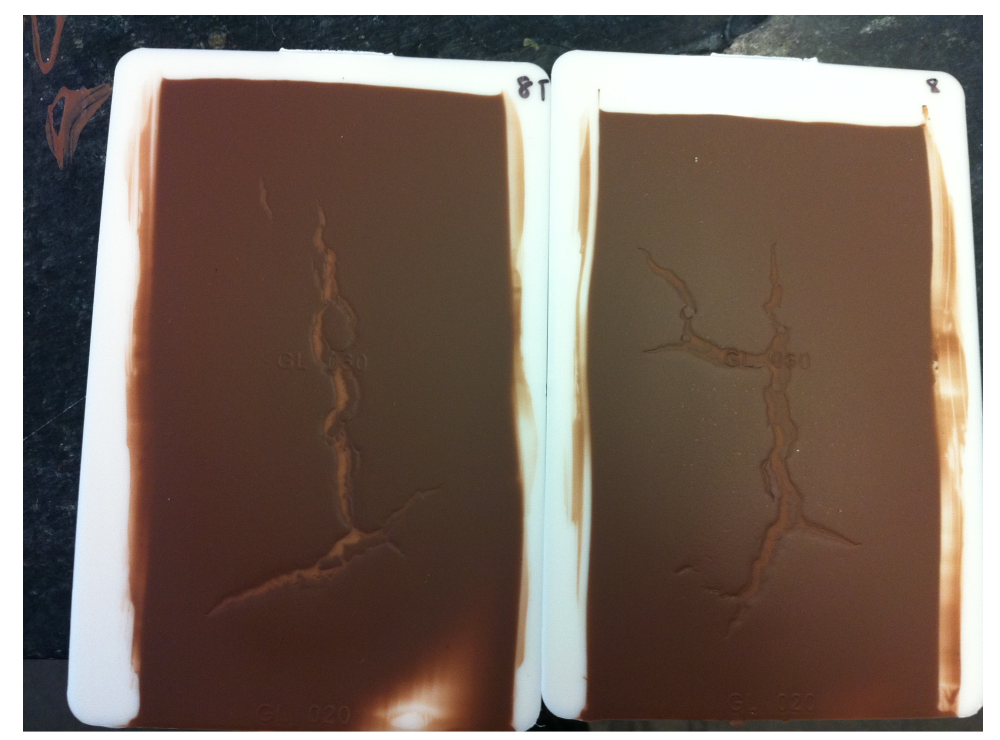

Figure 15: Mud-cracking or dewetting can be seen on both the treated and untreated Category 8 panels (treated on the left)

The pinhole problem is difficult to see in Figure 15, but the mud-cracking or dewetting problem is obvious. Categories 7, 12, and 16 panels were all prepared according to the method described in section 6.2.6.1, and all experienced the problems described above. To determine if other compositions were having the same problems, Categories 1, 4, 8, and 11 panels were also tested. All panels experienced the same problems. It was speculated the coating's ambient drying time of 5 minutes was not sufficient for this group of polypropylene panels, and that was one of the reasons the pinhole problem was occurring. To test this, five samples of Category 7 panels were 
prepared, and after the coating was applied, they were dried under ambient conditions for 30 minutes instead of five minutes. This seemed to alleviate the pinhole problem.

However, testing was repeated on Categories 12 and 16 panels, and the problem persisted once again.

To test if the substrate was part of the problem, drawdowns using the same coating were made on Byko-charts, glass panels, and steel panels. After being coated, they were left to set for 30 minutes and then dried in the oven for 5 minutes at $70^{\circ} \mathrm{C}$. Pinholes were found on all the substrates, but no dewetting was evident.

As Figure 15 depicts, the dewetting seemed to mostly occur in long bands in the middle of the panel. Therefore, three panels of each Category 6, 7, and 12 were picked and Dyne solutions ranging from 30-70 dynes/cm were placed across their surfaces. This was done in a purely observational way (non-scientific) to determine if any differences in the way the Dyne solutions wet (or didn't wet) different areas of the surface of the PP panel. The result is seen in Figure 16.

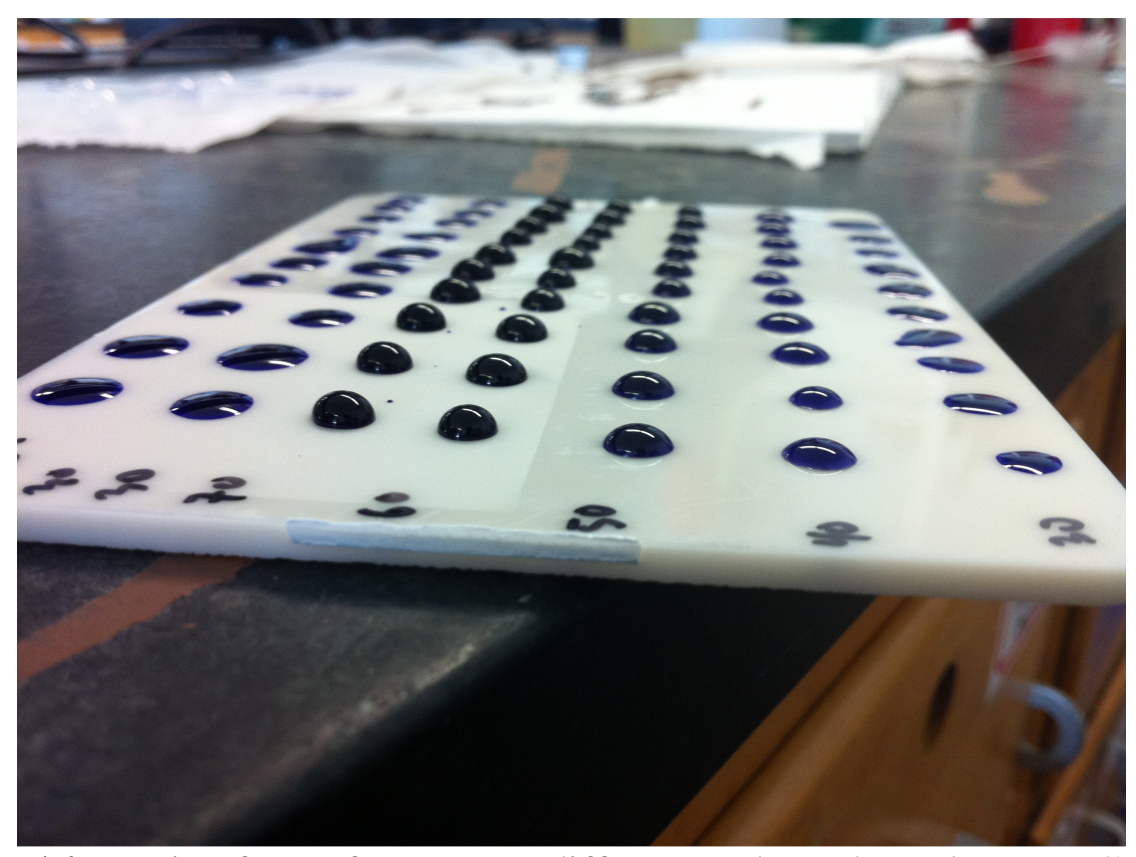

Figure 16: Testing for surface energy differences throughout the Type $C$ panels 
As seen in Figure 16, there are no deviations in how the Dyne solutions droplets wet the surface of the PP panel based on its position; the droplet shapes were very uniform. This was seen in all panels tested.

It was suspected the pinhole problem was at least partially due to the age of the paint; therefore CertainTeed supplied a new batch of paint (lot \# 3, received 7/07/2011). Samples of plasma treated panels following the normal procedure (but with a 30 minute ambient drying time after coating) were prepared, and the pinhole problem was not observed. However, the mud-cracking/dewetting problem was still apparent. Therefore, drawdowns on Byko-charts, steel panels, and glass panels were made once more. No pinholes or dewetting were observed for all substrate types.

Drawdowns were made on Byko charts with the first batch of paint used (opened 9/13/2010), the second batch of paint (opened 3/30/2011), and the third batch (opened 7/7/2011). Three drawdowns of each batch were made using a 4 mil drawdown bar. The coating was allowed to dry for 30 minutes before being placed in the oven at $70^{\circ} \mathrm{C}$ for 5 minutes. Upon drying, no differences could be seen visually, and there was no mudcracking, dewetting, or pinhole problems on any of the test samples.

To further characterize the differences in the paint batches, rheological testing was done using a TA Instruments AR 2000 Rheometer, using shear rates from $0.02 \mathrm{~s}^{-1}$ to $200 \mathrm{~s}^{-1}$ with 10 points per decade at $25^{\circ} \mathrm{C}$. A continuous ramp was also used with times of 2, 5, 10, and 20 minutes. A cone-and-plate geometry was used for all testing. 


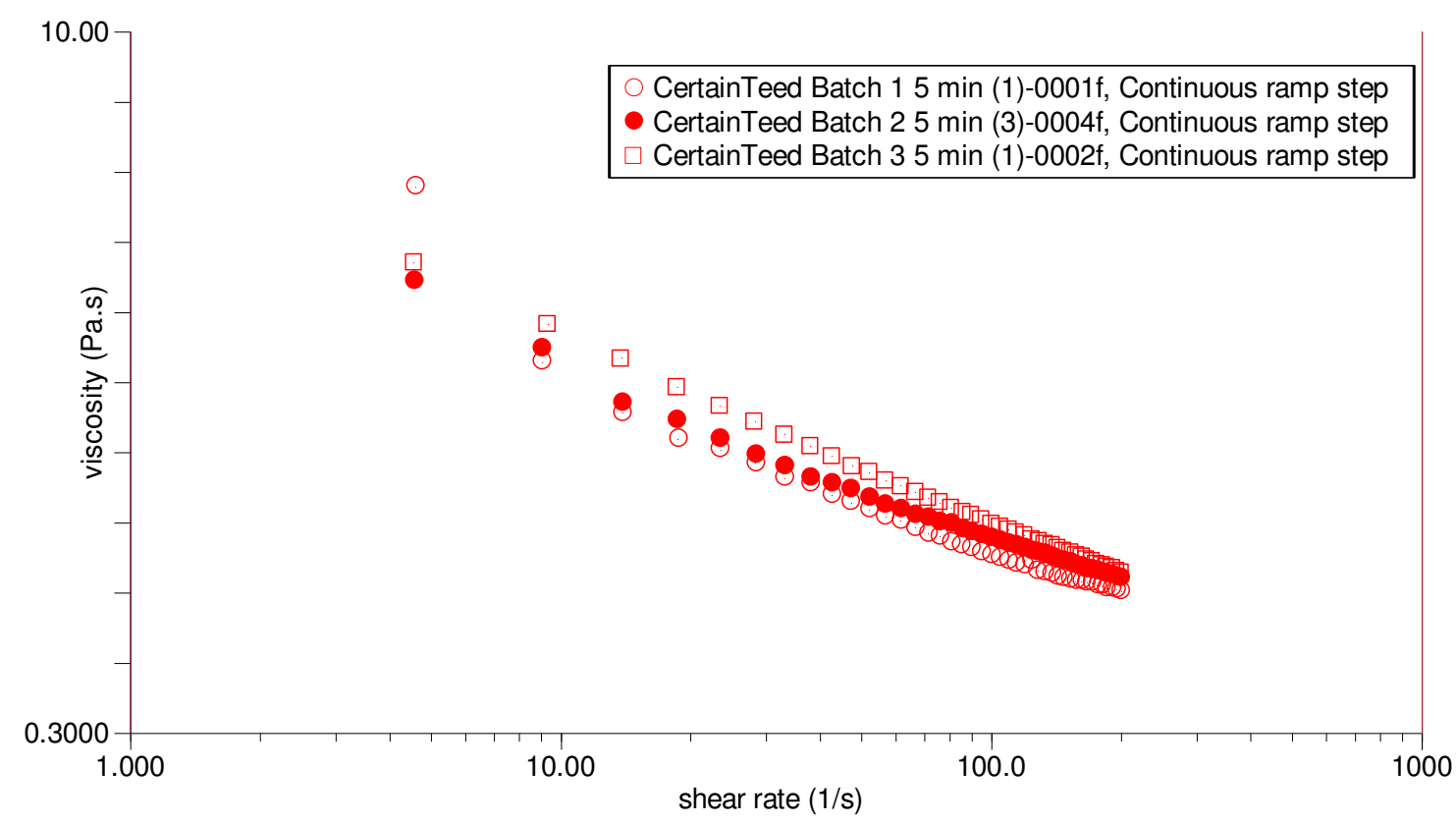

Figure 17:Viscosity vs. shear rate at 5-minute ramping time

As seen in Figure 17, the plot is slightly scattered in the low shear rate region.

This was seen at all testing times. However, as the shear rate increases, the plot levels out and batch looks very similar, as Figure 17 displays shear thinning. KU viscosity testing was completed, with the results seen in Table 15.

Table 15: Viscosity results

\begin{tabular}{|c|c|}
\hline Brown Coating (Lot \#) & Viscosity (KU) \\
\hline 1 & 52.4 \\
\hline 2 & 59.6 \\
\hline 3 & 61.6 \\
\hline
\end{tabular}

The results in Table 15 show the older the paint batch, the lower the viscosity. Although this is not seen throughout the entirety of the viscosity vs. shear rate plots, the $\mathrm{KU}$ viscosity testing applies a shear rate between 10 and $100 \mathrm{~s}^{-1}$. When the plot (figure 17) is examined in that specific range, the results are in agreement with Table 15 - the oldest paint has the lowest viscosity. This was true for all viscosity vs. shear rate testing. The effect of the differences between the three batches of coating will be investigated in a future project. 
It is believed the problem inherently lies with the substrate, as there were no problems seen with the previous two versions of the PP panels. A new procedure was established for sample preparation: Coated, plasma treated samples were prepared as defined in section 6.2.3, except that after the panel was coated, a 1 hour ambient drying time was introduced, followed by 5 minutes in the oven at $70^{\circ} \mathrm{C}$. Finally, the panels were left to dry at room temperature for 7 days before being used. This procedure produced much better results as the panels showed a significant decrease in mudcracking (approximately 1 in 10 panels would display mudcracking).

\subsubsection{Revised Procedure - Adhesion Testing Results}

Pull-off and crosscut adhesion testing were performed as described in section 6.2.6.1, but panel preparation followed the new procedure described in the previous section (section 7.4.2). The brown coating (lot \# 3 , received 07/07/2011) was used to coat the samples.

Adhesion is expected to improve for the 7 panel categories containing MAPE and MAPP, compared to the panel categories without them.

Table 16: Crosscut adhesion results for the Type C panels*

\begin{tabular}{|c|c|c|}
\hline \multirow{2}{*}{$\begin{array}{c}\text { Panel } \\
\text { Composition ID }\end{array}$} & \multicolumn{2}{|c|}{ Cross-Cut Adhesion Ranking } \\
\cline { 2 - 3 } & Non-Plasma-Treated & Plasma-Treated \\
\hline 1 & 0B & $5 \mathrm{~B}$ \\
\hline 2 & 0B & $5 \mathrm{~B}$ \\
\hline
\end{tabular}




\begin{tabular}{|c|c|c|}
\hline 3 & $0 \mathrm{~B}$ & $5 \mathrm{~B}$ \\
\hline 4 & $0 \mathrm{~B}$ & $5 \mathrm{~B}$ \\
\hline 5 & $0 \mathrm{~B}$ & $5 \mathrm{~B}$ \\
\hline 6 & $0 \mathrm{~B}$ & $5 \mathrm{~B}$ \\
\hline 7 & $0 \mathrm{~B}$ & $5 \mathrm{~B}$ \\
\hline 8 & $0 \mathrm{~B}$ & $5 \mathrm{~B}$ \\
\hline 9 & $0 \mathrm{~B}$ & $5 \mathrm{~B}$ \\
\hline 10 & $0 \mathrm{~B}$ & $5 \mathrm{~B}$ \\
\hline 11 & $0 \mathrm{~B}$ & $5 \mathrm{~B}$ \\
\hline 12 & $0 \mathrm{~B}$ & $5 \mathrm{~B}$ \\
\hline 13 & $0 \mathrm{~B}$ & $5 \mathrm{~B}$ \\
\hline 14 & $0 \mathrm{~B}$ & $5 \mathrm{~B}$ \\
\hline 15 & $0 \mathrm{~B}$ & $5 \mathrm{~B}$ \\
\hline 16 & $0 \mathrm{~B}$ & \\
\hline
\end{tabular}

* 0B - worst; 5B - best

$* *$ The category 8 panel showed inconsistent results after plasma treatment

Table 16 shows the average results from the crosscut adhesion testing. Each different panel category was tested using two panels, with three test spots per panel, for a total of 6 data points. The results are largely consistent, and show that once treated, the panels display vastly improved adhesion. However, this test does not illustrate the differences in adhesion between the three types of panels; it shows that adhesion improved once the panels were plasma treated, but nothing more.

Table 17: Pull-off adhesion test results of the 16 Type $C$ panels

\begin{tabular}{|c|c|c|}
\hline \multirow{2}{*}{$\begin{array}{c}\text { Panel } \\
\text { Composition ID }\end{array}$} & \multicolumn{2}{|c|}{ Pull-Off Adhesion Ranking (psi) } \\
\cline { 2 - 3 } & Non-Plasma-Treated & Plasma-Treated \\
\hline 1 & $50 \pm 13$ & $276 \pm 33$ \\
\hline
\end{tabular}




\begin{tabular}{|c|c|c|}
\hline 2 & $56 \pm 12$ & $262 \pm 42$ \\
\hline 3 & $98 \pm 21$ & $296 \pm 41$ \\
\hline 4 & $57 \pm 20$ & $269 \pm 37$ \\
\hline 5 & $50 \pm 13$ & $273 \pm 38$ \\
\hline 6 & $49 \pm 13$ & $225 \pm 28$ \\
\hline 7 & $64 \pm 14$ & $227 \pm 42$ \\
\hline 8 & $48 \pm 6$ & $208 \pm 15 *$ \\
\hline 9 & $49 \pm 4$ & $259 \pm 22$ \\
\hline 10 & $59 \pm 20$ & $289 \pm 45$ \\
\hline 11 & $41 \pm 10$ & $304 \pm 62$ \\
\hline 12 & $52 \pm 12$ & $222 \pm 35$ \\
\hline 13 & $81 \pm 25$ & $281 \pm 71$ \\
\hline 14 & $85 \pm 14$ & $297 \pm 23$ \\
\hline 15 & $55 \pm 24$ & $298 \pm 19$ \\
\hline 16 & $64 \pm 17$ & $1253 \pm 1310$ \\
\hline
\end{tabular}

It should be pointed out that category 8 had the lowest results for both crosscut and pulloff adhesion. Table 17 displays the results of the pull-off adhesion testing. As expected, the range of values for each panel is somewhat variable, although this does not detract from the fact that there is a large increase in the amount of force it takes to remove the dolly from plasma treated panels compared to untreated panels. The panels that showed the greatest overall adhesion strictly according to psi values are category 11 and 16 panels, although it is suspected that one of the treated panels in category 16 is an outlier. As stated in section 6.2.6.2, six total panels were used for pull-off adhesion testing. For category 16, two of the three panels produced pull-off results of $354 \mathrm{psi}$ and $434 \mathrm{psi}$. The dollies on the third panel, however, had such strong adhesion the PosiTest adhesion tester was unable to separate the dolly from the substrate after $3000 \mathrm{psi}$, and the adhesion was 
so strong the substrate failed cohesively (figure 18). The maximum force the PosiTest adhesion tester can produce is 3000 psi.



Figure 18: Cohesive failure of the PP substrate.

Taking into account the variability for the pull-off adhesion test, it can be stated with confidence that both tests show that plasma-treated panels display vastly improved adhesion compared to their untreated counterparts.

Due to the outlier in Table 17, pull-off adhesion testing was repeated for plasma treated Category 14, 15, and 16 panels. The brown coating (lot \# 4, received 08/02/2011) was used to coat the samples. The results are shown in Table 18.

Table 18: Repeat of pull-off adhesion testing

\begin{tabular}{|c|c|}
\hline Panel Composition ID & $\begin{array}{c}\text { Pull-Off Adhesion Ranking } \\
\text { (psi) }\end{array}$ \\
\hline
\end{tabular}




\begin{tabular}{|c|c|}
\hline & Plasma-Treated \\
\hline 14 & $169 \pm 24$ \\
\hline 15 & $193 \pm 26$ \\
\hline 16 & $173 \pm 30$ \\
\hline
\end{tabular}

Table 18 shows the results from the repeated version of the pull-off adhesion test. The results depict that less force was required to remove the dollies from the panels of category 14 and 15 when compared to the results from Table 17. The difference in results for panels from category 16 (Table 17 versus Table 18) is dramatic. In the repeat test no cohesive failure in the PP panel was observed. The results from Table 18 were completed with a different batch of brown coating, and at this point a better method for applying epoxy and removing the excess epoxy around the dolly had been established. This may have had an influence on the results.

A reason for the inconsistency of results for category 16 panels was not clear, although one theory was deemed highly likely: the epoxy used to adhere the aluminum dolly to the coated polypropylene substrate was migrating through the coating and interacting with the substrate, thereby artificially increasing the results from the pull-off adhesion test. Infrared spectroscopy was used to determine if this theory held merit.

\subsubsection{Peculiar Adhesion Result Investigation}

\subsubsection{Peculiar Adhesion Characteristics}

The pull-off adhesion results from section 7.4.3 revealed an outlier within Category 16 test panels. Testing was repeated (Table 18) and the results were not reproducible. It was hypothesized the epoxy used for pull-off adhesion testing was migrating through the coating and increasing the test results. Infrared spectroscopy was used to determine if this hypothesis holds merit. 
Category 6, 15, and 16 panels were used for testing and prepared as described in section 7.4.2. The brown coating (lot \# 2, received 3/30/2011 and lot \# 4, received 08/01/2011) was used to coat the samples. Category 16 was tested two times, using the two different paint batches. One category 16 panel was plasma treated and coated using lot \# 2 of the brown coating, while the other category 16 panel was plasma treated and coated using lot \#4. Two panels from category 6 and category 15 were tested as well. One panel from category 6 and 15 was plasma treated and coated, while the other panel was only coated. Pull-off adhesion testing was conducted on all panels, with three dollies on each panel, for a total of six data points. Excess epoxy was also placed on random spots on the coated panels so that an epoxy spectra could be obtained.

To determine if there the bond between the PP substrate and the epoxy was stronger than the bond between the coating and the epoxy, non-coated untreated and non-coated plasma treated category 16 panels and category 7 panels were prepared for pull-off adhesion. Three dollies (with epoxy on them) were placed directly onto each panel, which were allowed to dry overnight.

A Thermo Scientific Nicolet iS10 FT-IR with a diamond crystal, using the Attenuated Total Reflectance technique was used for infrared spectroscopy. IR spectra were obtained of the bare category 6 and 15 panels. For all panels, IR spectra were taken of the dried coating (1), the area where the dolly was removed by the pull-off adhesion tester (2), the area underneath where the random samples of epoxy were placed (3), the coating underneath the removed epoxy (4), and a random area where the coating had been removed to see the bare substrate (5). Also, IR spectra were taken of the cured epoxy (6). Figure 19 depicts areas where IR spectra were taken: 


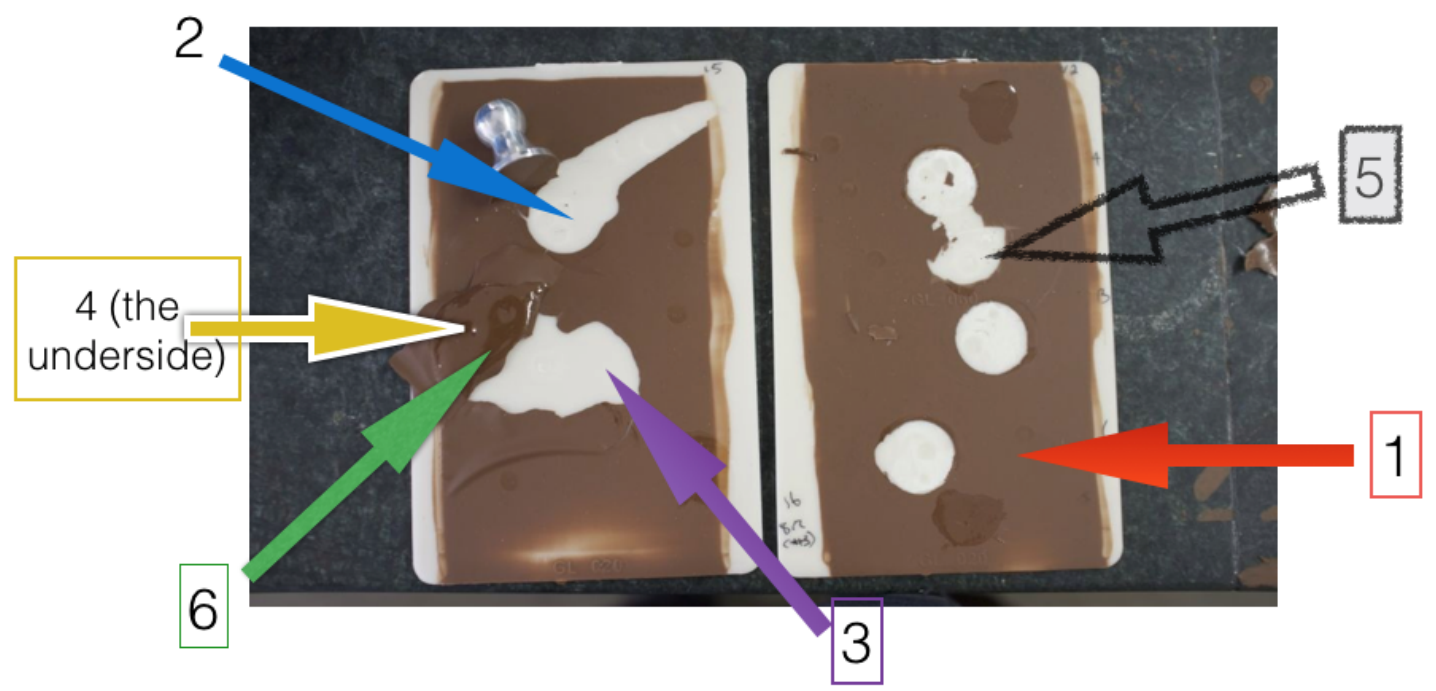

Figure 19: Diagram depicting panel location of FTIR analysis

\subsubsection{Peculiar Adhesion Test Results}

Category 6,15 , and 16 panels were prepared as described in section 7.4.2. It was hypothesized the epoxy was migrating through the coating to the substrate. It was also hypothesized the Category 16 substrate and epoxy had a very strong bond, and that may have been a reason as to why the Category 16 panels experienced unusually high pull-off results. This would be confirmed if the dollies (with epoxy) were applied to the bare panel and the pull-off adhesion results were extremely high.

Table 19: Pull-off adhesion results for Category 16 panels

\begin{tabular}{|c|c|c|c|c|c|c|}
\hline & \multicolumn{3}{|c|}{ Non-Plasma Treated (psi) } & \multicolumn{3}{c|}{ Plasma Treated (psi) } \\
\hline $\begin{array}{c}\text { Panel } \\
\begin{array}{c}\text { Composition } \\
\text { Category }\end{array}\end{array}$ & $A$ & $B$ & $C$ & $A$ & $B$ & $C$ \\
\hline 16 & 84 & 34 & 56 & 522 & 531 & 531 \\
\hline
\end{tabular}


Table 19 shows the force required to pull-off the dolly from the plasma treated panel without coating was much greater than the force required to pull-off the dolly from the non-treated panel without coating. When the adhesion testing was completed, the dollies on the non-plasma treated panel experienced a clean adhesive failure between the dolly and the substrate, with both the underside of the dolly and the substrate remaining smooth and residue free. On the other hand, the dollies on the plasma treated panel experienced cohesive failure of the substrate, as the polypropylene failed on a physical level. This shows the plasma treatment vastly increases the interaction between epoxy and polypropylene. This type of cohesive failure was also seen in the Category 16 panel outlier in Table 17. However, this was not seen in the repeat testing results provided in Table 18. Although the pull-off adhesion forces in Table 19 are less than the results found in Table 17, they still indicate the bond between the epoxy and the polypropylene is stronger than the bond between the epoxy and the brown coating. This suggests the epoxy migrating through the coating to the substrate is a valid hypothesis. To further investigate this hypothesis, IR spectra of Category 6,15, and 16 panels were taken. The spectra for each polypropylene category were compared for each spot identified in Figure 19. 


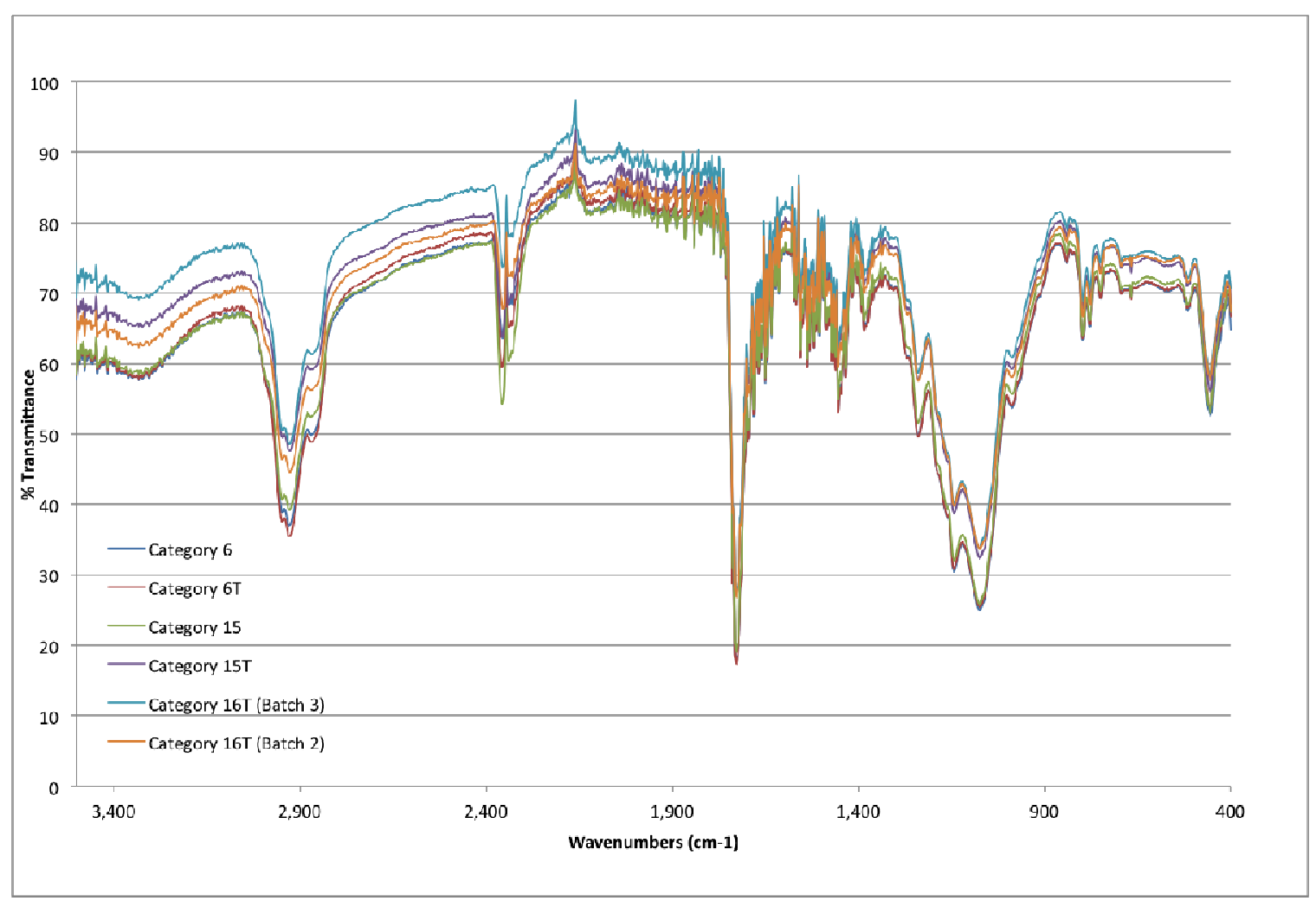

Figure 20: IR spectra of the dried coating (spot 1)

Figure 20 depicts the IR spectra of just the coating (spot 1). Since the coatings formulation is proprietary, the peaks seen in Figure 20 can only be used as a reference. There are peaks at $\sim 2900,1750$, and $1100 \mathrm{~cm}^{-1}$, which are characteristic of C-H stretching, $\mathrm{C}=\mathrm{O}$ stretching, and $\mathrm{C}-\mathrm{O}$ stretching, respectively. The small bump around $3,375 \mathrm{~cm}^{-1}$ is too weak to be indicative of $\mathrm{O}-\mathrm{H}$ stretching. 


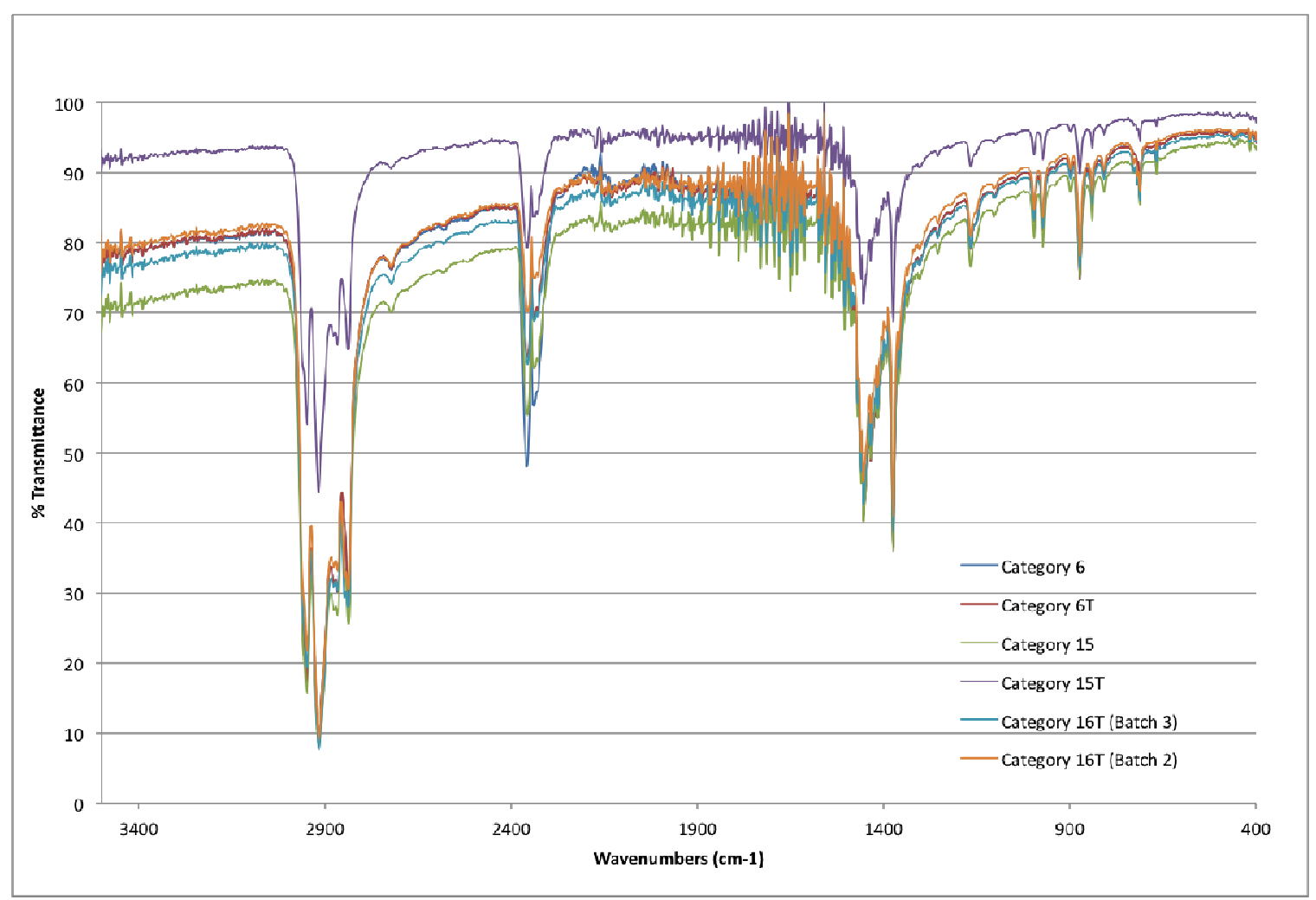

Figure 21: IR spectra of the area under the removed dolly (spot 2)

Figure 21 depicts the IR spectra of the area underneath the dolly, after it has been removed via the pull-off adhesion test (spot 2). Since the IR was taken on the polypropylene underneath the dolly, with the coating removed, the expected IR spectra should be similar or identical to the spectra of the bare substrate (spot 5). If there has been any migration of the epoxy through the coating and to the substrate, there should be peaks similar to those found in the epoxy spectra (spot 6). In Figure 21, there are peaks at $\sim 2900$, and $1400 \mathrm{~cm}^{-1}$, which are characteristic of C-H stretching, and C-H bending, respectively. 


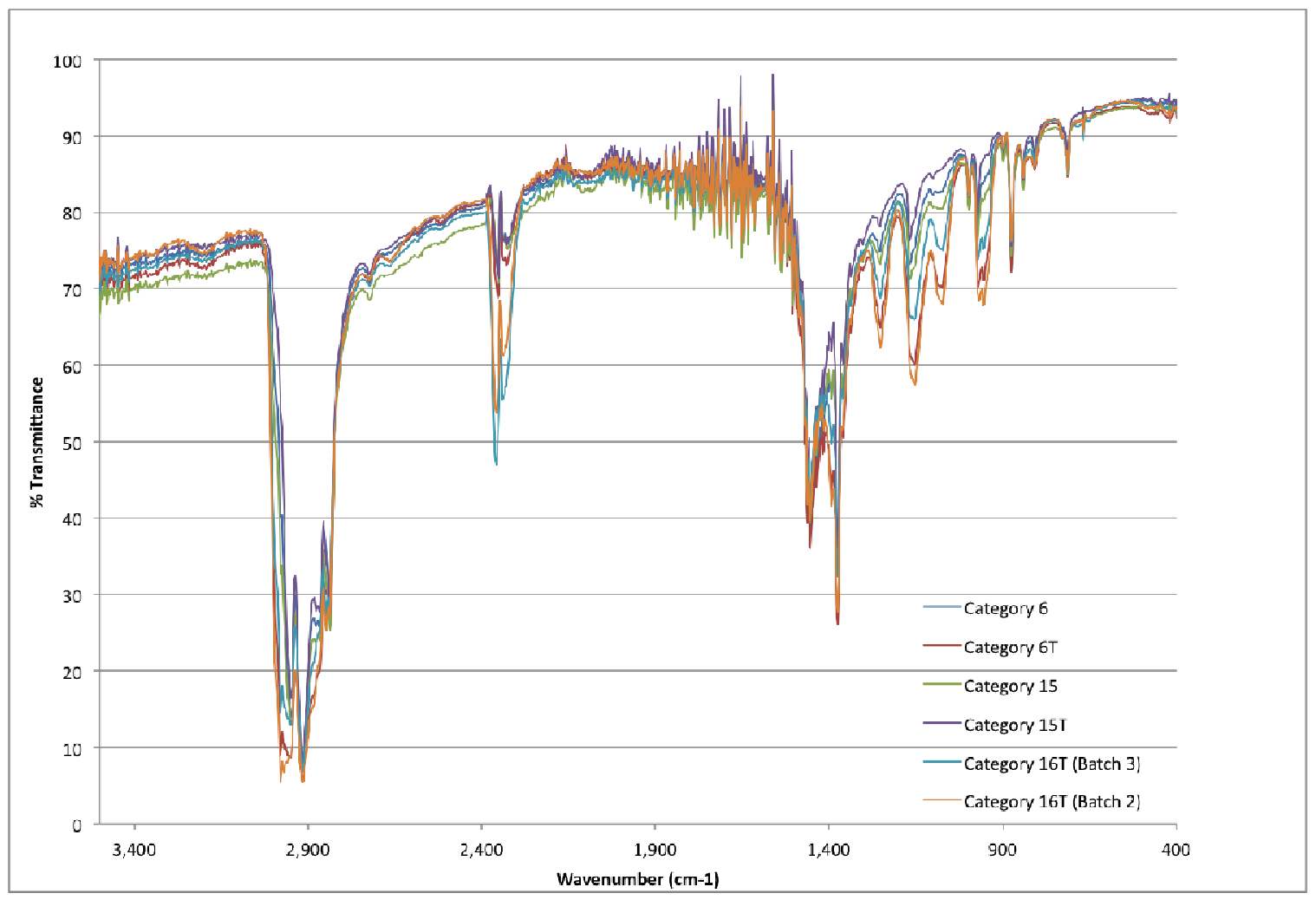

Figure 22: IR spectra of the area underneath where the random samples of epoxy were placed (spot 3)

Figure 22 depicts the IR spectra of the area underneath the epoxy that had been randomly placed on the dried panels (spot 3). The expected spectra should once again be similar to the bare substrate (spot 5). However, if migration has occurred, then peaks characteristic of an epoxy should be seen on the spectra. In Figure 22, there are peaks at 2900 , and $1400 \mathrm{~cm}^{-1}$, which are characteristic of C-H stretching and C-H bending, respectively. 


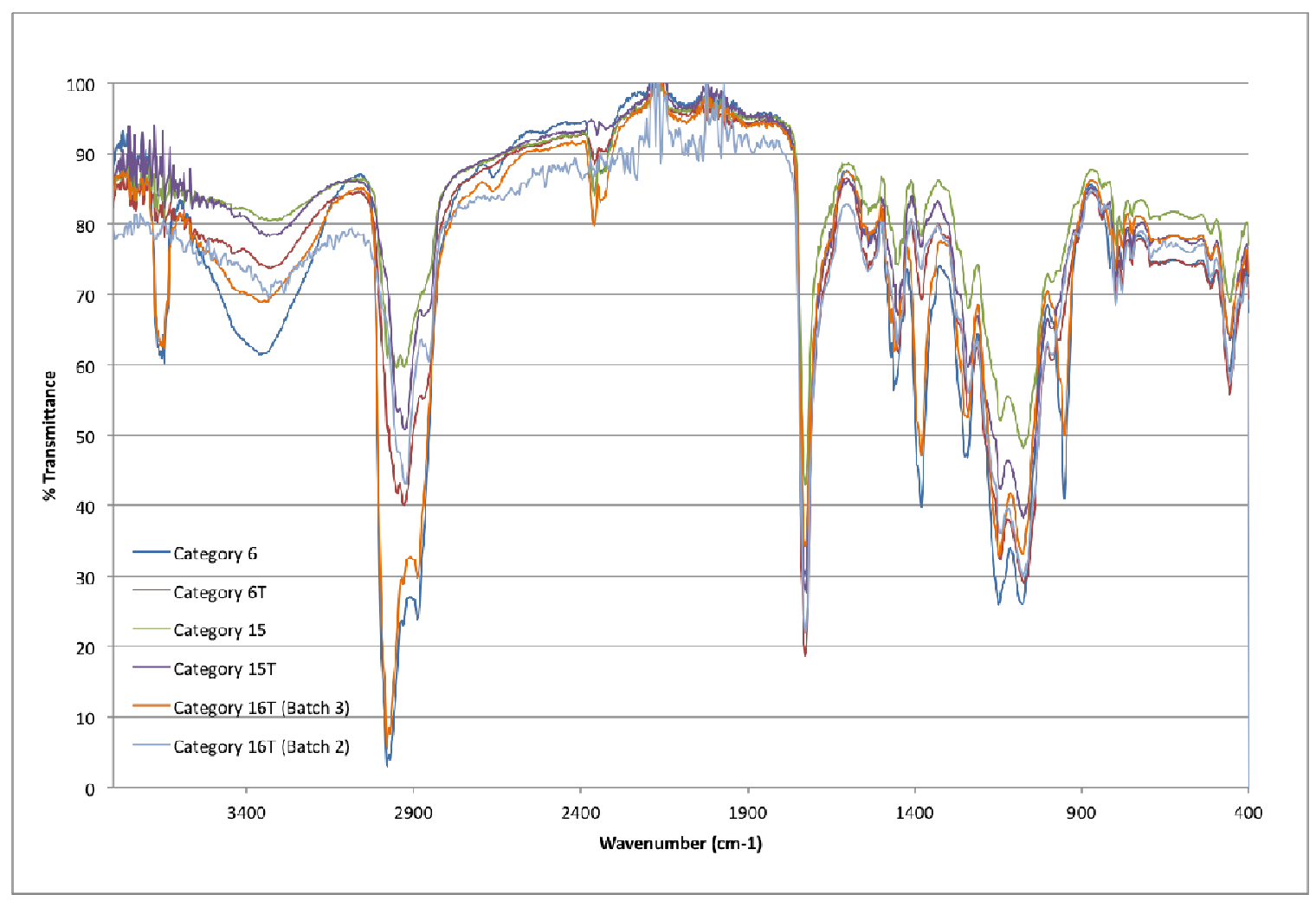

Figure 23: IR spectra of the underside of the coating that had epoxy on top of it (spot 4)

Figure 23 depicts the IR spectra taken on the backside of the removed coating, which had epoxy on top of it (spot 4). The expected spectra should look similar to that seen in Figure 20 (spot 1), although if epoxy migration occurred, there would be peaks characteristic of an epoxy seen in the spectra. In Figure 23, there are peaks at $\sim 3650$, $3350,3000,1750,1400$, and $1100 \mathrm{~cm}^{-1}$, which are characteristic of free hydroxyl, O-H stretching, C-H Stretching, $\mathrm{C}=\mathrm{O}$ stretching, $\mathrm{C}-\mathrm{H}$ bending, and $\mathrm{C}-\mathrm{O}$ stretching, respectively 


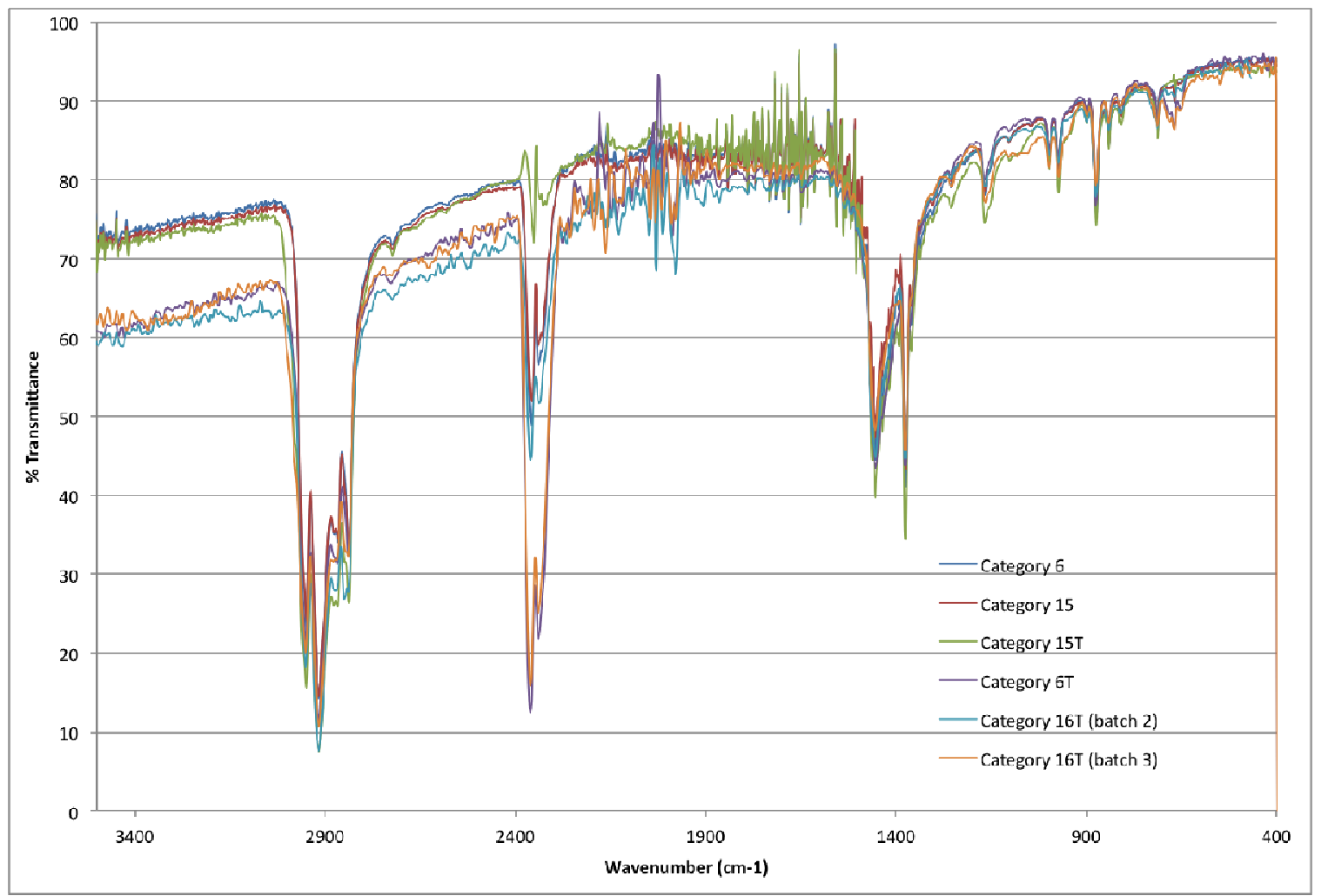

Figure 24: IR spectra of the bare substrate (spot 5)

Figure 24 depicts the IR spectra taken of the bare substrate (spot 5). A random sampling of the coating was removed from the polypropylene to reveal the bare substrate. The expected spectra should have only $\mathrm{C}-\mathrm{C}$ and $\mathrm{C}-\mathrm{H}$ peaks, as the substrate is polypropylene. However, the polypropylene categories with MAPP and MAPE (categories 15 and 16), could display $\mathrm{C}-\mathrm{O}$ and $\mathrm{O}-\mathrm{H}$ peaks due to the maleated compounds. In Figure 24, there are peaks at 2900 , and $1400 \mathrm{~cm}^{-1}$, which are characteristic of C-H stretching and C-H bending, respectively. 


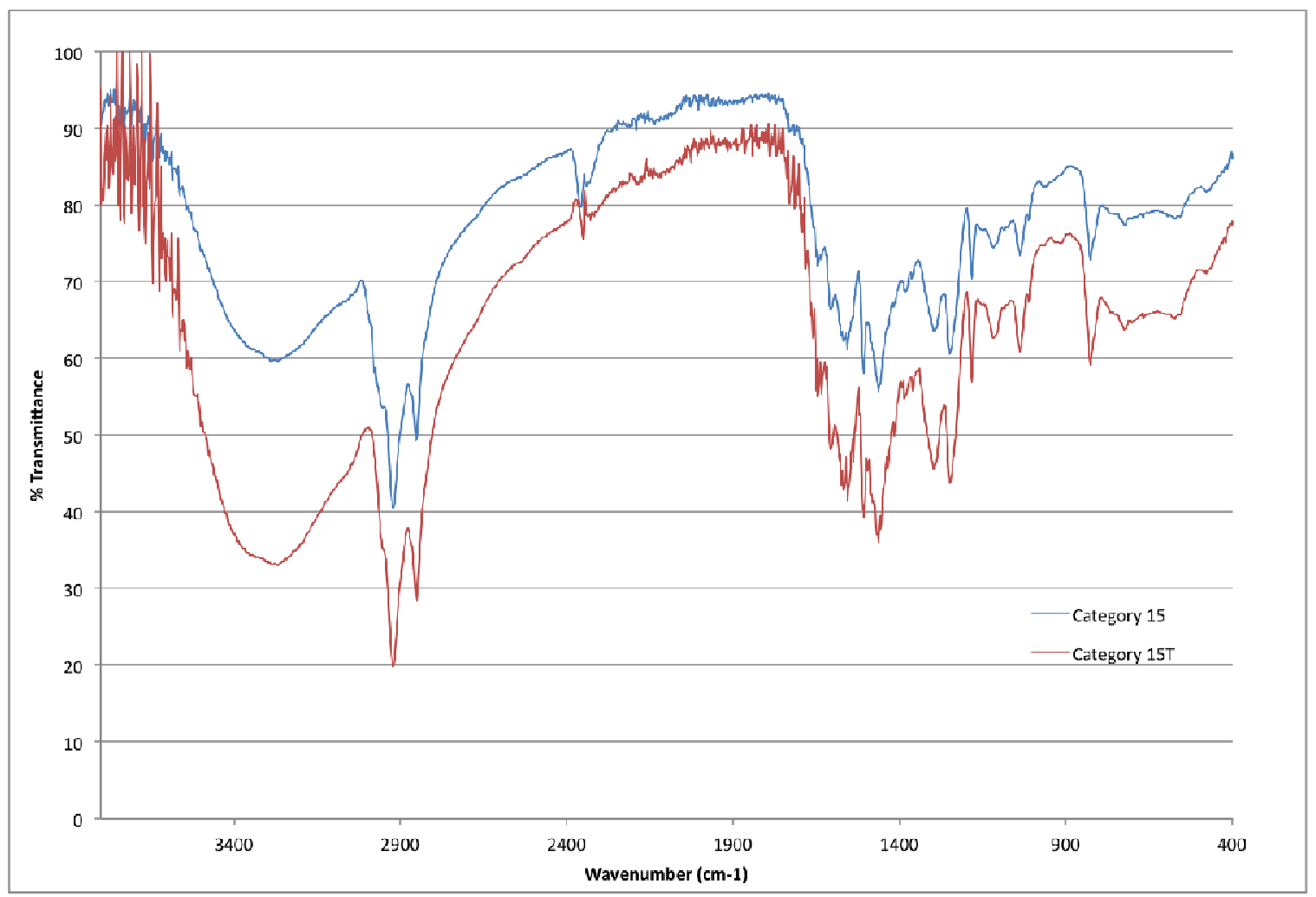

Figure 25: IR spectra of the epoxy ( spot 6)

Figure 25 depicts the IR spectra taken on the epoxy (which is on top of the coating - spot 6). The expected spectra should only have peaks representative of an epoxy coating. In figure 25 , there are peaks at $\sim 3350,2900,1450$, and $1200 \mathrm{~cm}^{-1}$, which are characteristic of $\mathrm{O}-\mathrm{H}$ stretching, $\mathrm{C}-\mathrm{H}$ stretching, $\mathrm{C}-\mathrm{H}$ bending, and $\mathrm{C}-\mathrm{O}-\mathrm{C}$ stretching, respectively. The IR spectra of spots 2,3 , and 5 look nearly identical. These were the spectra of the area under the removed dolly, the area underneath where a random sample of epoxy was placed, and the bare substrate, respectively. These were all spectra of the substrate, and the results showed spectra typical of a PP substrate. Although the IR spectra of spots 1 (Figure 20) and 4 (Figure 23) (the dried coating and the backside of the coating where the epoxy was placed, respectively) are very similar, spot 4 has $\mathrm{O}-\mathrm{H}$ peaks while spot 1 does not. This could indicate a similar $\sim \mathrm{OH}$ as found in the epoxy (Figure 25). In Figure 23 (spot 4), the peak at $3650 \mathrm{~cm}^{-1}$ could be a secondary amine, amide or free hydoxy. It is 
most likely free hydroxyl, as free amine would have shown up for all Type C PP panels tested (since all used epoxy). However, this sharp peak only appears for the Category 16 panels. This indicates it is not an amine group, rather the free hydroxyl group. Since this only occurs with Category 16 panels, it further substantiates the claim the Category 16 panel is unique. It should also be noted that a distinct peak can be seen at $3375 \mathrm{~cm}^{-1}$ on many of the spectra. This was $\mathrm{CO}_{2}$ that was not removed by the background spectra.

It was noticed the removal of the dolly from all panels via pull-off adhesion revealed only adhesive failure between the dolly and the substrate. Also, all other pieces of coating removed from the panels were done so by hand and with a razor blade. These pieces of coating came off with relative ease, and were visually confirmed to experience adhesive failure between the coating and the substrate.

The pull-off adhesion test results of the plasma treated, non-coated Category 16 and Category 7 panels showed a high pull-off force required to remove the dollies. However, the non-plasma treated panels for both categories revealed lower pull-off results. Table 20 displays the results.

Table 20: Pull-off results for non-coated Category 7 and 16 panels

\begin{tabular}{|c|c|c|}
\hline \multirow{2}{*}{ Panel } & \multicolumn{2}{|c|}{ Pull-Off Adhesion Ranking (psi) } \\
\cline { 2 - 3 } Composition ID & Non-Plasma-Treated & Plasma-Treated \\
\hline 7 & $31 \pm 22$ & $568 \pm 21$ \\
\hline 16 & $57 \pm 38$ & $528 \pm 5$ \\
\hline
\end{tabular}

There was no failure for the untreated Category 16 and 7 panels, similar to previous results. The plasma-treated Category 16 panels displayed cohesive failure of the PP, while the non-treated Category 16 panels did not. Also, neither treated or untreated Category 7 panels displayed cohesive failure of the PP. The IR spectra, coupled with these results, indicates a possible interaction of epoxy with the bare PP substrate, 
specifically plasma treated Category 16 panels. The process of plasma treatment may add surface-active groups that can interact with the epoxy coating, creating an unusually strong bond. However, the only concrete claim that can be made is the Category 16 panel's behavior is unique.

\subsubsection{X-ray Photoelectron Spectroscopy Results}

As described in section 6.2.5, surface of categories 7 and 16 panels were analyzed with an X-ray photoelectron spectroscopy (XPS) instrument available at the University of California Santa Barbara (UCSB). The UCSB XPS instrument was utilized to take highresolution spectra and wide-spectrum survey spectra of the panel surface. Category 16 panels were of particular interest, as they showed unusual pull-off adhesion results (Table 17). XPS is routinely used to characterize the effect of surface treatment on treated PP samples and other polymers (Pijpers, 2001). An example of each type of spectra can be seen in Figure 26. The results from the spectra were tabulated and are displayed in Tables 21 and 22. The $\mathrm{x}$-axis is proportional to the binding energy (in $\mathrm{eV}$ ) and the $\mathrm{y}$-axis is proportional to the number of electrons detected. The high-resolution spectra and widespectrum survey results can be seen in their entirety in appendix A. 

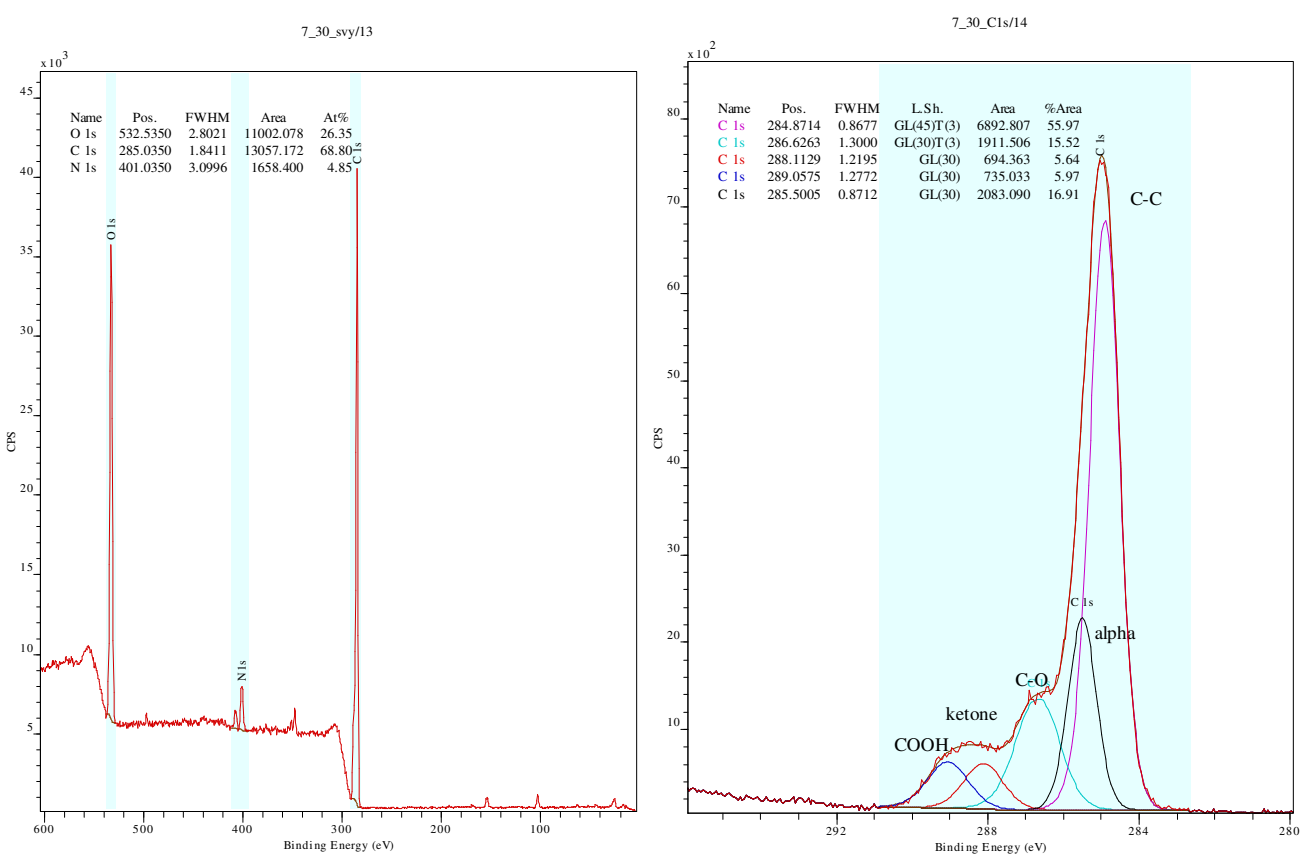

Figure 26: Wide-spectrum (left) and high-resolution spectrum (right) of 30 second plasma treated Category 7 sample

Table 21: Wide-spectrum survey results from XPS testing

\begin{tabular}{|c|c|c|c|c|c|c|c|c|}
\hline & \multicolumn{8}{|c|}{ \% Sample } \\
\hline & \multicolumn{5}{|c|}{ Category 7} & \multicolumn{3}{|c|}{ Category 16} \\
\hline & Untreated & & na & & ma & Untreated & Pla & ma \\
\hline $\begin{array}{c}\text { Element } \\
\text { (1s) }\end{array}$ & & $\begin{array}{c}5 \\
\text { Second }\end{array}$ & $\begin{array}{l}30 \\
\text { Second }\end{array}$ & $\begin{array}{c}5 \\
\text { Second } \\
\end{array}$ & $\begin{array}{c}30 \\
\text { Second }\end{array}$ & & $\begin{array}{c}5 \\
\text { Second } \\
\end{array}$ & $\begin{array}{c}30 \\
\text { Second }\end{array}$ \\
\hline $\mathrm{O}$ & 9.55 & 12.79 & 22.42 & 25.43 & 26.35 & 5.96 & 22.95 & 30.16 \\
\hline $\mathrm{C}$ & 90.45 & 84.89 & 73.91 & 69.91 & 68.80 & 94.04 & 73.06 & 64.58 \\
\hline $\mathrm{N}$ & & 2.32 & 3.67 & 4.65 & 4.85 & & 3.99 & 5.26 \\
\hline
\end{tabular}

Table 21 provides the wide-spectrum survey results from the corresponding spectra. This spectrum displays those elements found on the surface of the sample, as well as the percentage they appear. Carbon and oxygen were expected, but traces of nitrogen were found on all treated samples. When comparing the treated samples of Category 7 and 16 panels, the 5 second plasma treated Category 16 panels have a higher percentage of carbon than the Category 7 panels, but the 30 second plasma treated Category 16 panels have a higher percentage of oxygen than the Category 7 panels. 
Table 22: High-resolution C1s results from XPS testing

\begin{tabular}{|c|c|c|c|c|c|c|c|c|}
\hline & \multicolumn{8}{|c|}{ \% Functional Groups in Sample } \\
\hline & \multicolumn{5}{|c|}{ Category 7} & \multicolumn{3}{|c|}{ Category 16} \\
\hline & Untreated & Cor & & Pla & & Untreated & & \\
\hline $\begin{array}{c}\text { Functional } \\
\text { Group }\end{array}$ & & $\begin{array}{c}5 \\
\text { Second }\end{array}$ & $\begin{array}{l}30 \\
\text { Second }\end{array}$ & $\begin{array}{c}5 \\
\text { Second }\end{array}$ & $\begin{array}{c}30 \\
\text { Second }\end{array}$ & & $\begin{array}{c}5 \\
\text { Second }\end{array}$ & $\begin{array}{c}30 \\
\text { Second }\end{array}$ \\
\hline $\mathrm{C}-\mathrm{C}$ & 92.18 & 69.48 & 64.36 & 54.51 & 55.97 & 96.07 & 61.85 & 52.73 \\
\hline $\mathrm{COOH}$ & 3.57 & 0.86 & 2.67 & 5.75 & 5.97 & 1.71 & 2.77 & 11.94 \\
\hline $\mathrm{C}-\mathrm{O}$ & 0.67 & 4.30 & 12.74 & 13.90 & 15.52 & 0.50 & 14.12 & 18.88 \\
\hline Ketone & & 2.75 & 5.06 & 6.46 & 5.64 & & 5.31 & 4.11 \\
\hline
\end{tabular}

Table 22 shows the high-resolution XPS spectra results for all panel types. The functional groups found on the surface are determined by binding energies of the $\mathrm{C} 1 \mathrm{~s}$ photoelectric lines that appear in the actual spectra, and for these panels, included C-C, , COOH, C-O (as in ethers and alcohols), and ketones.

The percentage of each functional group varies for each sample. As expected, the surface of the untreated panels was mainly composed of C-C functional groups. Regardless of treatment type or time, the amount of C-C functional groups drastically drops in treated samples, with the other functional groups becoming more abundant. It was seen that a 5 second plasma treatment on Category 7 panels introduces more $\mathrm{COOH}$, $\mathrm{C}-\mathrm{O}$, and ketone functionality than a 5 second corona treatment on the same panel. Also, the plasma treated Category 16 panels had more C-O groups than the treated Category 7 panels. However, the treated Category 7 panels had more ketone and $\mathrm{COOH}$ groups. Another observation is that an extended treatment time (30 seconds) does not always provide a significant increase in oxygen-containing functional groups when compared to a 5 second treatment time. However, it is clear from both Table 21 and Table 22 that a five second plasma treatment introduces more oxygen-containing functionality to the surface of the PP panels than a five second corona treatment does. 
The added MAPE in the category 16 panels seems to have an effect on the surface species present. When compared to the 5 second plasma treated Category 7 panels, the 5 second plasma treated Category 16 panels had slightly less $\mathrm{COOH}$ and ketone functionality, but more C-O functionality. Comparing the two panels after 30 seconds of plasma treatment, the Category 16 panels had more $\mathrm{COOH}$ and $\mathrm{C}-\mathrm{O}$ functionality, and less ketone functionality.

Concurrent with the results from Table 22, the amount of oxygen increases for all treated samples when compared to untreated samples. This experiment was limited in scope and scale, but from these results it was observed that plasma treatment provides a larger amount of oxygen and nitrogen when compared to corona treatment (five second treatment time) and extended treatment times (30 seconds) do not increase the amount of oxygen or nitrogen on the samples significantly. Although the data did not display a significant difference between the Category 7 and Category 16 panels, a more detailed study is needed to conclude this. Raman spectroscopy is sensitive to carbonyls and bigger atoms, and would be useful in determining the difference in the Category 16 panels.

\section{Conclusions - Adhesion}

The experimental work showed the original characterization of the brown coating was almost identical to the newer characterization data completed on the second batch of 
Cedar blend received. The comparison was done to ensure the results from testing on all batches of paint would be similar.

The ideal plasma treatment conditions were established and used for all experiments. It was shown that increasing the surface tension of polypropylene from $\sim 30$ dynes $/ \mathrm{cm}$ to above 60 dynes/cm was attainable by plasma treatment, and subsequently, plasma treatment positively affects the adhesion of the coating to the substrate. This was confirmed by quantitative tests. Using the Type B PP panels, adhesion increased from no adhesion (0B) to greater than acceptable adhesion (4B) and the force needed to remove a dolly from an untreated panel $(91.92 \pm 26$ psi) greatly increased for plasma treated panels $(232.83 \pm 47 \mathrm{psi})$.

Using the modified procedure for pull-off adhesion testing, similar adhesion results were attained for the coated, plasma treated Category \# PP panels. Crosscut adhesion revealed an increase from no adhesion (0B) of untreated panels to perfect adhesion (5B) for all compositional variations of the Category \# panels. The pull-off adhesion testing rankings had a more diverse set of results, but the pertinent information gained was that plasma treated panels took $\sim 2.5$ times more force to remove the dollies than untreated panels. Although an outlier (Category 16) was initially found to have peculiar pull-off adhesion results (1253.4 $\pm 1310 \mathrm{psi})$, subsequent testing revealed this not to be the case. A hypothesis entailing epoxy migration was proposed and tested via ATR FT-IR. The IR spectra revealed no conclusive evidence that epoxy migration was occurring, although the Category 16 panels did experience cohesive failure of the PP substrate during pull-off adhesion testing of uncoated panels. XPS testing did revealed small differences in the surface composition of Category 7 and Category 16 panels, as well as a marked difference between plasma and corona treatment. However, as the scope and depth of the 
XPS section of the project was limited, a more detailed investigation is necessary to make conclusions.

\section{Long-Term Durability - Introduction}

\subsection{Accelerated Weathering}

As mentioned in section 2.2, polypropylene siding requires much less maintenance

then traditional wood siding. With wood siding, homeowners often desire to clean the outside of their house. With polypropylene siding, this is still true, although the cleaning 
is less often. All types of siding are also exposed to direct sunlight, humidity, rain, and other environmental factors, depending on location. The ability of siding to resist cleaning agents and natural elements for the long-term is a requirement to minimize the cost of repair or replacement for homeowners. However, real-world testing of new coating systems on the siding of a house is expensive, and most importantly, timeconsuming. To test the effectiveness of a coating for 10 years would take just that -10 years. During this amount of time a more efficient or similar product might reach the market first, which would have made the research, time, and money put into the product's development go to waste. Therefore, accelerated testing is done to save time and money, while producing results that attempt to mimic those seen after years of real-world testing.

One such testing method is QUV Accelerated Weathering testing. This laboratory simulated weathering test uses a Q-Panel Lab Products QUV weathering tester Model QUV/se. This weathering tester is capable of holding samples and keeping them under the harsh rays of UV-lamps that simulate the UV rays the sun emits, and some models are able to simulate the effects of humidity and rain. The temperature can be set to match a region on the globe as well. The samples are continuously exposed to these harsh settings. Due to the constant exposure to the 'elements,' this type of testing is referred to as accelerated, because in a real-world setting, there is not constant exposure to sunlight and/or rain. Although these instruments provide a good method to predict the durability of a material, it does not necessarily provide an accurate representation of reality, as only actual weathering testing can do that.

A more accurate representation could be obtained using EMMAQUA (Equatorial Mount with Mirrors for Acceleration with Water) testing. This testing concentrates natural sunlight via 10 highly reflective, specially coated mirrors onto the specimen target 
area with an intensity of approximately eight suns (Atlas, 2011). The device then tracks

the sun and exposes specimens to the full spectrum of sunlight, making it more realistic than QUV accelerated weathering (Atlas, 2011). The testing apparatus is a rack that follows the position of the sun, and has mirrors positioned as tangents to simulate a parabolic trough (Atlas, 2011). The apparatus also has a fan spray nozzle, which sprays specimens with water. This testing was not available to Cal Poly for this study, and therefore, QUV accelerated weathering testing was used.

\subsection{Cleaning Agent Resistance}

When an owner of a home or other property observes that their property has become dirty, the first response is to clean the stained area, usually with water. If this area includes particularly stubborn soiling, an attempt to remove the stain by a cleaning agent is done. This can range from a mixture of soap and water to typical cleaning agents recommended by the siding manufacturer. Therefore, it is imperative for the material in question (in this case a polypropylene-based siding product) to be a resistant to a variety of cleaning agents.

A home typically lasts many decades, and during that extended period of time, it will routinely be cleaned. Even if the building material is resistant to most cleaning agents, it would be costly to have to replace the material if this resistance is short-lived when compared to the life expectancy of a home. Therefore, any advantage that would increase the building material's life expectancy is welcomed. For CertainTeed's polypropylene sidings, they found the addition of a clear coat improved solvent resistance. A request was made to Cal Poly to test their findings in a controlled laboratory setting.

To quantify the improvement in cleaning agent resistance of a clear-coated siding compared to a non-clear coated siding, cleaning agent resistance testing of both types 
were be compared. This testing was done using typical cleaning agents recommended by CertainTeed, which will be repeatedly rubbed back and forth across the sample's surface for a set number of 'double-rubs.' The amount of coating removed from the surface is qualitatively judged, with an expected increase in resistance provided by the clear coat.

\subsection{Real World Panels from North Carolina}

CertainTeed provided Cal Poly with two samples of their commercial siding. One sample, PR-11-1, was a control sample that was produced approximately two years ago and was stored indoors at CertainTeed's Jackson Development Center. The other sample, PR-11-3, was a sample that had been exposed to the outdoors for two years.

CertainTeed desired to have the two samples compared and the modes of failure for the weathered sample identified by Cal Poly.

\subsection{Methods and Materials}

\subsubsection{QUV Weathering Testing}

A Q-Panel Lab Products QUV weathering tester Model QUV/se was used for weathering testing of the PP panels. Preparation of the panels to be tested followed the plasma treatment and coating procedures listed section 7.4.2. The weathering conditions followed ASTM G53, with 8 hours of UV exposure at $40^{\circ} \mathrm{C}$ followed by 4 hours of condensing humidity at $50^{\circ} \mathrm{C}$, with this cycle repeating daily for a total of 2400 hours. A total of four plasma treated panels of each polypropylene category were tested at the same time except for the category 7 panels (of which only three will be tested). Only three category 7 panels were tested due to the limited supply of category 7 panels, as they needed to be conserved to complete other portions of this study. Only twelve of the $16 \mathrm{PP}$ categories were tested. Therefore, there were a total of 47 test panels. The capacity of the QUV weathering tester is 48 panels. The panel categories tested were Categories 1-9 and 
14-16 panels. No non-plasma treated samples were used for testing. Gloss and color measurements were taken, and these tests were repeated weekly once weathering testing began. A DataColor Mercury Spectrophotometer was used for CIElab color measurements $\left(\mathrm{L}^{*}, \mathrm{a}^{*}\right.$, and $\left.\mathrm{b}^{*}\right)$. The initial color values and the final color values were compared by calculating the total change in color, or $\mathrm{E}$ :

$$
\mathrm{E}=\cdot\left(\mathrm{L} *^{2}+\mathrm{a}^{*^{2}}+\mathrm{b}^{*^{2}}\right)
$$

A large $\mathrm{E}$ means a large difference in color between the initial and final samples.

A BYK Gardener Micro-TRI-Gloss gloss meter at an $85^{\circ}$ angle was used for gloss measurements, and the statistic mode was used to provide the standard deviation of the 10 gloss measurements recorded for each panel. After four weeks, one of the four weathered panels of each category was removed from the QUV weathering tester for adhesion testing. Pull-off adhesion testing was conducted according to ASTM D4541-09. An Olympus Infinity 2 Microscope AT with a 10x magnification microscope was used in conjunction with Infinity Capture/Analyze software to compare the surface of the weathered samples as a function of time.

\subsubsection{Cleaning Agent Resistance Testing}

The PP panel's resistance to household cleaning agents was tested. Two different types of samples were prepared (a single coated panel and a double coated panel) and their cleaning agent resistance was compared. The single coated panel was coated with the brown coating. The double-coated panel was coated with the brown coating followed by a clear coating supplied by CertainTeed. Both panel types were plasma treated before coating, following the procedure in section 6.2.3. Once the panels were treated, the brown coating was immediately applied and allowed to set at room temperature for 5 minutes. The panels were then placed in an oven at $70^{\circ} \mathrm{C}$ for 5 minutes. They were removed and 
left to dry overnight (24 hours) at room temperature. After 24 hours, the panels that were to be top-coated were coated with the clear topcoat and allowed to remain at room temperature for 5 minutes. They were then placed in the oven at $70^{\circ} \mathrm{C}$ for 5 minutes. The panels were left to dry overnight (24 hours) at room temperature. A 4 mil drawdown bar was used for all drawdowns.

The testing procedure follows a mixed version of ASTM D4752 and ASTM D5402. The first ASTM uses MEK as the solvent, while the second ASTM is more liberal with solvent choice. The modified version used four different cleaning agents: Oxi-Clean, Simple Green, Formula 409, and a Tide detergent/trisodium phosphate/Clorox bleach vinyl siding cleaning mixture used by CertainTeed. The cleaning test was performed in duplicate on each panel. As depicted below, 6 inch by 4 inch panels were split evenly in three two-inch sections by a Sharpie marker.

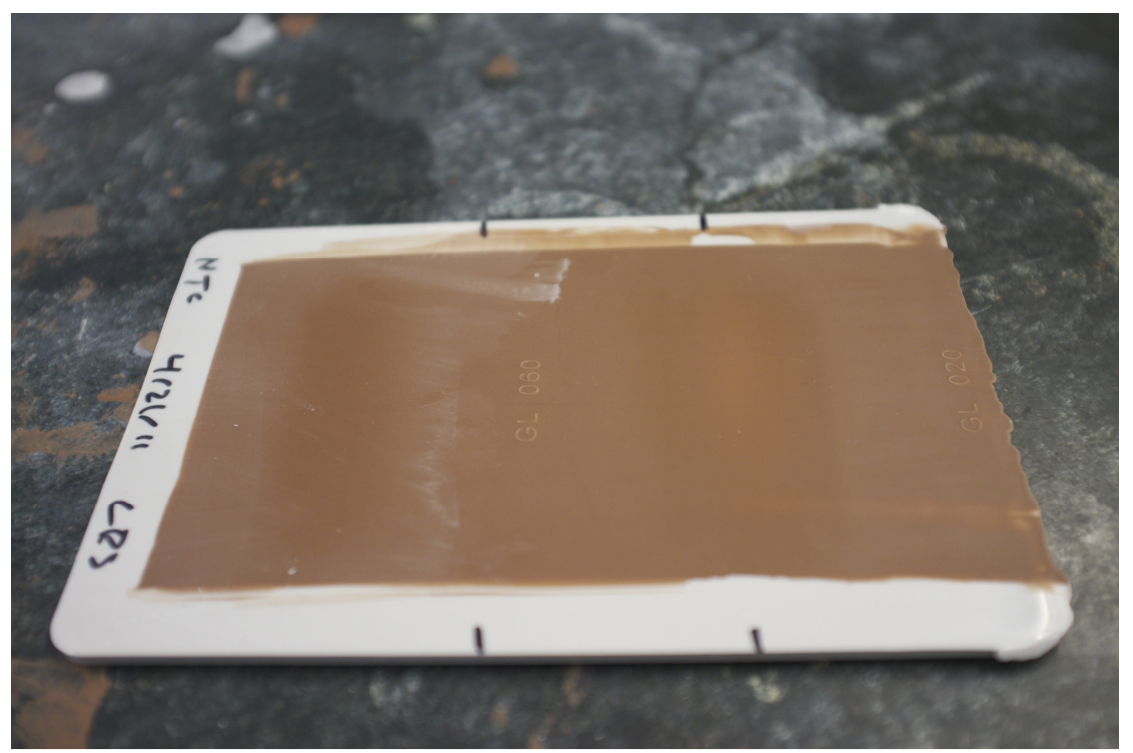

Figure 27: Cleaning agent resistance test panel

Two of the sections were used as a testing area for the cleaning agent resistance, while the third section acted as a control. For the control, the testing was approached in the same manner, except using a cheesecloth without cleaning agent. ASTM D4752 
quantifies the cleaning agent resistance on a $0-5$ scale, with 0 being the worst (less than 50 double rubs to penetrate through the coatings to the PP panel's surface) and 5 being the best (50 double rubs without any penetration or coating residue on the cheesecloth). However, ASTM D5402 does not use a scale. This ASTM method calls for 25 double rubs, and more if necessary. The tester is only to note how many double rubs it took before the substrate became visible. Therefore, a modified scale was used which incorporated aspects of both ASTMs. A new ranking scale of 0-5 was employed, and a total of 250 double rubs were performed. The ranking scale is described in section 10.2.

To perform the test, cheesecloth was soaked with the cleaning agent and then rubbed back and forth across the substrate in one of the three defined areas. The bottom of the cloth and the substrate were examined for coating residue and exposure to bare substrate, respectively, every 25 double rubs - up to a total of 250 double rubs.

An Olympus Infinity 2 Microscope AT with a 10x magnification microscope was used in conjunction with Infinity Capture/Analyze software to examine the surface of the panels before and after the cleaning agent resistance testing. This allows for a more detailed examination of any physical changes that have taken place due to the cleaning agents. This will also provide a method to qualitatively determine if the double rubs had any affect on the clear coat.

\subsubsection{Real World Samples}

An Olympus Infinity 2 Microscope AT with a 10x magnification microscope was used in conjunction with Infinity Capture/Analyze software to examine the surface of the panels. A Nexus 470 FT-IR and a Nicolet 380 FT-IR spectrometer were used in conjunction with EZ OMNIC E.S.P. 5.1 software to record and analyze attenuated total reflectance (ATR) infrared spectroscopy spectra. 


\section{Results and Discussion - Durability}

\subsection{QUV Testing}

QUV simulated weathering testing was performed on Category 1-9 and 14-16 panels following the procedure listed in section 9.4.1. Category 10-12 panels were omitted from the study because they were formulated with maleic anhydride 1, not maleic anhydride 2, which was seen to have unusual adhesion characteristics. Category 13 panels were excluded because they had smallest amount of maleic anhydride 2 . The color values $\left(\mathrm{L}^{*}\right.$, $\mathrm{a}^{*}$, and $\mathrm{b}^{*}$ ) and gloss values (measured at $85^{\circ}$ ) can be seen in their entirety in Appendix A. The initial color and gloss values were taken at the beginning of testing and the panels were removed once a week to have their color and gloss values determined. The final values are from 2400 hours of QUV exposure. Data can be seen in Figures 28-33. 


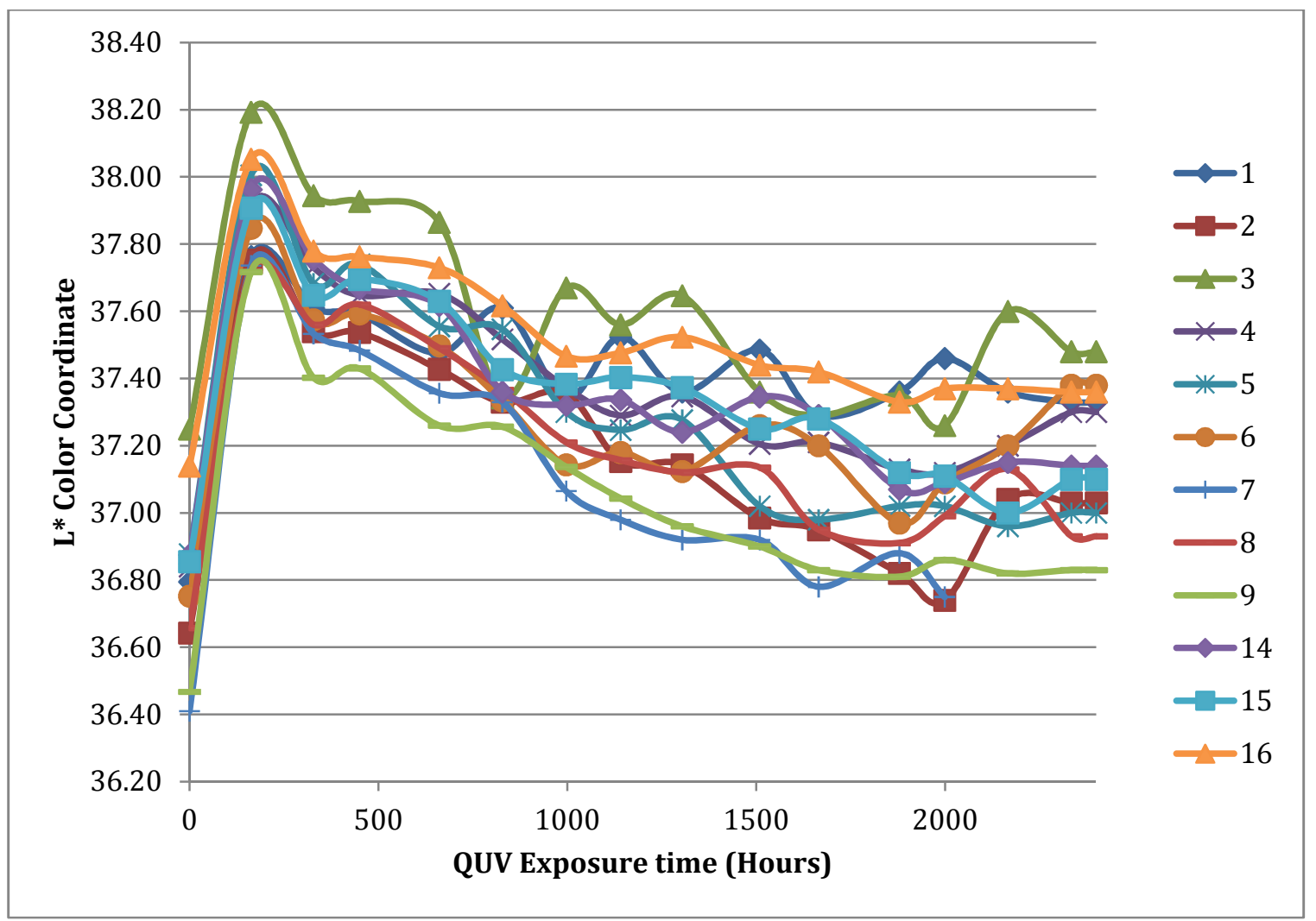

Figure 28: Change in $\mathrm{L}^{*}$ as a function of time 


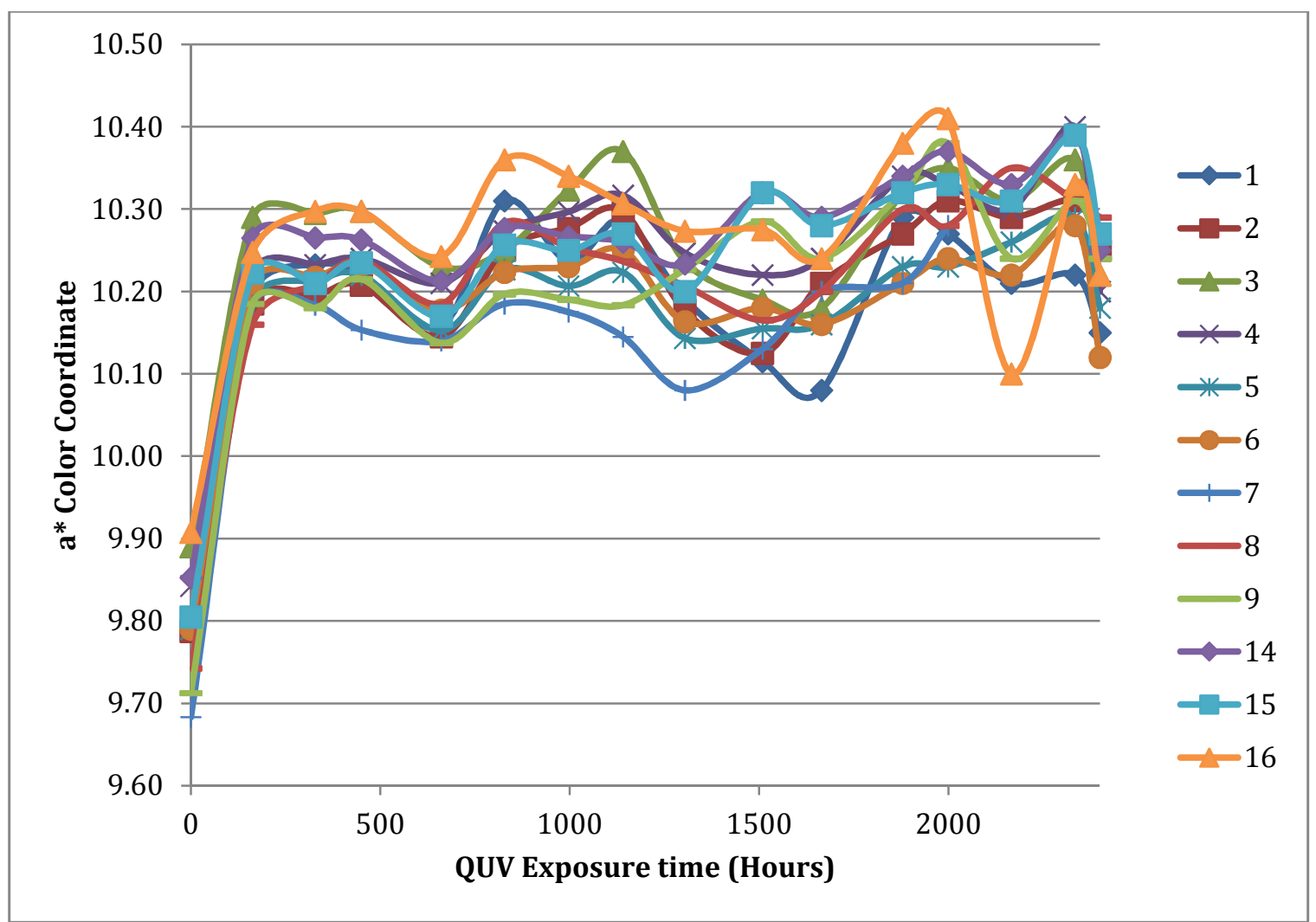

Figure 29: Change in $\mathrm{a}^{*}$ as a function of time

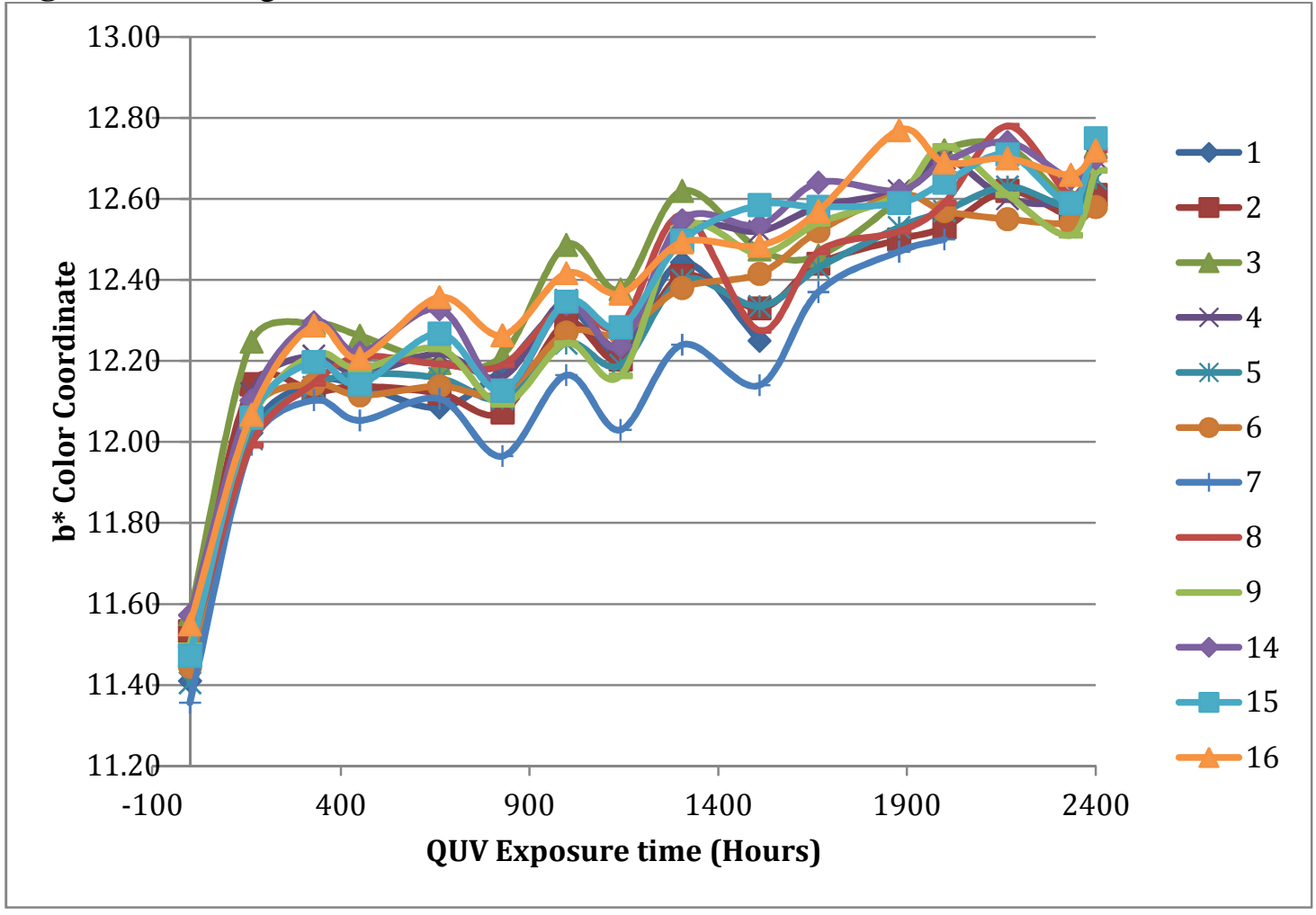

Figure 30: Change in $b^{*}$ as a function of time 


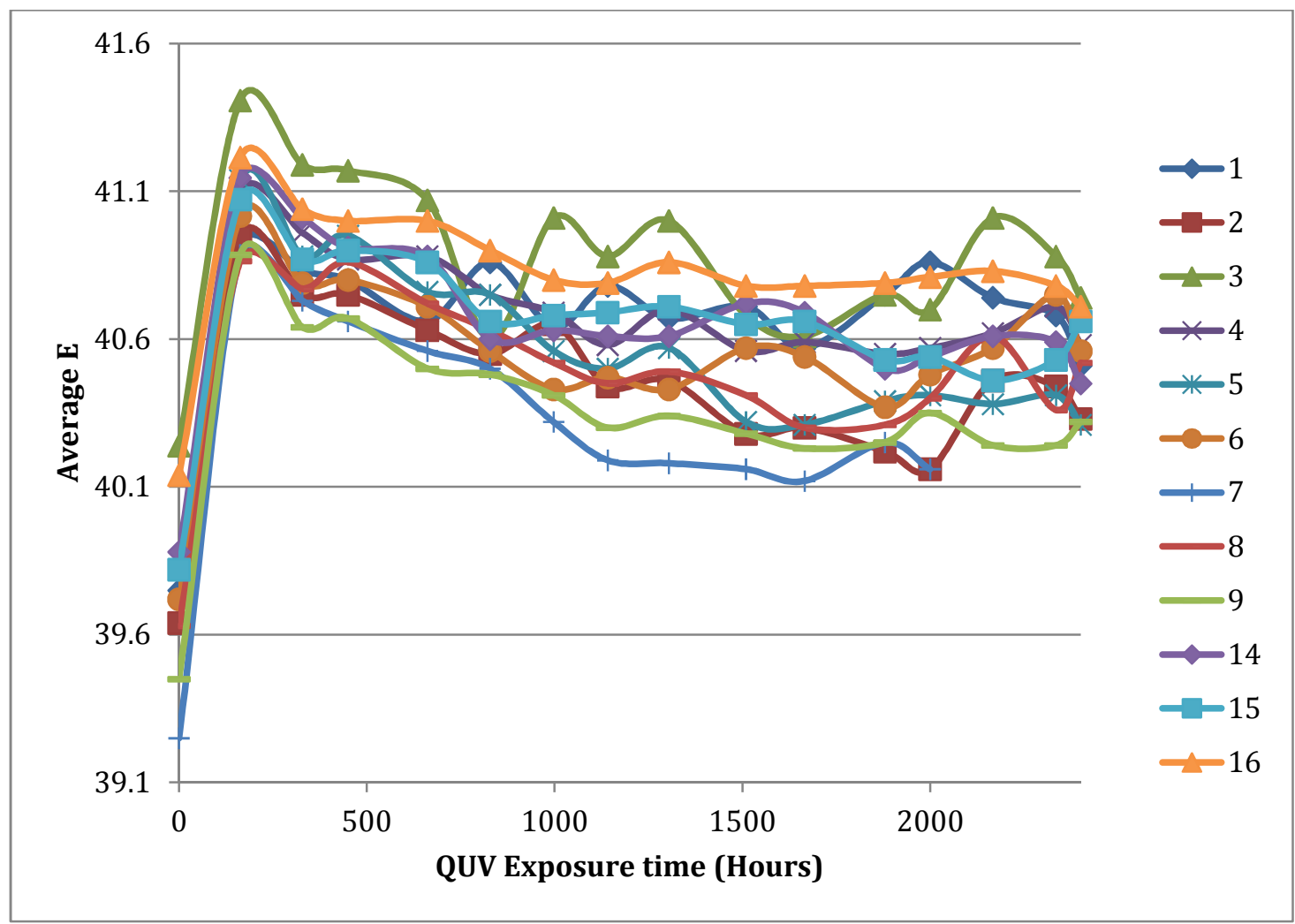

Figure 31: Change in $\mathrm{E}$ values as a function of time

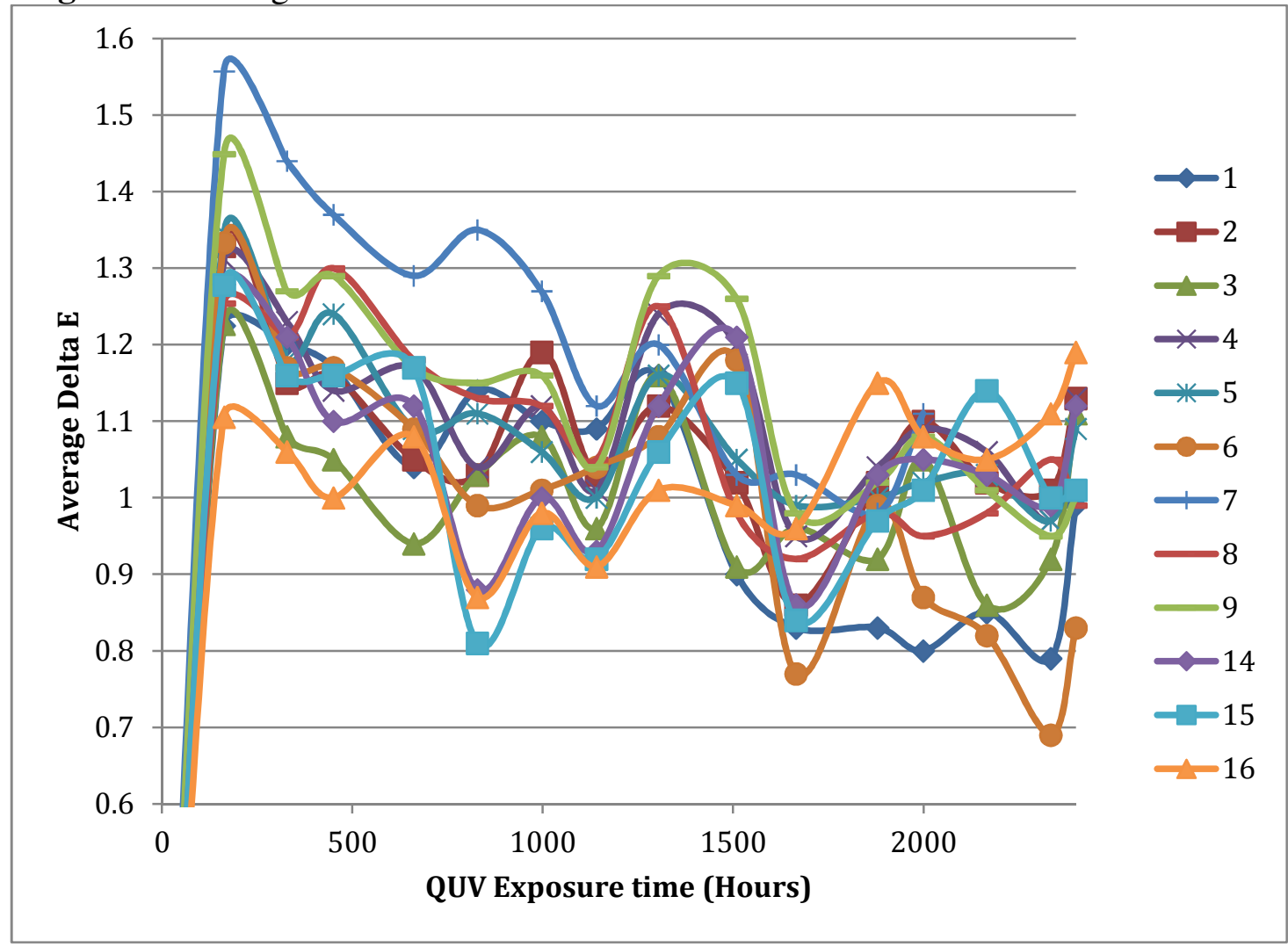

Figure 32: Delta $E$ as a function of time 
Figure 28-32 shows the colorspace data. Figure 31, which plots $E$ vs QUV exposure time, shows the change in $\mathrm{E}$ as a function of time for all panel categories is not substantial. Figure 32 shows the change in color, or E. The E after 163 hours (the first test point) for all polypropylene compositions was high, but as the weathering continued, the values fluctuated on a very small scale. A color change of less than $\mathrm{E} \sim 1$ is generally accepted as being imperceptible to the naked eye, and this was visually confirmed - all coatings looked identical. The largest $\mathrm{E}$ values were $\sim 1$, but the color difference was still not noticeable. The $b^{*}$ value, while still have a negligible overall change, displayed a potential increase over time, which indicates a more yellow color. However, a longer experiment would be needed to confirm this. Figures 28-32 all showed an initial increase in their respective values. This may be an artifact of the DataColor Mercury Spectrophotometer. The QUV accelerated weathering testing could be repeated to see if this initial jump in CIElab color data occurs again. 


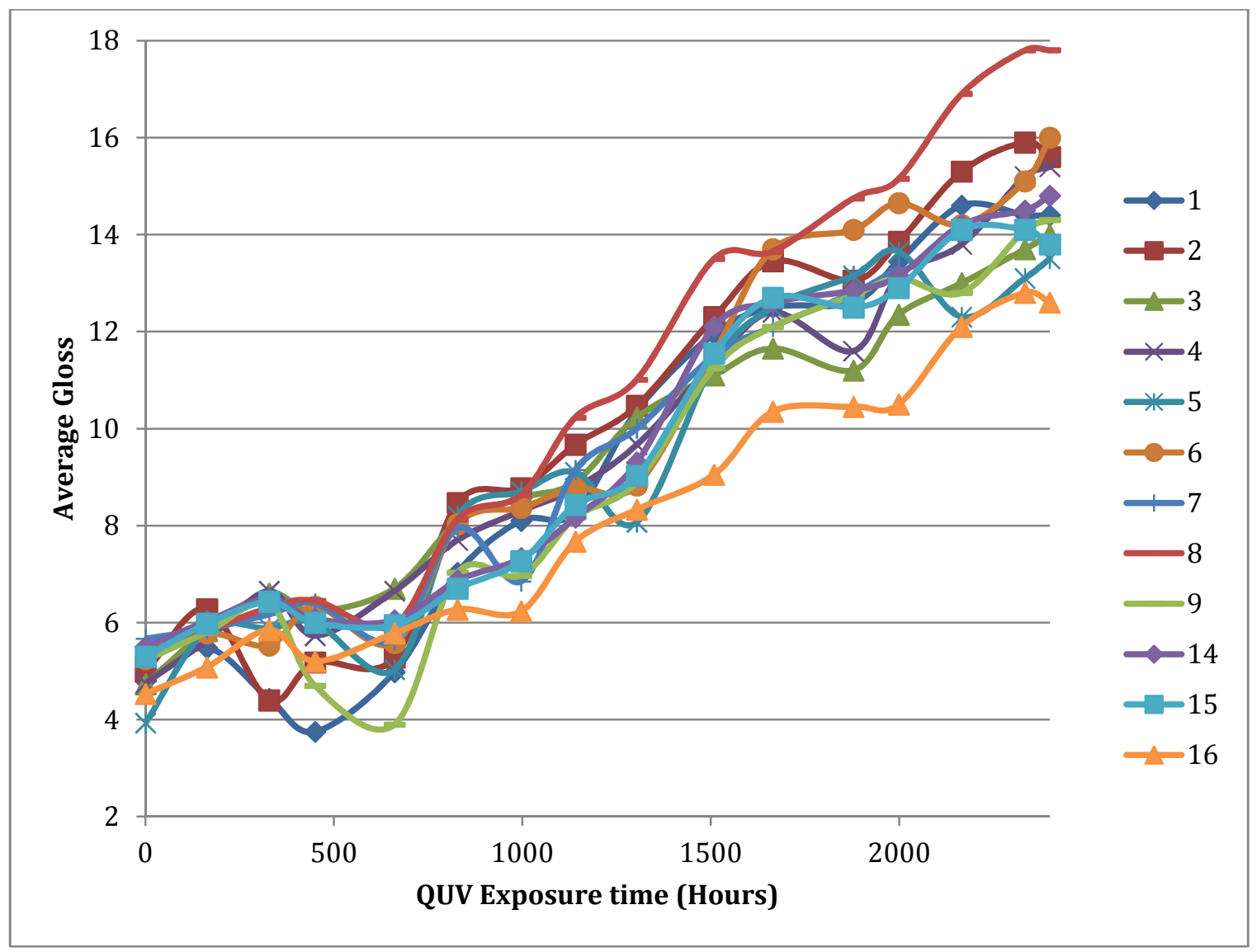

Figure 33: Gloss $\left(85^{\circ}\right)$ values as a function of time

Figure 33 shows the overall gloss values for all polypropylene compositions increased as a function of weathering time. Almost all the PP compositions were consistent in their gloss increase, although the Category 16 panel had the smallest increase. Although this was a surprising result, it has been documented that certain types of top coatings show an increase in gloss after relatively short exposure in outdoor and artificial tests (Hoeflaak, 2006). An increase in gloss is usually associated with a 'smoother' surface. Atomic force microscopy (AFM) could be used to determine the surface changes of the panels, as in the formation of pits and surface roughening or smoothing (Sung, 2004). Further XPS investigations could be completed on the weathered samples. Laser scanning confocal microscopy (LSCM) can characterize 
ablation, formation of pits, and other surface defects, as well as measure film thickness over time (Sung, 2004). This technique would be helpful in determining the reason for the gloss increase as well. XPS may be able to explain the increase in gloss, which may be due to additives or surfactants in the PP's formulation that may 'bloom' to the surface over time, smoothing the surface and increasing the gloss.

\subsubsection{QUV Testing - Microscopy}

Using an Olympus Infinity 2 Microscope AT, the surfaces of weathered panels were compared. All of the category panels were examined, but category 3, 7, and 16 panels examples are displayed, both at 10x and 50x magnification. Category 7 was chosen because it is the 'standard' coating, category 16 was chosen because it had unusual adhesion characteristics, and category 3 was chosen at random. The surfaces of all panels examined appeared to be uniform in composition. Microscopy results on category 3, 6, and 16 panels after 661 hours and 1509 hours in the QUV revealed similar panels. There were no visible differences between the surface morphology between all panels at both exposure times.

The microscopy data and QUV colorspace data support the statement that there is no noticeable change in performance or appearance of the coated panels after 2400 hours in the QUV simulated weathering tester. However, further resting using atomic force microscopy would be able to determine the surface qualities of the panels in a more quantitative manner.

\subsubsection{QUV Testing - Adhesion Results}


The results from adhesion testing can be seen in Table 23 .

Table 23: Pull-off adhesion results for QUV accelerated weathering testing

\begin{tabular}{|c|c|c|c|c|}
\hline \multirow{2}{*}{$\begin{array}{c}\text { Panel } \\
\text { Composition } \\
\text { ID }\end{array}$} & \multicolumn{4}{|c|}{ Pull-Off Adhesion Ranking (psi) } \\
\hline & 661 hours & 1304 hours & 2166 hours & 2400 hours \\
\hline 1 & $307 \pm 60$ & $330 \pm 48$ & $382 \pm 16$ & $269 \pm 55$ \\
\hline 2 & $320 \pm 55$ & $394 \pm 30$ & $356 \pm 98$ & $338 \pm 62$ \\
\hline 3 & $287 \pm 78$ & $356 \pm 99$ & $388 \pm 38$ & $314 \pm 69$ \\
\hline 4 & $305 \pm 29$ & $333 \pm 18$ & $378 \pm 21$ & $370 \pm 73$ \\
\hline 5 & $363 \pm 49$ & $412 \pm 42$ & $412 \pm 40$ & $409 \pm 4$ \\
\hline 6 & $390 \pm 21$ & $388 \pm 43$ & $426 \pm 48$ & $432 \pm 46$ \\
\hline 7 & $292 \pm 59$ & $462 \pm 112$ & $380 \pm 46$ & N/A \\
\hline 8 & $355 \pm 11$ & $435 \pm 142$ & $431 \pm 125$ & $375 \pm 122$ \\
\hline 9 & $362 \pm 50$ & $451 \pm 116$ & $440 \pm 7$ & $399 \pm 18$ \\
\hline 14 & $364 \pm 94$ & $254 \pm 17$ & $429 \pm 30$ & $353 \pm 93$ \\
\hline 15 & $338 \pm 90$ & $380 \pm 207$ & $292 \pm 42$ & $391 \pm 156$ \\
\hline 16 & $430 \pm 45$ & $423 \pm 22$ & $359 \pm 45$ & $363 \pm 18$ \\
\hline
\end{tabular}

Table 23 displays the results of the pull-off adhesion testing. As expected, the range of values for each panel is highly variable. Previous pull-off adhesion rankings on the same panel compositions (Table 17) revealed similar results. Category 16 panels did not show unusually high pull-off results, although each panel experienced cohesive failure. This gives further evidence that there is a connected between the epoxy used as an adhesive and the Category 16 panels, which will be investigated in the future. Overall, it can be stated that simulated weathering does not have an effect on adhesion properties.

\subsection{Cleaning Agent Resistance Results}


The cleaning agent resistance of double coated (clear coat and brown coating layer) and single coated (brown coating layer only) plasma treated panels was compared. The cleaning agent resistance of plasma treated, double coated (i.e., brown Cedar paint followed by clear coating) and single coated (brown Cedar paint only) panels are compared in Table 24.

A 0 to 5 ranking scale, specified below, was developed to rank the cleaner resistance of the coatings.

- 5 - No brown Cedar paint residue being observed on the cheesecloth.

- 4 - A minimal amount of Cedar paint residue could be seen on the cheesecloth

- 3 - A large amount of Cedar paint residue could be seen on the cheesecloth (i.e., the entire bottom of the cheesecloth has become brown in color)

- 2 - Cheesecloth turns completely brown with Cedar paint, and parts of the bare polypropylene substrate becomes visible

- 1 - Substrate can be clearly seen with few double rubs and more substrate becomes visible with further rubbing

- 0 - There is no cleaning agent resistance whatsoever and the substrate becomes visible after one rub.

Table 24: Cleaning agent resistance rankings* 


\begin{tabular}{|c|c|c|c|c|c|c|}
\hline $\begin{array}{r}\text { Number of } \\
\text { Double-rubs }\end{array}$ & \multicolumn{2}{|c|}{25} & \multicolumn{2}{c|}{50} & \multicolumn{2}{c|}{250} \\
\hline Clear Topcoat & Yes & No & Yes & No & Yes & No \\
\hline Oxi-Clean & 5,5 & 5,5 & 5,5 & 5,5 & 5,5 & 5,5 \\
\hline 409 & 5,5 & 3,3 & 5,5 & 3,3 & 5,5 & 3,3 \\
\hline SimpleGreen & 5,5 & 3,3 & 5,5 & 3,3 & 5,5 & 2,2 \\
\hline TSP mix & 5,5 & 3,3 & 5,5 & 3,3 & 5,5 & 3,3 \\
\hline Control & 5 & 5 & 5 & 5 & 5 & 5 \\
\hline
\end{tabular}

*0B - worst; 5B - best

As can be seen from Table 24, the control area (with no cleaner, just cheesecloth) did not break through any of the coatings and no residue could be seen on the cloth. The topcoated PP panels all received perfect scores regardless of cleaning agent used, while the non-topcoated panels had varying results. All cleaning agents, except for Oxi-clean, caused removal of coating with residue seen on the cheesecloth after just 25 double rubs. Simple Green was the most aggressive cleaner, as partial substrate was visible after 250 double rubs. For the Simple Green panels that scored a ranking of 2, the substrate could be seen, but not in the entire treated area. It was only seen in the middle of the treated area, and it was a small area.

Since these results were completed using the old coating drying protocol, it was proposed to repeat this test as future work, using the new drying protocol found in section 7.4.2

\subsection{Real World Sample Results}

As described in section 9.3, a naturally weathered and a non-weathered siding sample were examined and compared visually, under a microscope, and through ATR IR analysis. The visual appearance of both samples was very similar, and there were no discernable visual differences besides the color of sample PR-11-3, which was slightly faded compared to PR-11-1. 
The Infinity microscope was used to compare the surface features of both samples. The coating on both looked consistent at 50x magnification; the surfaces are rough. Sample PR-11-3 displayed noticeable pinholes and cracking on the surface. These defects could be either physical or chemical in nature, due to internal stresses or photooxidation, among other sources. However, a visual assessment of the samples cannot derive the source of the surface imperfections.

An attempt to characterize the two samples by gas chromatography was done following the procedure listed in section 9.4.3 However, after trying to achieve a complete solution using acetone and MEK the GC results only showed the typical peaks for the solvent used. It was decided to investigate differences between the two samples by ATR FT-IR.

CertainTeed provided Cal Poly with ATR FT-IR results generated at their R\&D laboratory. These spectra were compared to spectra generated at Cal Poly with two different FT-IR spectrometers. 


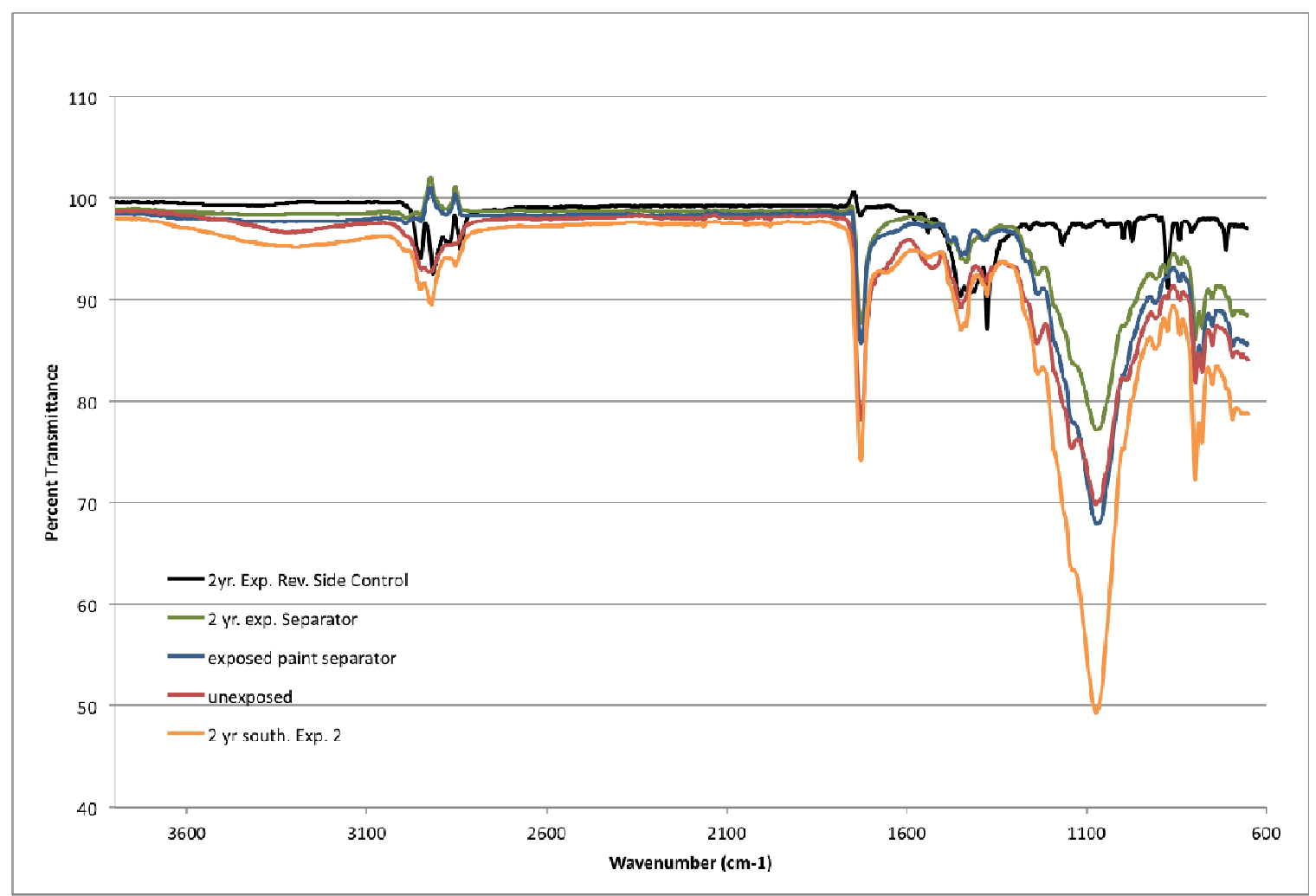

Figure 34: FT-IR results (CertainTeed)

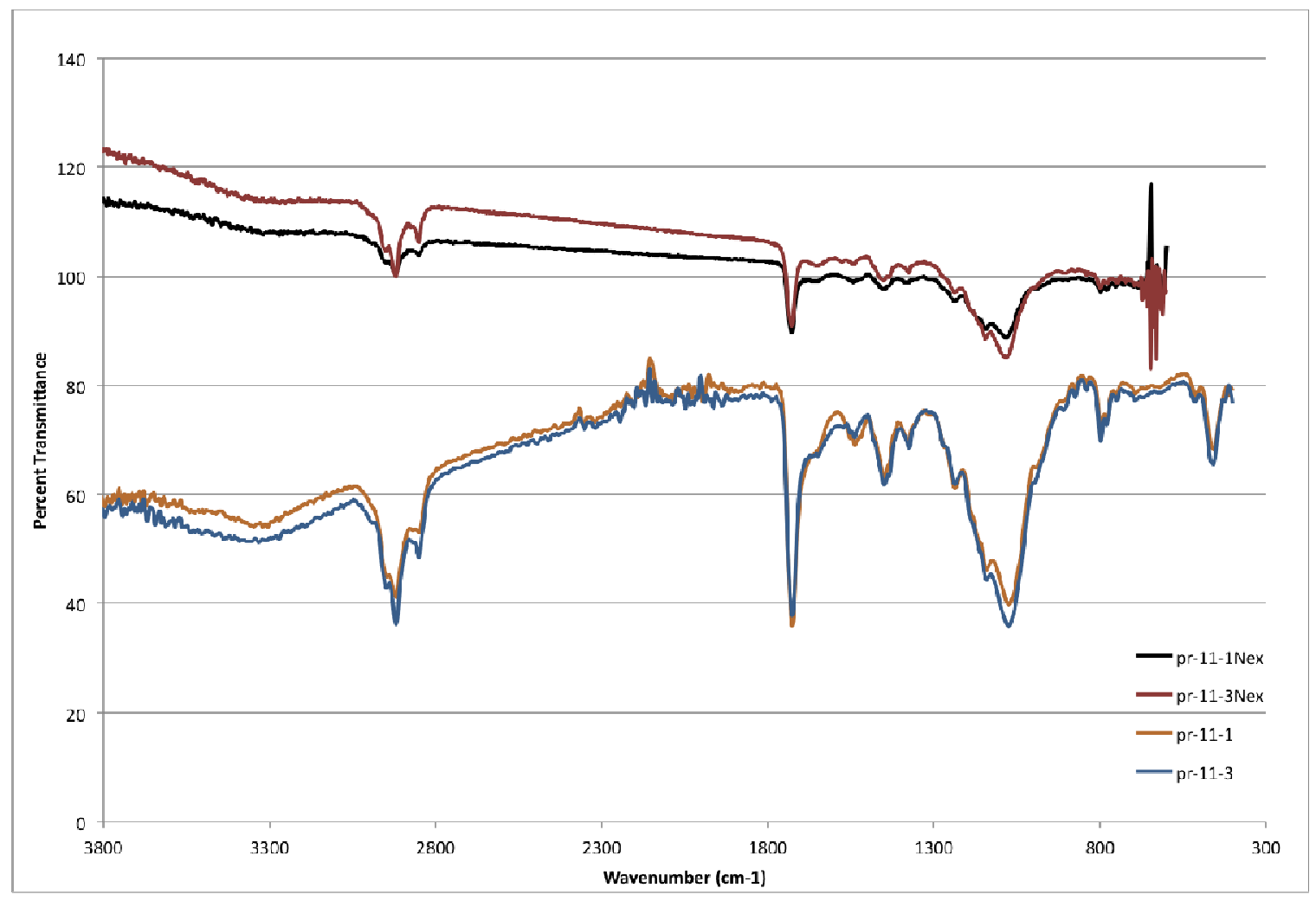

Figure 35: FT-IR results (Cal Poly) 
As can be seen by Figures 34 and 35, the IR results from both CertainTeed and Cal Poly are comparable. Figure 35 shows two results for each sample. The results with the "NEX" after the name were gathered using the Nexus 470 FT-IR, while the other results were obtained used the Nicolet 380 FT-IR. The variation in intensity between the spectra in Figure 35 is due to the different crystals used in the two machines; one uses a diamond crystal, while the other uses a germanium crystal. There are representative absorption peaks at approximately $1100 \mathrm{~cm}^{-1}, 1700 \mathrm{~cm}^{-1}$, and $2900 \mathrm{~cm}^{-1}$. The formulation for the coating used is proprietary information, so assigning functional groups to each peak is speculative, although typical groups found in these regions are $\mathrm{C}-\mathrm{O}$ (stretching), $\mathrm{C}=\mathrm{O}$ (stretching), and C-H (stretching), respectively. However, the main information gathered from these results is there is no discernable difference between the PR-11-1 and PR-11-3 samples.

Finally, the pull-off adhesion testing revealed that PR-11-1 had an average pulloff force of $183 \pm 7$ psi and PR-11-3 has an average pull-off force of $138 \pm 28$ psi. Although these results show the weathered sample took less force to remove, a conclusion cannot be made due to the testing parameters. This test did not accurately represent the adhesion of the coating to the panels, as the samples had deep grooves on the surface. Therefore, the dollies were unable to make full contact with the samples, and all conclusions would be speculative.

\section{Conclusions - Durability}


Accelerated weathering testing completed via QUV revealed that across all panel categories tested, their was minimal change in color ( E), as well as very small changes in color $(E), L^{*}, a^{*}$, and $b^{*}$ results over 2,400 hours. However, there was a clear trend of increasing gloss (measured at $85^{\circ}$ ) as a function of time. A close examination of nonweathered and weathered panel surfaces revealed no microscopic changes over time. The adhesion results from the weathering testing were similar to previous adhesion results, and furthered the conclusion that all coated panel categories can withstand a large degree of weathering with minimal physical degradation and color loss.

Cleaning agent resistance results revealed plasma treated panels with the brown coating followed by a clear coat outperformed plasma treated panels with only a brown coat. The cleaning agent resistance of the clear coated panels improved for all cleaners tested.

Finally, the weathered and non-weathered Cedar Impression samples had their failure mechanisms examined. Using a microscope, it was determined the weathered sample had experienced pin holing and microcracking. Utilizing IR spectroscopy, it was resolved the two samples were the same chemically. Adhesion testing revealed the two samples did not differ in adhesion characteristics. Internal stress and photo-oxidation may be the causes for the pin holes and micro-cracks.

\section{Future Work}


The work completed on this project has provided a solid foundation for future work related to the topics investigated. Atomic force microscopy could be used to determine the surface characteristics of treated and untreated panels, as well as panels exposed to accelerated weathering (which may help explain the gloss increase). Laser scanning confocal microscopy (LSCM) can be used to characterize surface defects, as well as measure film thickness over time. This may help determine the cause of the gloss increase. Further XPS investigations could be done on all Type $\mathrm{C}$ panels to investigate the gloss increase, which may be due to additives or surfactants in the PP's formulation that may 'bloom' to the surface over time. ATR FT-IR spectra could be obtained of samples prior to QUV accelerated weathering and after to examine any chemical changes that may have taken place after extended accelerated weathering. Finally, the entire accelerated weathering test could be repeated to determine if the increase in color for the Type C panels is really happening or if it was an instrumental artifact. A further investigation detailing the problem with the batch \# 2 coating should be conducted and the clear coat durability testing needs to be repeated with the revised procedure. Also, a more in-depth investigation needs to be launched to discover if epoxy migration through the coating onto the plasma treated Category 16 panels is occurring. Raman spectroscopy is sensitive to carbonyls and bigger atoms, and therefore would aid in the Category 16 investigation.

\section{References}

ACS.org, 1999, The Discovery of Polypropylene and the Development of a New High-Density Polyethylene. Visited 31 October 2011. 
http://portal.acs.org/portal/acs/corg/content?_nfpb=true\&_pageLabel=PP_ARTICLEMAI N\&node_id=924\&content_id=WPCP_007859\&use_sec=true\&sec_url_var=region $1 \& \_u$ uid=08dcc7c3-a412-4d25-be5a-cb54e10b313b\#P14_921

The Adhesive and Sealant Council (ASC), Inc. n.d., Adhesion and Cohesion, visited 11 May 2011.

http://www.adhesives.org/TrainingEducation/StudentResources/AdhesionandCohesion.as $\mathrm{px}$

Atlas.com, 2011, EMMAQUA, Visited 24 Novemeber 2011.

http://atlasmts.com/en/services/natural_weathering_testing/natural_weathering_testing_si tes/arizona/outdoor_accelerated_weathering/emmaqua/index.shtml

Awaja, Firas, et al., Adhesion of Polymers. Progress in Polymer Science 34 (2009), pgs. 948-968.

Bikerman, J.J., The Science of Adhesive Joints, 2nd ed., Academic Press, New York, 1968, pgs. 137-150.

Brewis, D.M., D. Briggs, Metal-polymer interfaces, Industrial Adhesion Problems, Orbital Press, Oxford, UK, Chapter 4, 1985.

Brown, Steven A., Nickerson, William, Kovaleski, Kevin, Matzdorf, Craig, Evaluation of Non-Chromate Primer-Containing Finishing Systems. Naval Air Systems Command. Presented at the Tri-Service Corrosion Conference (2005).

Carrino, L., Polini, W., Sorrentino, L. Ageing time of wettability on polypropylene surfaces processed by cold plasma. Journal of Materials Processing Technology, 153-154 (2004), pgs. 519-525.

Green, M.D., F.J. Guild, R.D. Adams, Characterisation and comparison of industrially pre-treated homopolymer polypropylene. HF 135M, Int. J. Adhes. Adhes. 22 (1) (2002), pgs. 81-90.

Hart, Megan. Evaluation of Stain Blocking Primer Coatings with Low Volatile Organic Compound (VOC) Content and Effects of Drying Conditions on the Properties of Water Reducible Coatings for Polypropylene. MS Thesis, Cal Poly San Luis Obispo, 2011.

Hintze-Bruning, Horst, Borgholte, Harald, Coating of untreated polyproylene with halogen free aqueous materials. Progress in Organic Coatings 40 (2000), pgs. 49-54.

Hoeflaak, M, et. al., Artificial Weathering and Outdoor Exposure of Polyester Coatings. Material Testing Procedure and Technology News, 36, 178 (2006).

ICIS.com., n.d., Polypropylene (PP) Uses and Market Data. Visited Oct. 16, 2010. http://www.icis.com/v2/chemicals/9076430/polypropylene/uses.html. 
Karian, Harutun. Handbook of Polypropylene and Polypropylene Composites. Mercel Dekker, Inc. Whitmore Lake, Michigan, 2003.

Lawniczak, J. E., Greene, P. J., Evens, R., and Sass, C., "Water-Reducible Adhesion Promoters for Coatings on Polypropylene-Based Substrates", Journal of Coatings Technology, 65(827), 21 (1993).

Levine, M., et al., Polymer Letters 2 (1964) pg. 915.

Meikle, Jeffrey, "American Plastic: A Cultural History,” Rutgers University Press, New Brunswick, New Jersey, 1997.

Pijpers, A.P., et al., Adhesion behavior of polypropylenes after flame treatment determined by XPS(ESCA) spectral analysis. Journal of Electron Spectroscopy and Related Phenomena 121 (2001), pgs. 299-313.

Placzankis, Brian E., Charleton, Elizabeth A. Accelerated Corrosion and Adhesion Assessments of CARC Prepared Aluminum Alloy 2139-T8 Using Three Various Pretreatment Methods and Two Different Primer Coatings. US Army Research Laboratory - presented at the DOD Corrosion Conference (2009).

Polini, Wilma, et al., Cold plasma treatment of polypropylene surface: a study on wettability and adhesion. Journal of Materials processing Technology 121 (2002), pgs. 373-382.

Ryntz, Rose Ann. Painting of Plastics. Federation of Societies for Coatings Technogoloy: Federation Series on Coatings Technology. Blue Bell, PA. 1994.

Sartomer. Adhesion of Radiation Cured Coatings to Plastics. Sartomer Application bulletin. October, 2006.

Sepeur, S., et al. UV Curable Hard Coatings on Plastics. Thin Solid Films, 351 (1999), pgs. 216-219.

Smeets, Stefan, et al. UV coatings for plastics. European Coatings Journal, Vol. 6, Issue 4. 2004.

Sorrentino, L., et al., Ageing time of wettability on polypropylene surfaces processed by cold plasma. Journal of Materials Processing Technology 153-154 (2004), pgs. 519-525.

Stewart, R., Goodship, V., Guild, F., Green, M., Farrow, J. Investigation and demonstration of the durability of air plasma pre-treatment on polypropylene automotive bumpers. International Journal of Adhesion \& Adhesives 25 (2005), pgs. 93-99.

Sung, Li-Piin, et al., Use of Laser Scanning Confocal Microscopy for Characterizing Changes in Film Thickness and Local Surface Morphology of UV- 
Exposed Polymer Coatings. Journal of Coatings Technology Vol. 1 No. 4 (2004), pgs. 267-276.

Tanizaki, et al. Polypropylene Compositoin and Uses Thereof. United States Patent number 5,998,039. Dec. 7, 1999.

Weldon, Dwight. Failure Analysis of Paints and Coatings. John Wiley \& Sons, Ltd. (2009), pg. 137.

Wicks, Zeno W Jr., et al., Organic Coatings: Science and Technology Third Edition. John Wiley \& Sons, Inc. Hoboken, New Jersey (2007), pgs. 44-47.

\section{Appendix A - Adhesion Data}

\section{Pull-off adhesion data for Table 14}

\begin{tabular}{|c|c|c|c|}
\hline Sample & Psi/\% & $\begin{array}{c}\text { Cohesive Failure } \\
\text { (where/\%) }\end{array}$ & $\begin{array}{c}\text { Adhesive Failure } \\
\text { (between what) }\end{array}$ \\
\hline No Treatment 1 & & & A/B \\
\hline 1 & $81 / 100$ & None & A/B \\
\hline 2 & $89 / 100$ & None & A/B \\
\hline 3 & $151 / 100$ & None & \\
\hline
\end{tabular}




\begin{tabular}{|c|c|c|c|}
\hline No Treatn & & & \\
\hline 1 & $82 / 100$ & None & $\mathrm{A} / \mathrm{B}$ \\
\hline 2 & $70 / 100$ & None & $\mathrm{A} / \mathrm{B}$ \\
\hline 3 & $98 / 100$ & None & $\mathrm{A} / \mathrm{B}$ \\
\hline \multicolumn{4}{|c|}{ No Treatment 3} \\
\hline 1 & $82 / 100$ & None & $\mathrm{A} / \mathrm{B}$ \\
\hline 2 & $63 / 100$ & None & $\mathrm{A} / \mathrm{B}$ \\
\hline 3 & $133 / 100$ & None & $\mathrm{A} / \mathrm{B}$ \\
\hline \multicolumn{4}{|c|}{ No Treatment 4} \\
\hline 1 & $84 / 100$ & None & $\mathrm{A} / \mathrm{B}$ \\
\hline 2 & $71 / 100$ & None & $\mathrm{A} / \mathrm{B}$ \\
\hline 3 & $99 / 100$ & None & $\mathrm{A} / \mathrm{B}$ \\
\hline \multicolumn{4}{|c|}{ Corona 1} \\
\hline 1 & $230 / 100$ & none & $\mathrm{A} / \mathrm{B}$ \\
\hline 2 & $275 / 100$ & $\mathrm{~A} / 5 \%$ & $\mathrm{~A} / \mathrm{B}$ \\
\hline 3 & $297 / 100$ & $\mathrm{~A} / 5 \%$ & $\mathrm{~A} / \mathrm{B}$ \\
\hline \multicolumn{4}{|c|}{ Corona 2} \\
\hline 1 & $230 / 100$ & $\mathrm{~A} / 5 \%$ & $\mathrm{~A} / \mathrm{B}$ \\
\hline 2 & $229 / 100$ & $\mathrm{~A} / 5 \%$ & $\mathrm{~A} / \mathrm{B}$ \\
\hline 3 & $249 / 100$ & $\mathrm{~A} / 5 \%$ & $\mathrm{~A} / \mathrm{B}$ \\
\hline \multicolumn{4}{|c|}{ Corona 3} \\
\hline 1 & $261 / 100$ & $\mathrm{~A} / 5 \%$ & $\mathrm{~A} / \mathrm{B}$ \\
\hline 2 & $264 / 100$ & $\mathrm{~A} / 5 \%$ & $\mathrm{~A} / \mathrm{B}$ \\
\hline 3 & $333 / 100$ & $\mathrm{~A} / 5 \%$ & $\mathrm{~A} / \mathrm{B}$ \\
\hline \multicolumn{4}{|c|}{ Corona 4} \\
\hline 1 & $219 / 100$ & $\mathrm{~A} / 5 \%$ & $\mathrm{~A} / \mathrm{B}$ \\
\hline 2 & $178 / 100$ & $\mathrm{~A} / 2 \%$ & $\mathrm{~A} / \mathrm{B}$ \\
\hline 3 & $245 / 100$ & $\mathrm{~A} / 5 \%$ & $\mathrm{~A} / \mathrm{B}$ \\
\hline \multicolumn{4}{|c|}{ Plasma 1} \\
\hline 1 & $148 / 100$ & None & $\mathrm{A} / \mathrm{B}$ \\
\hline 2 & $250 / 100$ & $\mathrm{~A} / 5 \%$ & $\mathrm{~A} / \mathrm{B}$ \\
\hline 3 & $281 / 100$ & $\mathrm{~A} / 5 \%$ & $\mathrm{~A} / \mathrm{B}$ \\
\hline \multicolumn{4}{|c|}{ Plasma 2} \\
\hline 1 & $183 / 100$ & $\mathrm{~A} / 2 \%$ & $\mathrm{~A} / \mathrm{B}$ \\
\hline 2 & $259 / 100$ & $\mathrm{~A} / 2 \%$ & $\mathrm{~A} / \mathrm{B}$ \\
\hline 3 & $312 / 100$ & $\mathrm{~A} / 2 \%$ & $\mathrm{~A} / \mathrm{B}$ \\
\hline \multicolumn{4}{|c|}{ Plasma 3} \\
\hline 1 & $179 / 100$ & $\mathrm{~A} / 2 \%$ & $\mathrm{~A} / \mathrm{B}$ \\
\hline 2 & $208 / 100$ & $\mathrm{~A} / 2 \%$ & $\mathrm{~A} / \mathrm{B}$ \\
\hline 3 & $229 / 100$ & $\mathrm{~A} / 5 \%$ & $\mathrm{~A} / \mathrm{B}$ \\
\hline \multicolumn{4}{|c|}{ Plasma 4} \\
\hline 1 & $232 / 100$ & $\mathrm{~A} / 5 \%$ & $\mathrm{~A} / \mathrm{B}$ \\
\hline 2 & $239 / 100$ & $\mathrm{~A} / 5 \%$ & $\mathrm{~A} / \mathrm{B}$ \\
\hline 3 & $274 / 100$ & $\mathrm{~A} / 5 \%$ & $\mathrm{~A} / \mathrm{B}$ \\
\hline
\end{tabular}

\section{Crosscut adhesion data for Table 16}




\begin{tabular}{|c|c|c|c|}
\hline & \multicolumn{3}{|c|}{ Tested Area } \\
\hline Panel \# & $\mathrm{A}$ & B & $\mathrm{C}$ \\
\hline $1-\mathrm{a}$ & OB & 0B & $\mathrm{OB}$ \\
\hline $1-b$ & OB & 0B & $\mathrm{OB}$ \\
\hline $1 \mathrm{~T}-\mathrm{a}$ & $4 \mathrm{~B}$ & $5 \mathrm{~B}$ & $5 \mathrm{~B}$ \\
\hline $1 \mathrm{~T}-\mathrm{b}$ & $5 \mathrm{~B}$ & $5 \mathrm{~B}$ & $5 \mathrm{~B}$ \\
\hline $2-a$ & OB & 0B & $\mathrm{OB}$ \\
\hline $2-b$ & OB & OB & OB \\
\hline $2 \mathrm{~T}-\mathrm{a}$ & 5B & 5B & $5 \mathrm{~B}$ \\
\hline $2 \mathrm{~T}-\mathrm{b}$ & $5 \mathrm{~B}$ & $5 \mathrm{~B}$ & $5 \mathrm{~B}$ \\
\hline $3-\mathrm{a}$ & OB & OB & $\mathrm{OB}$ \\
\hline $3-b$ & OB & 0B & $\mathrm{OB}$ \\
\hline $3 \mathrm{~T}-\mathrm{a}$ & $5 \mathrm{~B}$ & $5 \mathrm{~B}$ & $5 \mathrm{~B}$ \\
\hline $3 \mathrm{~T}-\mathrm{b}$ & $5 \mathrm{~B}$ & $5 \mathrm{~B}$ & $5 \mathrm{~B}$ \\
\hline 4-a & OB & 0B & $0 \mathrm{~B}$ \\
\hline $4-b$ & OB & 0B & $0 \mathrm{~B}$ \\
\hline $4 \mathrm{~T}-\mathrm{a}$ & 4B & $5 \mathrm{~B}$ & $5 \mathrm{~B}$ \\
\hline $4 \mathrm{~T}-\mathrm{b}$ & $5 \mathrm{~B}$ & $5 \mathrm{~B}$ & $5 \mathrm{~B}$ \\
\hline $5-a$ & OB & OB & $0 \mathrm{~B}$ \\
\hline $5-b$ & OB & 0B & $0 \mathrm{~B}$ \\
\hline $5 \mathrm{~T}-\mathrm{a}$ & $5 \mathrm{~B}$ & $5 \mathrm{~B}$ & $5 \mathrm{~B}$ \\
\hline $5 T-b$ & $5 \mathrm{~B}$ & $5 \mathrm{~B}$ & $5 \mathrm{~B}$ \\
\hline 6-a & OB & OB & $\mathrm{OB}$ \\
\hline $6-b$ & OB & OB & $0 \mathrm{~B}$ \\
\hline $6 \mathrm{~T}-\mathrm{a}$ & $5 \mathrm{~B}$ & $5 \mathrm{~B}$ & $5 \mathrm{~B}$ \\
\hline $6 \mathrm{~T}-\mathrm{b}$ & $5 \mathrm{~B}$ & $5 \mathrm{~B}$ & $5 \mathrm{~B}$ \\
\hline $7-a$ & OB & 0B & $\mathrm{OB}$ \\
\hline $7-b$ & OB & 0B & $0 \mathrm{~B}$ \\
\hline $7 \mathrm{~T}-\mathrm{a}$ & $5 \mathrm{~B}$ & $5 \mathrm{~B}$ & $5 \mathrm{~B}$ \\
\hline $7 \mathrm{~T}-\mathrm{b}$ & $5 \mathrm{~B}$ & $5 \mathrm{~B}$ & $5 \mathrm{~B}$ \\
\hline $8-a$ & OB & OB & $\mathrm{OB}$ \\
\hline $8-b$ & OB & 0B & $\mathrm{OB}$ \\
\hline $8 \mathrm{~T}-\mathrm{a}$ & 4B & $3 \mathrm{~B}$ & $5 \mathrm{~B}$ \\
\hline $8 \mathrm{~T}-\mathrm{b}$ & $5 \mathrm{~B}$ & $2 \mathrm{~B}$ & $5 \mathrm{~B}$ \\
\hline $9-a$ & OB & 0B & $\mathrm{OB}$ \\
\hline $9-b$ & OB & OB & $\mathrm{OB}$ \\
\hline $9 \mathrm{~T}-\mathrm{a}$ & 4B & $5 \mathrm{~B}$ & $5 \mathrm{~B}$ \\
\hline $9 \mathrm{~T}-\mathrm{b}$ & $5 \mathrm{~B}$ & $5 \mathrm{~B}$ & $5 \mathrm{~B}$ \\
\hline $10-\mathrm{a}$ & 0B & 0B & $\mathrm{OB}$ \\
\hline $10-b$ & OB & 0B & $\mathrm{OB}$ \\
\hline 10T-a & $5 \mathrm{~B}$ & $5 \mathrm{~B}$ & $5 \mathrm{~B}$ \\
\hline 10T-b & $5 \mathrm{~B}$ & $5 \mathrm{~B}$ & $5 \mathrm{~B}$ \\
\hline $11-\mathrm{a}$ & OB & OB & $\mathrm{OB}$ \\
\hline $11-b$ & OB & OB & OB \\
\hline 11T-a & $5 \mathrm{~B}$ & $5 \mathrm{~B}$ & $5 \mathrm{~B}$ \\
\hline 11T-b & $5 \mathrm{~B}$ & $5 \mathrm{~B}$ & $5 \mathrm{~B}$ \\
\hline
\end{tabular}




\begin{tabular}{|c|c|c|c|}
\hline $12-\mathrm{a}$ & OB & 0B & 1B \\
\hline 12-b & OB & $1 \mathrm{~B}$ & OB \\
\hline $12 \mathrm{~T}-\mathrm{a}$ & $5 B$ & $5 B$ & $5 B$ \\
\hline $12 \mathrm{~T}-\mathrm{b}$ & $5 B$ & $5 B$ & $5 \mathrm{~B}$ \\
\hline $13-\mathrm{a}$ & OB & 0B & 0B \\
\hline 13-b & OB & OB & OB \\
\hline 13T-a & $5 \mathrm{~B}$ & $5 \mathrm{~B}$ & $5 \mathrm{~B}$ \\
\hline 13T-b & $5 \mathrm{~B}$ & $5 \mathrm{~B}$ & $5 \mathrm{~B}$ \\
\hline $14-\mathrm{a}$ & OB & OB & OB \\
\hline 14-b & OB & OB & OB \\
\hline 14T-a & $5 \mathrm{~B}$ & $5 B$ & $5 \mathrm{~B}$ \\
\hline 14T-b & $5 \mathrm{~B}$ & $5 \mathrm{~B}$ & $5 \mathrm{~B}$ \\
\hline $15-\mathrm{a}$ & OB & OB & OB \\
\hline $15-\mathrm{b}$ & OB & 0B & OB \\
\hline 15T-a & $5 \mathrm{~B}$ & $5 \mathrm{~B}$ & $5 \mathrm{~B}$ \\
\hline 15T-b & $5 \mathrm{~B}$ & $5 B$ & $5 \mathrm{~B}$ \\
\hline $16-\mathrm{a}$ & OB & 0B & 0B \\
\hline 16-b & OB & 0B & OB \\
\hline 16T-a & $5 \mathrm{~B}$ & $5 \mathrm{~B}$ & $5 \mathrm{~B}$ \\
\hline 16T-b & $5 \mathrm{~B}$ & $5 \mathrm{~B}$ & $5 \mathrm{~B}$ \\
\hline
\end{tabular}

Pull-off adhesion data for Table 17

\begin{tabular}{|c|c|c|c|c|c|}
\hline & \multicolumn{3}{|c|}{ Psi for Each Test Spot } & Average & Group Average \\
\hline Panel & A & B & $\mathrm{C}$ & & \\
\hline $1-\mathrm{a}$ & 54 & 45 & 42 & $47.0 \pm 6.2$ & \\
\hline $1-b$ & 76 & 35 & 39 & $50.0 \pm 22.6$ & \\
\hline $1-\mathrm{c}$ & 68 & 46 & 49 & $54.3 \pm 11.9$ & $50.4 \pm 13.5$ \\
\hline $1 \mathrm{~T}-\mathrm{a}$ & 285.0 & 221.0 & 290.0 & $265.3 \pm 38.5$ & \\
\hline $1 \mathrm{~T}-\mathrm{b}$ & 250.0 & 232.0 & 293.0 & $258.3 \pm 31.3$ & \\
\hline $1 \mathrm{~T}-\mathrm{c}$ & 298.0 & 306.0 & 306.0 & $303.3 \pm 4.6$ & $275.7 \pm 32.6$ \\
\hline $2-\mathrm{a}$ & 50 & 66 & 70 & $62.0 \pm 10.6$ & \\
\hline $2-b$ & 62 & 38 & 35 & $45.0 \pm 14.8$ & \\
\hline $2-c$ & 68 & 56 & 61 & $61.7 \pm 6.0$ & $56.2 \pm 12.8$ \\
\hline $2 \mathrm{~T}-\mathrm{a}$ & 314.0 & 232.0 & 243.0 & $263.0 \pm 44.5$ & \\
\hline $2 \mathrm{~T}-\mathrm{b}$ & 331.0 & 217.0 & 276.0 & $274.7 \pm 57.0$ & \\
\hline $2 \mathrm{~T}-\mathrm{c}$ & 293.0 & 227.0 & 229.0 & $249.7 \pm 37.5$ & $262.4 \pm 42.2$ \\
\hline $3-\mathrm{a}$ & 133.0 & 77.0 & 79.0 & $96.3 \pm 31.8$ & \\
\hline $3-b$ & 95.0 & 79.0 & 91.0 & $88.3 \pm 8.3$ & \\
\hline $3-\mathrm{c}$ & 93.0 & 128.0 & 110.0 & $110.3 \pm 17.5$ & $98.3 \pm 21.0$ \\
\hline $3 \mathrm{~T}-\mathrm{a}$ & 349.0 & 220.0 & 309.0 & $292.7 \pm 66.0$ & \\
\hline $3 \mathrm{~T}-\mathrm{b}$ & 295.0 & 255.0 & 312.0 & $287.3 \pm 29.3$ & \\
\hline $3 \mathrm{~T}-\mathrm{c}$ & 348.0 & 283.0 & 296.0 & $309.0 \pm 34.4$ & $296.3 \pm 41.2$ \\
\hline $4-\mathrm{a}$ & 65.0 & 34.0 & 35.0 & $44.7 \pm 17.6$ & \\
\hline 4-b & 57.0 & 44.0 & 67.0 & $56.0 \pm 11.5$ & \\
\hline $4-\mathrm{c}$ & 101.0 & 66.0 & 49.0 & $72.0 \pm 26.5$ & $57.6 \pm 20.7$ \\
\hline
\end{tabular}




\begin{tabular}{|c|c|c|c|c|c|}
\hline $4 \mathrm{~T}-\mathrm{a}$ & 305.0 & 276.0 & 251.0 & $277.3 \pm 27.0$ & \\
\hline $4 \mathrm{~T}-\mathrm{b}$ & 294.0 & 189.0 & 320.0 & $267.7 \pm 69.4$ & \\
\hline $4 \mathrm{~T}-\mathrm{c}$ & 259.0 & 260.0 & 271.0 & $263.3 \pm 6.7$ & $269.4 \pm 37.9$ \\
\hline $5-a$ & 57.0 & 44.0 & 69.0 & $56.7 \pm 12.5$ & \\
\hline $5-b$ & 43.0 & 33.0 & 74.0 & $50.0 \pm 21.4$ & \\
\hline $5-c$ & 50.0 & 37.0 & 46.0 & $44.3 \pm 6.7$ & $50.3 \pm 13.9$ \\
\hline $5 \mathrm{~T}-\mathrm{a}$ & 265.0 & 253.0 & 266.0 & $261.3 \pm 7.2$ & \\
\hline $5 \mathrm{~T}-\mathrm{b}$ & 287.0 & 211.0 & 302.0 & $266.7 \pm 48.8$ & \\
\hline $5 \mathrm{~T}-\mathrm{c}$ & 282.0 & 242.0 & 345.0 & $289.7 \pm 51.9$ & $272.6 \pm 38.1$ \\
\hline 6-a & 57.0 & 40.0 & 46.0 & $47.7 \pm 8.6$ & \\
\hline $6-b$ & 38.0 & 37.0 & 58.0 & $44.3 \pm 11.8$ & \\
\hline 6-c & 76.0 & 58.0 & 34.0 & $56.0 \pm 21.2$ & $49.3 \pm 13.8$ \\
\hline $6 \mathrm{~T}-\mathrm{a}$ & 226.0 & 193.0 & 226.0 & $215.0 \pm 19.1$ & \\
\hline $6 \mathrm{~T}-\mathrm{b}$ & 197.0 & 191.0 & 273.0 & $220.3 \pm 45.7$ & \\
\hline $6 \mathrm{~T}-\mathrm{c}$ & 251.0 & 244.0 & 220.0 & $238.3 \pm 16.3$ & $224.6 \pm 28.1$ \\
\hline $7-a$ & 85 & 58 & 81 & $74.7 \pm 14.6$ & \\
\hline $7-b$ & 66 & 46 & 52 & $54.7 \pm 10.3$ & \\
\hline $7-\mathrm{c}$ & 64 & 49 & 82 & $65 \pm 16.5$ & $64.8 \pm 14.9$ \\
\hline $7 \mathrm{~T}-\mathrm{a}$ & 314 & 236 & 226 & $258.7 \pm 48.2$ & \\
\hline $7 \mathrm{~T}-\mathrm{b}$ & 253 & 178 & 220 & $217 \pm 37.6$ & \\
\hline $7 \mathrm{~T}-\mathrm{c}$ & 242 & 172 & 202 & $205.3 \pm 35.1$ & $227 \pm 42.8$ \\
\hline $8-a$ & 49 & 57 & 40 & $48.7 \pm 8.5$ & \\
\hline $8-b$ & 52 & 52 & 40 & $48.0 \pm 6.9$ & \\
\hline 8-c & 40 & 49 & 50 & $46.3 \pm 5.5$ & $47.7 \pm 6.2$ \\
\hline $8 \mathrm{~T}-\mathrm{a}$ & 242 & 202 & 200 & $214.7 \pm 23.7$ & \\
\hline $8 \mathrm{~T}-\mathrm{b}$ & 208 & 209 & 214 & $210.3 \pm 3.2$ & \\
\hline $8 \mathrm{~T}-\mathrm{c}$ & 214 & 184 & 200 & $199.3 \pm 15.0$ & $208.1 \pm 15.7$ \\
\hline 9-a & 53.0 & 50.0 & 46.0 & $49.7 \pm 3.5$ & \\
\hline $9-b$ & 46.0 & 45.0 & 51.0 & $47.3 \pm 3.2$ & \\
\hline 9-c & 56.0 & 43.0 & 54.0 & $51 \pm 7$ & $49.3 \pm 4.5$ \\
\hline $9 \mathrm{~T}-\mathrm{a}$ & 236 & 195 & 235 & $235.5 \pm 0.7$ & \\
\hline $9 \mathrm{~T}-\mathrm{b}$ & 292 & 254 & 269 & $271.7 \pm 19.1$ & \\
\hline 9T-c & 292 & 247 & 249 & $262.7 \pm 25.4$ & $259.3 \pm 22.8$ \\
\hline 10-a & 63.0 & 59.0 & 47.0 & $56.3 \pm 8.3$ & \\
\hline $10-b$ & 37.0 & 47.0 & 92.0 & $58.7 \pm 29.3$ & \\
\hline $10-c$ & 68.0 & 34.0 & 84.0 & $62.0 \pm 25.5$ & $59.0 \pm 20.0$ \\
\hline $10 \mathrm{~T}-\mathrm{a}$ & 307.0 & 225.0 & 263.0 & $265.0 \pm 41.0$ & \\
\hline $10 \mathrm{~T}-\mathrm{b}$ & 346.0 & 292.0 & 320.0 & $319.3 \pm 27.0$ & \\
\hline $10 \mathrm{~T}-\mathrm{c}$ & 351.0 & 248.0 & 246.0 & $281.7 \pm 60.1$ & $288.7 \pm 45.7$ \\
\hline $11-\mathrm{a}$ & 55.0 & 27.0 & 47.0 & $43.0 \pm 14.4$ & \\
\hline 11-b & 45.0 & 44.0 & 28.0 & $39.0 \pm 9.5$ & \\
\hline $11-c$ & 50.0 & 29.0 & 47.0 & $42.0 \pm 11.4$ & $41.3 \pm 10.5$ \\
\hline $11 \mathrm{~T}-\mathrm{a}$ & 243.0 & 246.0 & 326.0 & $271.7 \pm 47.1$ & \\
\hline $11 \mathrm{~T}-\mathrm{b}$ & 284.0 & 289.0 & 433.0 & $335.3 \pm 84.6$ & \\
\hline $11 \mathrm{~T}-\mathrm{c}$ & 367.0 & 271.0 & 274.0 & $304.0 \pm 54.6$ & $303.7 \pm 62.0$ \\
\hline $12-a$ & 64 & 33 & 59 & $52 \pm 16.6$ & \\
\hline
\end{tabular}




\begin{tabular}{|c|c|c|c|c|c|}
\hline $12-b$ & 47 & 51 & 71 & $56.3 \pm 12.9$ & \\
\hline $12-c$ & 49 & 38 & 56 & $47.7 \pm 9.1$ & $52 \pm 12.1$ \\
\hline $12 \mathrm{~T}-\mathrm{a}$ & 247 & 245 & 218 & $236.7 \pm 16.2$ & \\
\hline $12 \mathrm{~T}-\mathrm{b}$ & 289 & 208 & 232 & $243 \pm 41.6$ & \\
\hline $12 \mathrm{~T}-\mathrm{c}$ & 196 & 181 & 180 & $185.7 \pm 9.0$ & $221.8 \pm 35.5$ \\
\hline $13-a$ & 37.0 & 56.0 & 86.0 & $59.7 \pm 24.7$ & \\
\hline 13-b & 68.0 & 82.0 & 85.0 & $78.3 \pm 9.1$ & \\
\hline 13-c & 122.0 & 95.0 & 94.0 & $103.7 \pm 15.9$ & $80.6 \pm 24.5$ \\
\hline $13 \mathrm{~T}-\mathrm{a}$ & 307.0 & 259.0 & 269.0 & $278.3 \pm 25.3$ & \\
\hline $13 \mathrm{~T}-\mathrm{b}$ & 228.0 & 258.0 & 273.0 & $253.0 \pm 22.9$ & \\
\hline $13 \mathrm{~T}-\mathrm{c}$ & 461.0 & 236.0 & 242.0 & $313.0 \pm 128.2$ & $281.4 \pm 71.3$ \\
\hline 14-a & 85.0 & 69.0 & 93.0 & $82.3 \pm 12.2$ & \\
\hline 14-b & 101.0 & 80.0 & 107.0 & $96.0 \pm 14.2$ & \\
\hline 14-c & 74.0 & 86.0 & 66.0 & $75.3 \pm 10.1$ & $84.6 \pm 14.0$ \\
\hline $14 \mathrm{~T}-\mathrm{a}$ & 342.0 & 285.0 & 306.0 & $311.0 \pm 28.8$ & \\
\hline 14T-b & 303.0 & 286.0 & 283.0 & $290.7 \pm 10.8$ & \\
\hline $14 \mathrm{~T}-\mathrm{c}$ & 323.0 & 267.0 & 282.0 & $290.7 \pm 29.0$ & $297.4 \pm 23.5$ \\
\hline $15-a$ & 48.0 & 51.0 & 31.0 & $43.3 \pm 10.8$ & \\
\hline $15-b$ & 91.0 & 31.0 & 68.0 & $63.3 \pm 30.3$ & \\
\hline $15-c$ & 57.0 & 31.0 & 91.0 & $59.7 \pm 30.1$ & $55.4 \pm 23.9$ \\
\hline $15 \mathrm{~T}-\mathrm{a}$ & 326.0 & 301.0 & 289.0 & $305.3 \pm 18.9$ & \\
\hline $15 \mathrm{~T}-\mathrm{b}$ & 303.0 & 269.0 & 296.0 & $289.3 \pm 18.0$ & \\
\hline $15 \mathrm{~T}-\mathrm{c}$ & 319.0 & 269.0 & 309.0 & $299.0 \pm 26.5$ & $297.9 \pm 19.8$ \\
\hline $16-a$ & 87 & 44 & 54 & $61.7 \pm 22.5$ & \\
\hline $16-b$ & 66 & 49 & 82 & $65.7 \pm 16.5$ & \\
\hline $16-c$ & 89 & 58 & 46 & $64.3 \pm 22.2$ & $63.9 \pm 17.9$ \\
\hline $16 \mathrm{~T}-\mathrm{a}$ & 400 & 402 & 339 & $380.3 \pm 35.8$ & \\
\hline $16 \mathrm{~T}-\mathrm{b}$ & 2999 & 2999 & 2999 & $2999 \pm 0.0$ & \\
\hline $16 \mathrm{~T}-\mathrm{c}$ & 355 & 434 & 354 & $381 \pm 45.9$ & $1253.4 \pm 1309.5$ \\
\hline
\end{tabular}

Pull-off adhesion data for repeated testing (Table 18)

\begin{tabular}{|c|c|c|c|c|c|}
\hline & \multicolumn{3}{|c|}{ Psi for Each Test Spot } & Average & Group Average \\
\hline Panel & A & B & $\mathrm{C}$ & & \\
\hline $14 \mathrm{~T}-\mathrm{a}$ & 147 & 142 & 173 & $154.0 \pm 16.6$ & \\
\hline $14 \mathrm{~T}-\mathrm{b}$ & 218 & 169 & 176 & $187.7 \pm 26.5$ & \\
\hline $14 \mathrm{~T}-\mathrm{c}$ & 169 & 181 & 142 & $164.0 \pm 20.0$ & $168.6 \pm 23.8$ \\
\hline $15 \mathrm{~T}-\mathrm{a}$ & 238 & 211 & 194 & $214.3 \pm 22.2$ & \\
\hline $15 \mathrm{~T}-\mathrm{b}$ & 172 & 181 & 147 & $166.7 \pm 17.6$ & \\
\hline $15 \mathrm{~T}-\mathrm{c}$ & 205 & 193 & 196 & $198.0 \pm 6.2$ & $193.0 \pm 25.5$ \\
\hline $16 \mathrm{~T}-\mathrm{a}$ & 126 & 152 & 159 & $145.7 \pm 17.4$ & \\
\hline $16 \mathrm{~T}-\mathrm{b}$ & 220 & 205 & 182 & $202.3 \pm 19.1$ & \\
\hline $16 \mathrm{~T}-\mathrm{c}$ & 176 & 146 & 191 & $171.0 \pm 22.9$ & $173.0 \pm 30.0$ \\
\hline
\end{tabular}




\section{Appendix B - XPS Data}

\section{High-resolution and survey spectra of XPS results from section 7.4.4.3}






\section{Untreated Category 7}

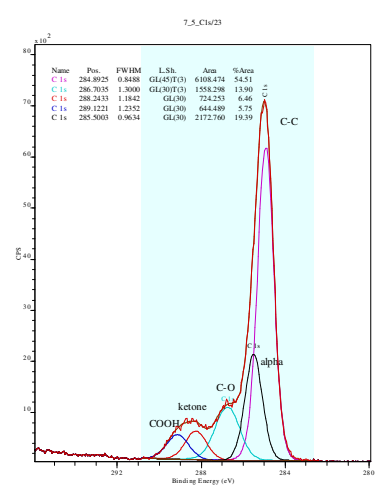

Plasma treated Category 7 (5 seconds)

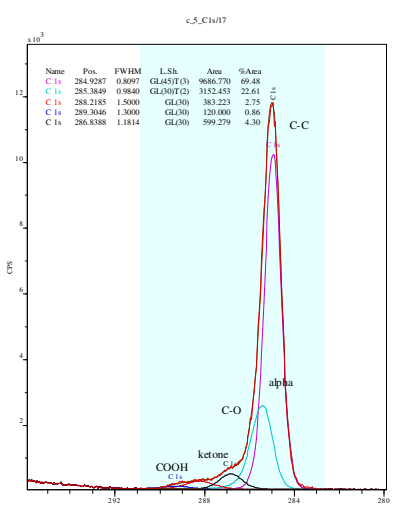

Corona treated Category 7 (5 seconds)

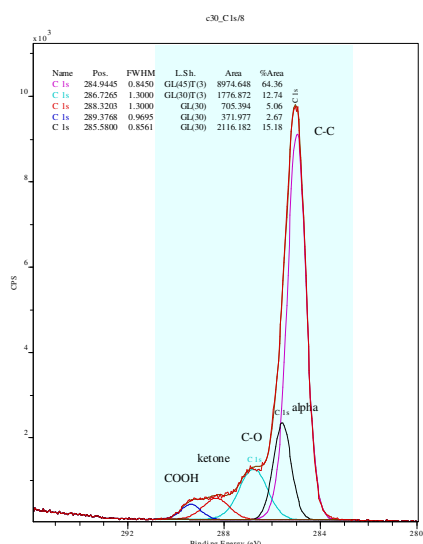

Corona treated Category 7 (30 seconds) 


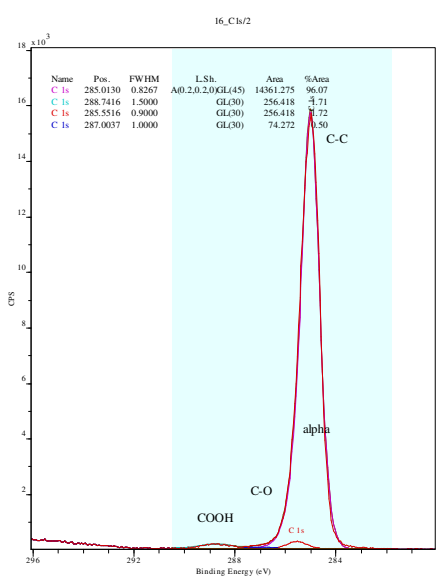

Untreated Category 16

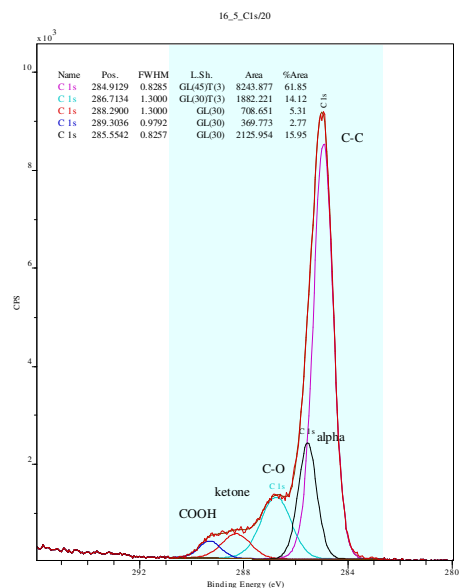

Plasma treated Category 16 (5 seconds)

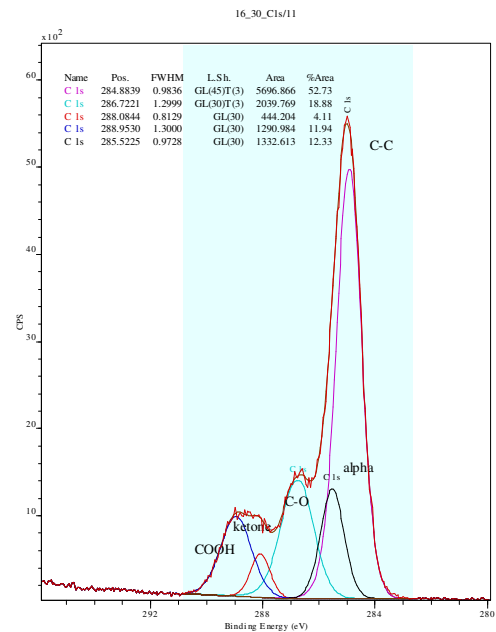

Plasma Treated Category 16 (30 seconds) 




Survery spectra of untreated Category 7

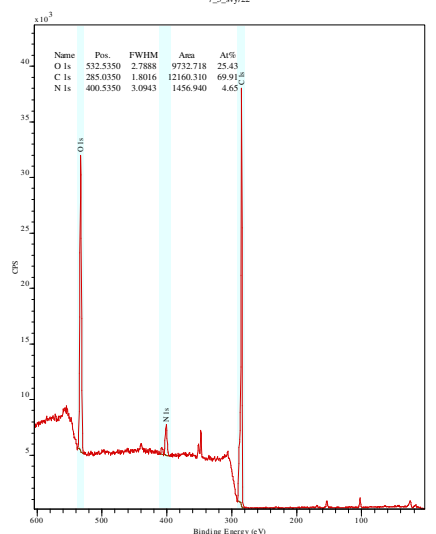

Survey spectra of plasma treated Category 7 (5 seconds)

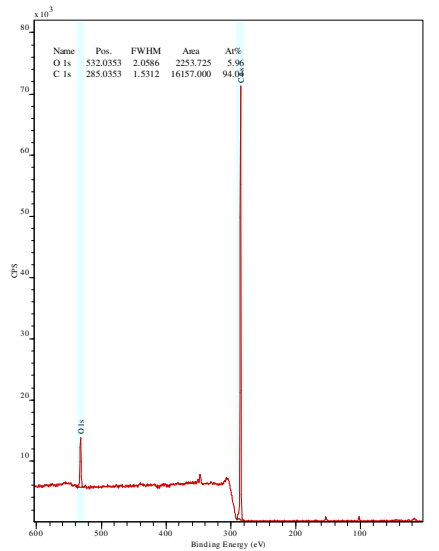

Survey spectra of untreated Category 16 


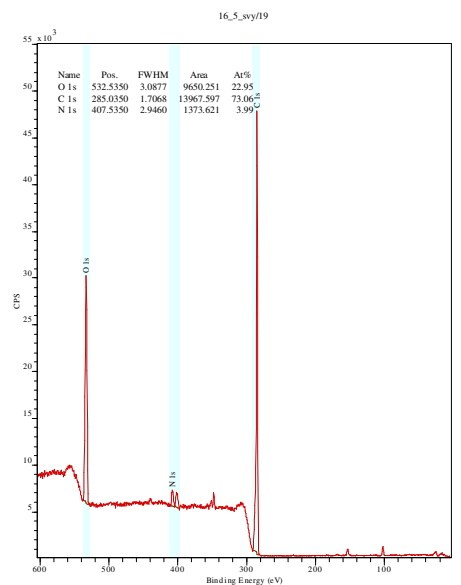

Survey spectra of plasma treated Category 16 (5 seconds)

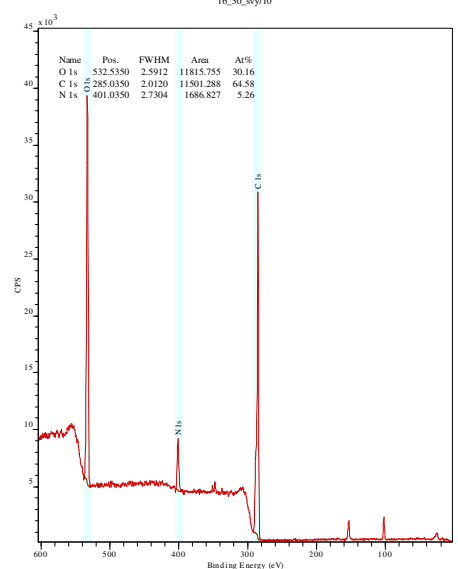

Survey spectra of plasma treated Category 16 (30 seconds)

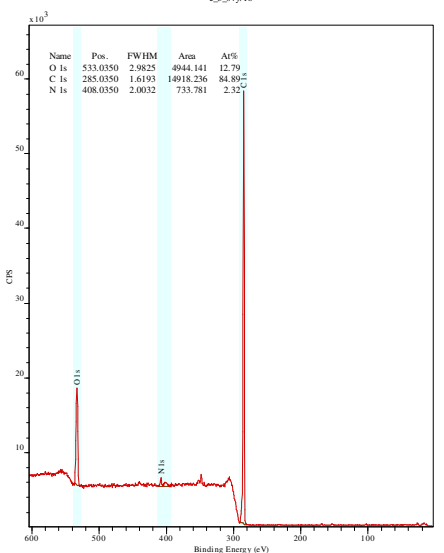

Survey spectra of corona treated Category 7 (5 seconds) 


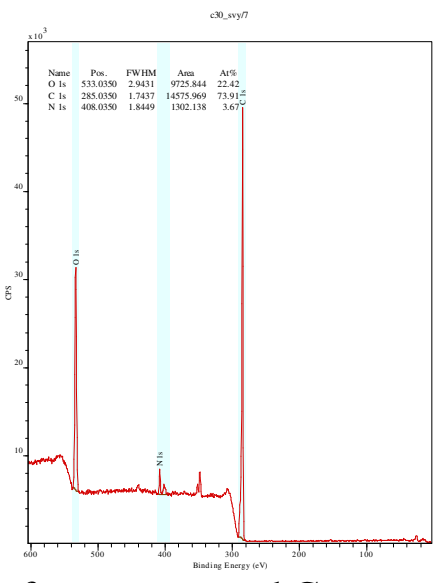

Survey spectra of corona treated Category 7 (30 seconds) 